\title{
Abstracts of the 40th Annual Meeting of THE JAPAN SOCIETY OF HUMAN GENETICS
}

September 20-22, 1995, Kumamoto, Japan

President: Ichiro MATSUDA, M.D., D.M.Sc.

(Professor, Department of Pediatrics, Kumamoto University School of Medicine, Kumamoto) 


\section{Plenary Lectures}

PL-1

TOWARDS THE SECOND PHASE OF THE HUMAN GENOME PROJECT. Yoshivuki SAKAKI(Human Genome Center, Inst. of Med.Sci., Univ. of Tokyo, Tokyo)

The Human Genome Project (HGP), started about five years ago as an international project, has made remarkable progress. Major achievements are (1) a fine genetic (about $1 \mathrm{cM}$ interval) and a back-bone YAC contig maps of the human genome, (2) discovery of various disease genes including those for cancer and neurological disorders, (3) large collection of (partial ) cDNA sequences, (4) extensive sequence analysis of several organisms' genomes including those of yeast and nematode, (5) establishment of databases and computer networks for HGP. Under those progress, HGP is now shifting to the second phase, in which major goals are more fine and ultimately sequence analysis of the human genome, extensive analysis of the genes related to common diseases, complete cDNA catalogues, functional analysis of various organisms' genomes on the basis of their complete nucleotide sequences, and development of bioinformatics for relating sequence information to biological functions. Various new activities for the second phase including new sequence centers are now under way.

\section{PL-2}

EPISODIC DIVERSIFICATION OF GENE FAMILIES AND RELATIONSHIP WITH ORGANISMAL EVOLUTION. Takashi MIYATA, Naoyuki IWABE, Keiichi KUMA, Naruo NIKOH, Hiroshi SUGA (Dept. Biophys., Kyoto Univ., Kyoto)

To know a possible relationship between organismal and molecular evolution, a molecular phylogenetic analysis was carried out for 25 different gene families. Based on the inferred phylogenetic trees, the pattern of gene diversification was examined by taking special notice of functional difference, tissue distribution and intracellular localization of the members. Vertebrate tissue-specific isoforms, a group of members carrying virtually identical function to one another, but differing in tissue distribution, have been shown to had undergone extensive gene duplications and rapid accumulation of amino acid substitutions in the early evolution of chordates before the separation of fishes and tetrapods. In contrast, in the later period the genetic variations are relatively low. The rapid and episodic pattern of evolution observed at the molecular level is correlated well with that of tissue evolution, and thus evolution at the two levels may be related. A similar phylogenetic analysis of $\mathrm{Ca}^{2}+$ pump and rab families revealed very remote divergence of compartmentalized isoforms, a group of molecules localizing in cell compartments, possibly going back to an early stage of eukaryotic evolution. 
PL-3

RECENT PROGRESS IN MOLECULAR ANALYSIS OF PYRUVATE KINASE DEFICIENCY Hitoshi KANNO (Okinaka Memorial Institute for Medical Research, Tokyo)

Pyruvate kinase (PK) deficiency is the most common erythroenzymopathy associated with hereditary hemolytic anemia in Japan. Among 36 PK deficient families which we have analyzed, 16 cases were found to be homozygous, and they included 8 missense, one splicing and one frame-shift mutations. The frame-shift mutant were found to be a null variant of the L-PK gene, suggesting that the null expression of the L/R-PK gene did not cause lethal effects on the PK-deficient subjects and that the affected red cells can survive if reactivation or persistence of the M-PK gene expression is achieved. The biochemical characteristics of the variant enzyme such as the Michaelis constant for phosphoenolpyruvate or the allosteric activation by fructose-1, 6-diphosphate correlate to the expected effects of the missense mutation on the PK subunit. Recent studies showed that 5 unrelated families have the $1261 \mathrm{~A}(\mathrm{Q} 421 \mathrm{~K})$ mutation, suggesting that the $1261 \mathrm{~A}$ was the most prevalent homozygous mutation in the Japanese PK variants. In compound heterozygotes, $1468 \mathrm{~T}$ was identified in 11 unrelated families, thus it was the most prevalent mutation among the Japanese PK variants. Using both the 12 th exonic and 5 th intronic polymorphism which we have found, the DNA haplotype analysis were performed to categorize the five $1261 \mathrm{~A}$ variants, and revealed these variants were classified into three DNA haplotypes. Recently we found a novel mice model of the PK deficiency, and identified the molecular abnormality. The strain is quite useful for understanding pathophysiology of PK-deficient hemolytic anemia as well as to explore new therapeutic methods for the disease in humans.

\section{PL-4}

\section{Molecular Basis of Mucopolysaccharidoses}

The mucopolysaccharidoses (MPS) are group of lysosomal storage disorders caused by deficiency of enzymes catalyzing the stepwise degradation of glycosaminoglycans (mucopolysaccharides). There are 10 known enzyme deficiencies that give rise to six distinct MPS. Depending on the enzyme deficiency, the catabolism of dermatan sulfate, heparan sulfate, chondroitin sulfate or keratan sulfate may be blocked, singly or in combination. Lysosomal accumulation of glycosaminoglycan molecules eventually results in cell, tissue and organ dysfunction. The MPS share many clinical features, though in variable degrees. These include a chronic and progressive course, multisystem involvement, organomegaly, dystosis multiplex, mental retardation, and abnormal facies. Hearing, vision, cardiovascular function, and joint mobility may be affected. Recent advanced molecular technology has made it possible to analize most of MPS diseases. First of all, isolation of cDNA and gene in MPS VII has been performed. $\beta$-glucuronidase is a lysosomal enzyme responsible for hydrolysis of glycosaminoglycans, cleaving $\beta$-glucuronosyl residue at the nonreducing end of oligosaccharides. Mutations destroying the function of this enzyme lead to autosomal recessive mucopolysaccharidosis VII. The disease is very heterogeneous and its clinical heterogeneity is due to a large number of mutations within the gene encoding $\beta$-glucuronidase. We represent the mutations and their characterization and show the current status of molecular anajysis of this disorder. The identification of mutations has explained a broadening of the spectrum of clinical phenotypes that can be classified and used for accurate and early detection of affected or carrier individuals.

Jpn J Human Genet 
Mucopolysaccharidosis IVA (MPS IVA) is an autosomal recessive disorder caused by a deficiency in N-acetylgalactosamine-6-sulfate sulfatase (GALNS). Studies on the molecular basis of MPS IVA have been facilitated following cloning of the fulllength cDNA and genomic DNA. We detected various mutations from over 150 patients using Southern blot and SSCP system and compared mutations of Caucasian origin with those of Japanese origin. The results showed the presence of 32 various mutations (4 small deletions, 2 nonsense and 25 missense mutations for Caucasian patients and 15 ( 1 deletion, 2 large alteration and $14 \mathrm{~m}$ issense mutations) for Japanese. Moreover, two common mutations existed; one is double gene deletion characteristic for Japanese ( 6 alleles; $15 \%)$ and the other is a point mutation (I113F $\mathrm{A} \rightarrow \mathrm{T}$ transition) characteristic for Caucasian (9 alleles; 22.5\%). Useful 16 polymorphisms were also identified through the entire gene. The clear genotype/phenotype relationship among 1342delCA, IVS1(-2), P151S, Q148X, R386C, I113F, Q473X, W220G and P77R, for a severe type, G96V N204K and $\mathrm{V} 138 \mathrm{~A}$ for a milder type was observed. Only $\mathrm{R} 386 \mathrm{C}$ and P151L mutations were seen in both of populations. Further the precise DNA analysis for double gene deletion has been performed by defining the breakoints and the results showed that one deletion was caused by homologous recombination due to Alu repetitive sequences and the other was due to nonhomologous recombination of short direct repeat. Haplotype analysis for six alleles with doube deletion were similar except VNTR element, indicating the common ancestral origin of this mutation. Thus the mutaions in GALNS gene are very heterogeneous and the racial difference is characteristic.

PL-5

ROLES OF DNA MARKERS IN MEDICINE

Yusuke NAKAMURA (Lab. of Mol. Med., Inst. of Med. Sci., Univ. of Tokyo, Tokyo)

DNA markers, particularly, polymorphic DNA markers, have significantly contributed to researches in the medical field. I isolated a large number of highly polymorphic markers, called VNTR (variable number of tandem repeat) markers. VNTR are useful for linkage studies for genetic diseases, individual identification including paternity and maternity test in forensic medicine, and loss of heterozygosity $(\mathrm{LOH})$ in cancer tissues in cancer genetics. Particularly, as frequent LOHs in certain chromosomal regions indicate a presence of tumor suppressor genes, VNTR have contributed significantly for detection of candidate loci for tumor suppressor genes. I, combining LOH in colorectal cancer and linkage analysis of families carrying familial adenomatous polyposis (FAP), isolated the APC gene from chromosome 5q21-22 that is responsible for FAP as well as plays a significant role for development of sporadic colorectal adenomas. 


\section{Morning Lectures}

ML-1

PRENATAL AND PREIMPLANTATION DIAGNOSIS. Kaoru SUZUMORI, Setsuo OKADA, Tadashi IIDA, Manami KAWAMURA

(Dept. Obstet. Gynecol., Nagoya City University, Nagoya)

In the early 1970s, amniocentesis was the main tool for the prenatal. diagnosis of genetic diseases, and it has become possible relatively early in pregnancy with the introduction of chorionic villus sampling in the 1980s. However, no matter how early this procedure is taken, of necessity each must be performed after the pregnancy is established. The propriety of then selecting artificial abortion for a fetus in which an abnormality is diagnosed is an ethical dilemma that continues to provoke much controversy. Recentlly, it has become feasible to diagnose genetic diseases at the early embryo stage, namely preimplantation diagnosis. At the present time, the most commonly used diagnostic approach is to remove 1 to 2 blastomeres from a 4-8 ce11 stage embryo. Initially, application of this method was limited to amplification by PCR of the Y chromosomespecific region and determination of the sex of the embryo for carrier of X-linked inherited diseases, while at present using FISH not only the determination of sex but also the diagnosis of chromosomal numerical abnormalities has become possible, with single gene defects such as Tay-Sachs disease, cystic fibrosis, and Duchenne muscular dystrophy also being successfully diagnosed with the sophisticated molecular genetic technologies.

ML-2

ONCOGENES AND TUMOR SUPPRESSOR GENES. Hideyuki SAYA (Dept. Oncology, Kumamoto University School of Med., Kumamoto)

Proliferation and differentiation of cells are known to be regulated by complicated interactions in which various intracellular molecules are involved. Recent molecular genetic analyses have revealed that the genesis and progression of tumors are the result of accumulated changes in two major classes of growthregulatory genes - the oncogenes and the tumor suppressor genes. Several sequential genetic alterations, especially the inactivation of tumor suppressor genes, appear to allow cells to develop toward a more malignant phenotype.

More than 10 tumor suppressor genes have been identified since the retinoblastoma susceptibility gene (RB1) was found as the first suppressor gene of mammalian cells in 1986. These genes can be grouped into four classes according to the functions; genes which are involved in 1) regulation of cell cycle, 2) DNA mismatch repair pathway, 3) cell-cell contact signals, and 4) regulation of ras proto-oncogene product. Especially, genes which encode cell cycle regulatory proteins such as RB1, p53, and p16 have been found to have frequent mutations in various cancer cells, and these functions are rapidly being characterized. The biochemical characters of these cell cycle regulators will be discussed. 


\section{Luncheon Seminar}

\section{LS-1}

Genomic imprint ing. Yoshihiro JINNO(Dept. Hum. Genet , Nagasaki Univ., Nagasaki)

It is increasingly well accept ed not only in geneticists and biologists but also in physicians that maternal and paternal chromosomes in mammals can function differently. This heritable, sex-specific difference in gene expression is thought to be brought about by marking genes during gamatogenes is and has been termed genomic imprinting. Mre than 10 imprint ed genes have been identified so far in mice or humans. They have shown their own characterist ic patterns of gene expression which provide import ant clues to underst and the molecular mechanism of imprinting. DNA methylation has been regarded as a promising candidate for the primary mark of imprint ed genes. DNA methyltransferase knockout mice have demonstrated that DNA methylation plays a critical role in genomic imprinting. While regions with gamate-specific differential methylation have been ident ified in the $H 19$ and $\operatorname{Igf} 2 r$ genes and a targeted deletion of the $H 1.9$ gene demonstrated the predicted disruption of Igf 2 imprinting, the molecular mechanism of genomic imprint ing is still largely unknow $n$ and is a challenging is sue.

\section{Symposium}

\section{S-I-1}

Overview on triplet repeat diseases

Shoji TSUJI

(Dept. Neurol., Brain Research Institute, Niigata Univ., Niigata)

It took ten years from the discovery of chromosomal localization of the gene for Huntington disease (HD) was determined to the discovery of the causative gene in 1993. The recognition of the unstable expansions of trinucleotide repeats as a common mechanism for neurodegenerative diseases opened a new avenue for the molecular genetics of hereditary neurodegenerative diseases. Until now seven diseases including fragile X syndrome (FRAXA, FRAXE), myotonic dystrophy, Kennedy disease, HD, spinocerebellar ataxia 1, dentatorubral-pallidoluysian atrophy, and Machado-Joseph disease have been identified to be caused by unstable expansion of trinucleotide repeats.

The discovery of the causative genes raised new questions as to the pathogenesis of these diseases. The symposium is focused to address the following issues. 1 . What are the molecular mechanisms of the mitotic and meiotic instabilities of the trinucleotide repeats?, 2. What are the physiological functions of the gene products? 3. What are the mechanisms of neuronal degeneration in these diseases? 
S-I-2

\section{CHARACTERISTICS OF DYNAMIC MUTATION ASSOCIATED WITH FRAGILE $x$ SYNDROME.}

Tada-aki HORI (Genome Research Group, National Institute of Radiological sciences, Chiba)

Fragile $x$ syndrome is one of the most cormon form of familial mental retardation and is known to be associated with the cytogenetic expression of a folate-sensitive fragile site (FRAXA) at Xq27.3, but has an unusual mode of inheritance. It has recently been characterized as involving an unusual expansion of a heritable unstable triplet repeat, $p(C C G) n / p$ (CGG)n, in the 5 '-untranslated region of a FMR1 gene at the FRAXA locus. In fragile $X$ patients, the copy number of the CCG repeat is increased dramatically (called full mutation, $n=200-1000$ ). The full mutation is associated with methylation in a CDG island and failure of expression of the FMR1 gene. A smaller increase in size was also detected in phenotypically normal carriers (premutation, $n=60-200$ ), although the copy number of the CCG repeat is polymorphic among normal individuals $(n=5-50)$. The mechanism of triplet repeat expansion has referred as dynamic mutation: the transition from a normal copy number to clinically significant copy number may involve a number of steps. In general, the CCG repeat in the fragile $X$ chromosome usually increased in size when transmitted by female carriers, but not males. Although the mechanism of dynamic mutation is not clear, the full mutation and its somatic instability appears to occur at early postzygotic stages.

\section{S-I-3}

\section{ISOLATION OF THE GENE RESPONSIBLE FOR MACHADO-JOSEPH DISEASE Akira KAKIZUKA (Dept. of Pharmacology, Kyoto Univ. Faculty of Medicine, Kyoto )}

The molecular bases of the inherited progressive neuro-muscular degenerative disorders had long remained unknown. These disorders commonly demonstrate dominant inheritance, if autosomal, and late onset of their manifestations. Recently, expansions of the certain triplet repeats have been identified in the putative responsible genes from patients of inherited degenerative diseases such as Kennedy's disease, Huntington's disease, spinocerebellar ataxia type 1 (SCA1), and dentatorubral and pallidoluysian atrophy. These lines of evidence have indicated that there exists a common mechanism underlying these inherited degenerative diseases, and this in turn emphasizes the possibility that similar CAG expansions are present in the genes responsible for other dominantly inherited neurodegenerative disorders, such as SCA2 and Machado-Joseph disease. We have screened a human brain CDNA library by an oligo probe with thirteen CTG repeats, complementary nucleotides for CAG repeats, and have identified a novel cDNA containing CAG repeats. The corresponding gene was mapped to chromosome $14 \mathrm{q} 32.1$, the genetic locus for Machado-Joseph disease (MJD). In normal individuals the gene contains between 13 to 36 CAG repeats, whereas most of the clinically diagnosed patients and all of the affected members of a family with clinical and pathological diagnosis of MJD show expansion of the repeat-number (from 68-79). This establishes MJD as the 8th inherited disease known to be associated with expansions of a trinucleotide repeat. The CAG repeat is in the coding region of a cDNA and is predicted to give rise to a long glutamine tract, and those patients with longer repeats have an early onset of disease. 


\section{S-I-4}

Molecular mechanisms of the meiotic instability of the CAG array of the MJD1 gene

Shuichi IGARASHI (Dept. Neurol., Brain research Institute, Niigata Univ.,Niigata)

Machado-Joseph disease (MJD) is an autosomal dominant inherited spinocerebellar degeneration, which causative mutation was detected recently as expansions of unstable CAG trinucleotide repeats in MJDI gene. To test the influence of the single base polymorphism adjacent to the CAG repeat to meiotic instability in MJD1 gene, we have investigated two sites of intragenic polymorphisms in MJD1 gene on 572 normal chromosomes and 262 MJD affected chromosomes. One is CAG/CAA polymorphism located in the CAG repeat itself, the other is CGG/GGG polymorphism located closely at the $3^{\prime}$ end of CAG repeat. The $\mathrm{CGG}$ allele is associated with the variation of higher CAG repeat length on normal chromosoms, furthermore, all Japanese affected chromosomes have CGG allele, and Azorean and French affected chromosomes showed high frequency of CGG allele which showed apparent linkage disequilibium. On the other hand, GGG allele is associated with the distribution of lower CAG repeat length on both normal and affected chromosomes. These findings lead to the suspicion suggesting that single base substitution at the $3^{\prime}$ end of CAG repeat affects the instability of CAG trinucleotide repeat. These findings might contribute to the mechanism of instability of CAG repeat in MJD gene in meiotic transmission.

\section{S-I-5}

\section{LINKAGE DISEQUILIBRIUM OF MYOTONIC DYSTROPHY}

Tetsuro MIKI (Dept. Geriat. Med., Osaka Univ. Med. Sch., Osaka)

The gene for myotonic dystrophy (DM) was found to be an expansion of an unstable CTG repeat located in the 3'-UTR of the putative protein kinase gene. In the general population 5-37 copies of the repeat are present, but in DM patients the repeat number varies from 50 up to thousands of copies. We have determined the copy number of the CTG repeat and made a haplotype using the closely linked markers to the CTG repeat in 93 Japanese DM families. The normal allele from the Japanese and Caucasian populations have qualitatively the same association of the CTG repeat and the Alu insertion/deletion polymorphism. The absolute linkage disequilibrium was observed in patients from both populations, between the DM gene and the linked markers. These data strongly suggest a common origin of Caucasian and Japanese DM alleles. 


\section{S-I-6}

LINKAGE DISEQUILIBRIUM IN HUNTINGTON'S DISEASE. IChiro KANAZAWA

(Dept. Neurol., Inst. Brain Res., Univ. Tokyo, Tokyo)

Huntington's disease(HD) is characterized clinically by choreic involuntary movement and psychiatric problems, and pathologically by a loss of striatal small neurones. Since the discovery of the gene locus of HD in $4 \mathrm{pl} 16.3$ region by Gusella and his colleagues, a gene hunting for HD was started. During the period, collaborated with Gusella, we have performed a linkage analysis using DNAs from Japanese HD families and found the Japanese HD gene to be located exactly the same locus as caucasian HD. However, linkage disequilibrium was not found in Japanese HD families mainly due to the shortage of the informative families. In 1993, the IT15 gene was found as a causative gene for $H D$, in which the CAG repeat was expanded more than 37 in patients. Adjacent to the CAG repeat in the gene, there is a CCG repeat which shows polymorphism; practically 7 or 10 alleles. There is no difference in distribution of the 7 $(40 \%)$ or $10(60 \%)$ allele between normal Japanese and caucasian. In cases of HD patients, a more than $90 \%$ of caucasian HD patients has 7 allele, whereas only a 15\% of Japanese HD patients has 7 allele and a $85 \%$ has 10 allele. This means that in Japan there should be at least two origins for HD gene; one (7 allele) could come from western europe and the other $(10$ allele $)$ could emerge inside Japan or could come from somewhere in Asia.

\section{S-II-1}

THE ROLE OF PAX GENES DURING EMBRYOGENESIS, Kazuhiro ETO and Noriko OSUMI-YAMASHITA (Dept. of Devel. Biol., Tokyo Med. \& Dent. Univ., Tokyo)

The paired box was first found in Drosophila segmentation genes. At the present nine murine and human paired box $(\mathrm{Pax})$ genes have been isolated and they are classified into four groups by their sequence homology and genomic organization. Pax proteins are considered to bind to specific DNA sequences and modulate transcriptional activity. In addition, both murine mutants and human congenital diseases such as undulated, Splotch (Waadenburg syndrome I in human) and Small eye (aniridia in human) have been assigned to some of the Pax family members, i.e., Pax-1, Pax-3 and Pax-6, respectively. Recently, we found a new mutant rat $(r S e y)$ with the lack of eyes and nose in the homozygote. The phenotype and genetical trait of $r S e y$ is similar to that of the mouse Sey strain with mutations in the Pax-6 gene. At the genomic level, $r$ Sey posses a single base $(G)$ insertion in an exon of Pax- 6 gene, generating an abnormal $5^{\prime}$ donor splice site, thereby producing the truncated mRNA. Anterior midbrain crest cells in the homozygous $r$ Sey embryos reached the eye rudiments but did not migrate any further to the nasal rudiments. $P a x-6$ gene is intensely expressed in the frontonasal ectoderm which serves as scaffold for migratiaon of anterior midbrain crest cells, suggesting that the $P a x-6$ gene is involved in conducting migration of these crest cells toward the frontonasal region. Recombination study revealed that the failure of lens differentiation in homozygous $r$ Sey embryos is assumed to be the result also from defects in the head ectoderm that could not respond to inductive signals from the presumptive retina. Pax-6 gene is also expressed in the basal plate of the hindbrain and spinal cord. We found that the abducent and hypoglossal nerves are missing in $r$ Sey homozygotes, suggesting that $P a x-6$ is involved in development of motor neurons. Taking together, $P$ ax -6 has multiple functions in several developmental events where cell-cell interaction/recognition is important. 


\section{S-II-3}

IDENTIFICATION OF MUTATIONS IN THE GENES RESPONSIBLE FOR CONSTITUTIONAL BONE DISEASES. Masafumi MATSUO(ICMR, Kobe University School of Medicine, Kobe)

In the name of constitutional bone disease wide varieties of diseases are included from a simple rickets to severe thanatophoric dysplasia. Recent advance of molecular genetics make it possible to identify the responsible gene and its mutation in many constitutional bone diseases.

In achondroplasia, gene mutations have been identified in the fibroblast growth factor receptor (FGFR) 3. Since then much attention has been paid to look for mutations in FGFR family genes in cases showing similar claniofacial dysplasia as achondróplasia. Until now Pfeiffer, Crouzon, Jackson-Weiss, and Apert syndromes have been elucidated to have mutations in one of the FGFR1, FGFR2, and FGFR3 genes.

Collagen, a main component of bone, consists of many kinds of fibers and abnormalities in one of the collagen fiber genes have been reported. Recent advance in understanding constitutional bone diseases at the molecular level is elucidation of mutation in minor collagen gene. Schmid type metaphyseal chondrodysplasia is one example of minor collagen abonormalities.

In this report I would like to present our results that disclosed mutations in the FGFR3 gene of achondroplasia patients and in the type X collagen gene of a case of Schmid metaphyseal chondrodysplasia.

S-II-4

POSITIONAL CLONING OF GENES ASSOCIATED WITH DISEASES

Yusuke NAKAMURA (Lab. of Mol. Med., Inst. of Med. Sci., Univ. of Tokyo, Tokyo)

Recent advances in "Human Genome Analysis" have accelerated finding of genes responsible of hereditary diseases as well as genes associated with development and progression of cancer. The genes associated with diseases can be mapped by various approaches such as linkage analysis using families carrying a disease, chromosomal transfer, and chromosomal abnormalities found in patients. Among them, de novo balanced chromosomal translocations found in patients with certain diseases have played significant roles in identification of responsible genes. We have constructed cytogenetic maps of 9 human chromosomes with more than 3,300 cosmid markers by means of the FISH method. If appropriate patients with de novo balanced chromosomal translocation are found, these clones will become useful resources for cloning the chromosomal breakpoints and for isolation of candidate genes. 


\section{General Contributions}

A-1

DNA DIAGNOSIS OF MYOTONIC DYSTROPHY IN 3 FAMILIES, USING NON-RI PCR SOUTHERN BLOTTING. Iunko MATSUDA, Michinori ITO, Ichiro YOKOTA, Etsuo NAITO, Yasuhiro KURODA (Dept. Pediat., Univ. Tokushima.), Mitsuru IIDA, Tsukasa KODAIRA (Otsuka Pharmac. Co., Ltd. Dept. Diag. regent Develop. Diag. Div., Tokushima.)

The cause of myotonic dystrophy (DM) has recently been identified as an unstable expansion of (CTG) repeat located at the $3^{\prime}$ untranslated region of myotonin-protein kinase gene. We used the method of non-RI PCR southern blotting to analyze the (CTG) repeat expansion for the DNA diagnosis of DM in 3 families. The region of (CTG) repeat was amplified by the LA-PCR. The PCR products were electrophoresed on the 3\% NuSieve agarose gel and were transferred to the nylon membrane followed by the hybridization with the digoxigenin labeled (CTG) 10 DNA probe for the detection of the (CTG) repeat expanded PCR products. The size and the number of the (CTG) repeat of the PCR products were determined using the DNA sequencer. In 2 families of congenital DM, heterogeneous expanded longer bands were clearly defined in the mothers and children whose band were longer than the mothers' band, reflecting the anticipation. In one family whose mother was DM, the expansion of the (CTG) repeats were detected in the maternal grandmother and mother. In three children of this family, (CTG) repeat expansion were not detected. They were diagnosed as normal. We concluded that non-RI PCR southern blotting is a useful and convenient method for the DNA diagnosis of DM.

\footnotetext{
A-2

DECREASED LEVEL OF MT-PK (MYOTONIN-PROTEIN KINASE) TRANSCRIPT OF VARIOUS TISSUES IN CONGENITAL MYOTONIC DYSTROPHY . Kazuhiro OHYA, Shunzo CHIBA(Dept of Pediatrics, Sapporo Medical University School of Medicine), Nobutada TACHI (Sapporo Medical University School of Health Science), Shin-ichiro Kon, and Kokichi Kikuchi(1st Dept of Pathology, Sapporo Medical University School of Medicine)

Myotonic dystrophy (DM) results from the expansion of an unstable CTG trinucleotide repeat in the $3^{\prime}$ untranslated region of mRNA encoding a putative serine/threonine protein kinase (MT-PK). We have examined an expression of MT-PK mRNA levels in various tissues (liver, cerebral cortex, spinal cord, tongue, urinary bladdar, psoas muscle, and diaphragm) from a severe congenital DM (CDM) patient, skeletal muscles from an adult DM and a CDM patients using allele-specific transcript (exon 3 to 6 and exon 11 to 14 of MT-PK gene) amplification and quatitative RT-PCR. In samples of liver from two normal controls, a level of MT-PK mRNA was reduced clearly. We observed decreased levels of MT-PK mRNA in all various tissues from a severe congenital DM patient, skeletal muscles from an adult DM and aCDM patients compared to skeletal muscles from three normal controls.
} 
A-3

A JAPANESE BOY OCCASIONALLY SHOWING MYALGIA AND CRAMPS HAD A NOVEL IN-FRAME DELETION OF THE DYSTROPHIN GENE

Chieko ISHIGAKI (Div. Genet., ICMR, Kobe Univ. Med., Hyogo)

Hisahide NISHIO (Dept. Public Health, Kobe Univ. Med., Hyogo)

Miharu YABE (Dept. of Pediatr., Tokai Univ. Med., Kanagawa)

Masafumi MATSUO(Div. Genet., ICMR, Kobe Univ. Med., Hyogo)

We report a Japanese Becker muscular dystrophy patient, who had occasional myalgia and cramps during usual activity. Muscle biopsy analysis shows a normal picture.He was

diagnosed at 10 years old, when persistant high serum creatine kinase prompted to screen deletion mutation of the dystrophin gene by amplification of exons from the genomic DNA by PCR. Exons 13 and 17 were disclosed to be deleted. Sequencing result of the amplified product encompassing exons 10 to 20 from CDNA disclosed that the sequence from exon 13 to $18(810 \mathrm{bp})$ disappeared. This in-frame deletion would be expected to cause the production of a dystrophin protein lacking 270 amino acids in rod domain. This result indicates that myalgia and cramps can be the earliest clinical finding, especially in those who have deletion in rod domain and that deletion screening of the dystrophin gene can be only method to diagnose mild BMD.

\section{A-4}

FACIOSCAPULOHUMERAL MUSCULAR DYSTROPHY (FSHD) : CLINICAL DIVERSITY AND GENETIC ABNORMALITY. Masanori NAKAGAWA, Ryuuichi OHKUBO, Itsuro HIGUCHI, Hirohisa YAMADA, Mitsuhiro OSAME (Dept. 3rd. Int. Med., Kagoshima University, Kagoshima), Hiroaki YOSHDOME, Hiroyuki IWAKI, Hidetoshi FUKUNAGA (Dept. Neurol., National Minamikyushu Hospital, Kagoshima) and Toshio MATSUZAKI (Dept. Neurol., National Okinawa Hospital, Okinawa)

We studied 26 patients with FSHD (20 familial and 6 sporadic cases) clinically and genetically by using a chromosome 4qter DNA marker p13E-11. Clinical features showed early onset FSHD in 6 patients, tortuosity of retinal arterioles and hearing impairment in 2, respiratory failure in 2, limb-girdle type weakness in 6 and distal type myopathy in 1 . Muscle biopsy showed myogenic changes in 14 of 17 patients studied and neurogenic change in 2 . Perivascular cell infiltration was detected in 4 patients and lobulated fibers in 3 patients. Southern blot analysis showed shorter EcoRI fragment than $30 \mathrm{~kb}$ in 22 of the 26 patients. Patients with early onset of disease showed rather shorter EcoRI fragments. Our study confirmed the phenotypic and genetic diversities in FSHD by using the 4qter DNA marker. Other genetic factor(s) which reflect the phenotypic expression may exist in FSHD patients. 


\section{CLINICO-GENETIC ANALYSIS ON NON-FUKUYAMA (CLASSICAL) FORM OF CONGENITAL MUSCULAR DYSTORHY. Ikuya NONAKA, Osamu KOBAYASHI and Shin-ichi OSARI (National Center of Neurology and Psychiatry)}

Among approximately 4,400 muscle biopsies in our laboratory from 1978 to 1993,164 patients were diagnosed as having congenital muscular dystrophy (CMD), i.e., 112 with Fukuyama type CMD (FCMD), 53 with non-FCMD (classical CMD). The 53 non-FCMD patients were further divided into 2 with the merosin-negative and 50 with the merosin-positive form on immunohistochemical staining with an anti-merosin antibody. The 3 patients with the merosin-negative form exhibited marked muscle weakness and hypotonia from early infancy, white matter lucency on brain CT-MRI and a dystrophic muscle pathology with dense fibrosis. On the other hand, the 50 patients with the merosin-positive form had relatively mild symptoms and muscle pathology, and a slowly progressive course.

\footnotetext{
A-6

ADHALIN GENE MUTATIONS IN MALIGNANT LIMB-GIRDLE MUSCULAR DYSTROPHY AND CLINICAL FEATURES IN ADHALIN-DEFICIENT MUSCULAR DYSTROPHY. TakenOII ENDO, HISAOMI KAWAI, Makoto KUNISHIGE, Hideki MINE, Setsuko KASHIWAGI, Masashi AKAIKE, Takao MITSUI, Shiro SAITO (First Dept. of Internal Med. , School of Med., The Univ. of Tokushima, Tokushima) and Rijchiro MATSUMURA (Dept. of Neurology, School of Med. Teikyo Univ., Tokyo)

We reported adhalin gene mutations in 4 patients from 3 families with malignant limb-girdle muscular dystrophy (MLGMD) and summarized the clinical features in adhalin-deficient muscular dystrophy (adhalin-deficient MD) reported as severe childhood autosomal recessive muscular dystrophy (SCARMD), which is essentially identical to MLGMD.

Adhalin CDNA was sequenced in 3 patients from 2 consanguinous families with MLGMD, and the genomic DNA was sequenced in 1 patient from a non-consanguinous family. In the patient from Family 1, a cytosine to thymidine substitution at nt. 229 was identified. In each of the two patients from Family 2, an adenine to guanine substitution at nt.410 and an insertion of 15 bases between nt. 408 and 409 were identified. In the patient from Family 3 , a deletion of adenine at nt. 404 (or 405 ) and a thymidine to cytosine substitution at nt. 470 were identified. Sixty-six cases from 49 families with adhalin-deficient $M D$ reported in the literature were reviewed. There was no essential difference between the two groups in the clinical features, but the former was characterized by more severe clinical features than the latter. These patients may be classified into two groups; complete and incomplete adhalin-deficient. Mental retardation and cardiac dysfunction were rarely observed in those patients. A cytosine to thymidine substitution at nt. 229 lies in exon 3, which seem to be a hot-spot of the mutation, was found in 7 families with adhalin-deficient MD.
} 
A-7

ANALYSIS OF CAG TRINUCLEOTIDE EXPANSION ASSOCIATED WITH MACHADO-JOSEPH DISEASE (MJD). Mitsunori WATANABE ${ }^{1,2}$, Koji ABE $^{1}$, Masashi AOKI $^{1}$, Takeshi KAMEYA ${ }^{1}$, Mikio SHOJI ${ }^{2}$, Tomomichi IIZUKA ${ }^{2}$, Yoshio

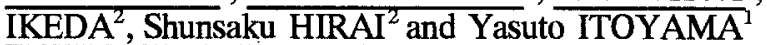
Department of Neurology, ${ }^{1}$ Tohoku University School of Medicine, Sendai; ${ }^{2}$ Gunma University School of Medicine, Maebashi, Japan.

Machado-Joseph disease (MJD) is an autosomal dominant neurodegenerative disorder characterized by cerebellar ataxia, pyramidal and extrapyramidal signs, amyotrophy, peripheral nerve palsy, external ophthalmoplegia and bulging eyes. A recent study has identified an unstable trinucleotide $\mathrm{CAG}$ repeat expansion as the mutation causing MJD. Twenty cases of MJD in 13 unrelated Japanese families were genetically and clinically examined in comparison with 20 cases of age at onset- and duration-matched spinocerebellar ataxia type 1 (SCA1). The CAG repeat number of expanded MJD and SCA1 allele was $72.2 \pm 3.1$ (mean \pm SD), and $47.3 \pm 4.4$, respectively. The repeat size was inversely correlated with age at onset, and the repeat number in leukocytes increased from parents to children with acceleration of age at onset (anticipation) in both MJD and SCA1. MJD was clinically characterized by a relatively higher frequency of ocular signs such as eyelid retraction, bulging eyes, ophthalmoparesis, and nystagmus, spasticity in lower limbs, and sensory and urinary disturbances in contrast to the SCA1 patients except for slow eye movement.

These results suggest that the expanded CAGrepeat and clinical features are correlated in both MJD and SCA1, and MJD can be differentiated from SCA1 by clinical characteristics as well as DNA analysis.

\section{A-8}

MOLECULAR ANALYSIS OF THE MJDI GENE IN JAPANESE AND CAUCASIAN SUBJECTS WITH MACHADO-JOSEPH DISEASE. Y. TAKIYAMA, S. IGARASHI, K. ENDO, M. SAITO, H. TANAKA, S. TSUJI (Dept. Neurol,, Brain Res. Inst., Niigata Univ., Niigata), Y. NOMURA, M. SEGAWA (Segawa Neurol. Clin. for Children,Tokyo), M. YOSHIDA, M. NISHIZAWA (Dept. Neurol., Jichi Med. Sch., Tochigi), E.A. Rogaeva and P.H.St George-Hyslop (Dep. Med., The Tronto Hosp. \& Univ. of Tronto, CANADA)

Molecular analysis of the MJD1 gene in 127 Japanese and Caucasian subjects with Machado-Joseph disease (MJD) was performed. Our data provide several novel findings. First, MJD is associated with expansion of the array from the normal range of 14-37 repeats to 68-84 repeats in most Japanese and Caucasian subjects, but no subjects were observed with expansions intermediate in size between those of the normal and MJD groups. Second, the expanded allele displays inter-generational instability, particularly in male meioses, and this instability was associated with anticipation. Third, the size of the expanded allele is not only inversely correlated with the age-of-onset of $\operatorname{MJD}(\mathrm{r}=-0.738, \mathrm{p}<0.001)$, but is also correlated with the frequency of bulging eyes and pyramidal signs ( $p<0.05$ and $p<0.001$, respectively). Finally, Japanese and Caucasian MJD subjects share haplotypes at several markers surrounding the $M J D 1$ gene, which are uncommon in the normal population, and which suggests the existence either of common founders in these populations or of chromosomes susceptible to pathologic expansion of the CAG repeat in the MJD1 gene. 


\begin{abstract}
$\mathbf{A}-9$
6-PYRUVOYL-TETRAHYDROPTERIN SYNTHASE DEFICIENCY, PRESENTING AS GENERALIZED DYSTONIA WITH DIURNAL FLUCTUATION. Tokiji HANIHARA. Ken INOUE. Chiaki KAWANISHI Naoya SUGIYAMA. Yoshiteru YAMADA. Kenji KOSAKA. (Dept. Psychiatry, Yokohama City Univ. Yokohama.) Kiyoshi IWABUCHI. (Dep. Psychiatry, Kanagawa Rehabilitation Center. Atsugi.) MisaoOWADA. (Dept. Pediat. Nihon University. Tokyo)
\end{abstract}

A patient with 6-pyruvoyl tetrahydropterin synthase (PTS) deficiency is reported. The characteristic symptom of this patient was generalized dystonia with marked diurnal fluctuation. Dystonia present in eyelids, oro-mandibular, trunk and extremities (Meige syndrome plus double-hemiplegic dystonia). A marked and sustained response to levodopa was observed. The ratio of biopterin to neopterin was reduced in the urine excretion. An A-to-G substitution (Ile $114 \mathrm{Val}$ ) in the 6-PTS gene was detected. The patient was homozygous for this mutation. 6-PTS deficiency present as an inherited generalized dystonia syndrome. The dystonia in this patient was partially similar to that of hereditary progressive dystonia with marked diurnal fluctuation (Segawa)/doparesponsive dystonia.

MOLECULAR ANALYSES OF $\mathrm{Cu} / \mathrm{Zn}$ SUPEROXIDE DISMUTASE GENE IN PATIENTS WITH FAMILIAL AMYOTROPHIC LATERAL SCLEROSIS (ALS)

Masashi AOKI, Koji ABE, (Dept. Neurology, Tohoku Univ. School of Med., Sendai), Masahito OGASAWARA, Yoko AOKI, Yoichi MATSUBARA, Kuniaki NARISAWA (Dept. Biochem. Genet., Tohoku Univ., Sendai), Mitsunori WATANABE, Masaki IKEDA (Dept. Neurology, Gunma Univ., Maebashi), Kouji HOUI, Soichiro MOCHIO (Third Depart. of Internal Medicine, Jikei Univ., Tokyo), Katsuro KUROKAWA, Takeo KATO, Hideo SASAKI (Third Depart. of Internal Medicine, Yamagata Univ., Yamagata), Ryo SAKUMA, Takeshi KAMEYA, Shyozo NAKAMURA, and Yasuto ITOYAMA (Dept. Neurology, Tohoku Univ., Sendai)

Amyotrophic lateral sclerosis (ALS) is a degenerative disorder characterized by selective damage to the neural system that mediates voluntary movement. Death usually occurs within a few years of onset. Although the pathophysiologic process of ALS remains unknown, about 5 to $10 \%$ of cases are familial. We recently identified five different mutations in six familial ALS (FALS) families. The mutations identified in our FALS families are H46R, L84V, I104F, S134N, V148I. The enzymatic activities of $\mathrm{Cu} / \mathrm{Zn} \mathrm{SOD}$ of erythrocyte or skin fibroblasts were significantly reduced in the all affected patients.

These mutations account for fifty percent of all FALS families screened, although $\mathrm{Cu} / \mathrm{Zn}$ SOD mutations are responsible for less than twenty percent in Western population. Our results indicate that the progression of the disease with $\mathrm{Cu} / \mathrm{Zn}$ SOD mutations is usually related to each mutation. 


\section{A-11}

MOLECULAR ANALYSIS OF EXTRACELLULAR-SUPEROXIDE DISMUTASE GENE. Harutaka YAMADA, Arao FUTENMA, Katsumi KATO (First Dept. Internal Med., Aichi Med. Univ., Aichi), Yasukazu YAMADA, Haruko GOTO, Nobuaki OGASAWARA (Dept. Genet., Inst. Developmental Res., Aichi Prefectural Colony, Aichi), Tetsuo ADACHI, Kazuyuki HIRANO (Dept. Pharm., Gifu Pharm. Univ., Gifu)

Extracellular-superoxide dismutase (EC-SOD) is the major SOD isozyme in plasma and forms an equilibrium between plasma and heparan sulfate proteoglycans on the cell surface. EC-SOD levels in sera from both healthy persons and hemodialysis patients clearly divide into two discontinuous groups: a low-level group (Group I, below 400 $\mathrm{ng} / \mathrm{ml}$ ) and a high-level group (Group II, adove $400 \mathrm{ng} / \mathrm{ml}$ ). By molecular analysis of the EC-SOD coding region from Group II individuals, a single nucleotide substitution of G to $\mathrm{C}$ generating an amino acid change of arginine to glycine has been identified in the region associated with the heparin affinity of the enzyme. This mutation was detected as a homozygote in 3 hemodialysis patients and as a heterozygote in all healthy Group II individuals and most of the other Group II hemodialysis patients. The binding of mutant EC-SOD to bovine aortic endothelial cells was about 50 -fold less than that of normal EC-SOD These results suggest that the binding of mutant EC-SOD to vascular endothelial cells is extensively decreased in vivo, which results in the high level of serum EC-SOD in Group II individuals.

A-12

GENETIC ASSOCIATION STUDY OF SPORADIC EARLY-ONSET ALZHEIMER DISEASE. Yumiko NISHIWAKI, Kouzin KAMINO, Aoi YOSHIIWA, Tetsuro MIKI, Toshio OGIHARA (Dept. Geriat. Med., Osaka Univ. Med. Sch., Osaka) and Hideki YAMAMOTO, Toshiko KOBAYASHI (Osaka Municipal Kohsaiin Hospital, Osaka)

Causative genes of familial early-onset Alzheimer disease (AD) had been proposed by genetic analysis, and the amyloid protein precursor (APP) gene, S182 gene at 14q24.3, and STM2 gene at 1q31-42 had been reported. Based on the hypothesis that sporadic AD also results from genetic factors, fifty seven patients with early-onset sporadic AD were investigated by mutational and association analysis. No patients disclosed known mutations in the APP gene using mismatched PCR-RFLP. D14S43 and FOS loci showed no significant association with the onset of AD. These results suggested molecular or etiological variations of the cause of early-onset sporadic AD. 
A-13

ASSOCIATION STUDY OF ALZHEIMER'S DISEASE AND APOE GENE REGION. Aoi YOSHIIWA,Kouzin KAMINO, Yumiko NISHIWAKI, Hidehisa YAMAGATA, Tetsuro MIKI, Toshio OGIHARA

(Dept.Geriat.Med., Osaka Univ.Med.Sch., Osaka, Japan).

ApoE- $\varepsilon 4$ allele has been shown as a risk factor of Alzheimer's disease (AD) in both familial and sporadic forms. APOE/APOC1/APOC2 gene cluster locates at 19q13.2, and myotonic dystrophy protein kinase (DMPK) gene locates less than $2 \mathrm{cM}$ distal to the APOE gene. To elucidate risk locus precisely, we performed association study between $A D$ and the ApoC1 gene by RFLP located in its promoter region, and between $\mathrm{AD}$ and the DMPK gene. A significant association between the APOC1 gene and late-onset AD was found $(p<0.001)$, and allele $h$ of the APOC1 gene was associated with AD. But, no significant association between the DMPK gene and AD was found. These results suggested a possibility that genetic interaction between APOE and APOC1 might affect in the onset of AD.

A-14

SEGREGATION RATIO OF AN EXPANDED CAG REPEAT ALLELE IN THE DENTATORUBRAL-PALLIDOLUYSIAN ATROPHY(DRPLA) FAMILIES. Ikuko KONDO, Fumie TAKAKUBO, Yuji MORIMOTO, Akira KUWANO (Dept. of Hygiene, Ehime Univ. School of Med., Ehime) and Ichiro KANAZAWA (Dept. of Neurol., Tokyo Univ. School of Med., Tokyo)

Unstable CAG repeat has been identified in a gene for dentatorubral-pallidoluysian atrophy (DRPLA) in 12p12.3 and the CAG expansion is observed in patient with DRPLA usually associated with paternal transition(genetic anticipation).

We have examined the segregation ratio of the expanded CAG alleles of the DRPLA gene in fully ascertained sibships in 13 families. In sibships, 26 were found to have expanded alleles, while 13 were with normal alleles. The expanded CAG allele transmission occurred more often than $50 \%$ of the times $(\chi 2=4.333, d f=1, p, 0.05)$. These data suggest that the genetic anticipation may be associated not only with severity of the disease but also with higher transmision of the abnormal alleles in the families. 
A-15

ISOLATION AND CHARACTERIZATION OF THE RERE1 GENE WHICH HAS A HIGH HOMOLOGY TO THE DRPLA GENE. Miki BUNDO ${ }^{1,2}$, Shigeo NAGAFUCHI', YANAGISAWA $^{1,2}$, Tatsushi TODA ${ }^{2}$, Yutaka NAKAHORI ${ }^{2}$ \& Masao YAMADA $^{1}$.

('Natl. Children's Med. Res. Ctr., 3-35-31, Taishido, Setagaya-ku, Tokyo 154, ${ }^{2}$ Dept. of Human Genetics, Univ. of Tokyo)

Dentatorubural and pallidoluysian atrophy (DRPLA) is a progressive neurodegenerative disorder caused by expansion of unstable CAG repeats on chromosome 12p. We reported cDNA and genomic forms of the DRPLA gene (Nagafuchi et al. 1994). A computer search revealed that the DRPLA sequence showed a homology to M78755 of $395 \mathrm{bp}$, an expressed sequence tag of the brain. Here, we report the gene represented by the M78755 sequence. The gene produces $5.5 \mathrm{~kb}$ mRNA in most tissues examined. Several cDNA clones were isolated and a nucleotide sequence of $5496 \mathrm{bp}$ was determined. cDNA of the gene is consisted of $244 \mathrm{bp} \mathrm{5'-} \mathrm{untranslated,} 2514$ bp open-reading-frame and 2728 bp 3'-untranslated regions, thus seems to form a protein of 838 amino acids. The C-terminal portion of the product shows a $65.5 \%$ homology to that of the DRPLA protein, and several interesting motifs are also conserved. Two stretches of alternative arginine - glutamic acid dipeptide repeats (RE) are essentially kept in the corresponding positions, but the order of charged residues was slightly modified. Since we assumes this motif play an important role in a normal function the DRPLA protein, we designated this protein family as RERE family and this gene as RERE-1 (RE repeat encoding protein). We also analyzed a genomic organization of the gene.

A-16

FAMILIAL MYOCLONUS EPILEPSY: AN AUTOSOMAL DOMINANT FORM NOT LINKED TO THE DENTATORUBRAL PALLIDOLUYSIAN ATROPHY (DRPLA) GENE. Akira KUWANO, Fumie TAKAKUBO, Iuji MORIMOTO, Ikuko kONDO(Dpt. Hygiene, Fhime University, Ehime) and Eiichiro UYAMA, Makoto UCHINO, Masayuki ANDO(Fst. Dpt. Int. Med., Kumamoto University, Kumamoto)

The CAG repeat expansion responsible for the dentatorubral pallidoluysian atrophy(DRPLA) has been isolated. Another type of dominantly inherited myoclonus epilepsy, benign adult familial myoclonus epilepsy (BAFME), is known to be non-progressive. The distinct difference between DRPLA and BAFME is the genetic anticipation, which is observed not BAFME but DRPLA. We have analyzed the DRPLA gene in the five families with BAEME. Abnormal CAG expansion of the gene was not observed in the affected individuals. Further linkage analyses using the DNA polymorphisms in the DRPLA, and the genes for r-aminobutyric acid (GABA) receptor subunits, GABARB1, GABARB3 and GABARa6, showed that these genes were not responsible for BAFME. 
A-17

GENOMIC ORGANIZATION AROUND THE DRPLA GENE. Takayuki TAKEDA ${ }^{1,2}$, Hiroko YANAGISAWA $^{1,2}$, Shigeo NAGAFUCHI ${ }^{1}$, Tatsushi TODA ${ }^{2}$, Yutaka NAKAHORI ${ }^{2}$ \& Masao YAMADA ${ }^{1}$. ('Natl. Children's Med. Res. Ctr., 3-35-31, Taishido, Setagaya-ku, Tokyo 154, ${ }^{2}$ Dept. Human Genetics, Faculty of Medicine, Univ. of Tokyo)

Dentatorubral and pallidoluysian atrophy (DRPLA) is a neurodegenerative disorder caused by expansion of triplet repeats on the short arm of chromosome 12. We have reported cDNA and genomic forms of the gene. Recently the chromosomal location of the gene was more specified by FISH at 12p13.31 (Takano et al. in press). We screened CEPH YAC pools for clones carrying the DRPLA gene as well as several markers located at $12 \mathrm{p} 13$. We then analyzed isolated clones to determine whether nearby markers co-existed in the same clone. Based on our experimental evidences together with Genethon data-base, we successfully made a YAC contig covering a 8-10 $\mathrm{Mb}$ region of D12S93-D12D77. Analyses of genomic clones containing the DRPLA gene revealed ENO2, snRNAU7 and PTPN6 were situated adjacent to the DRPLA with the same transcriptional direction. Putting these data together, we concluded that (telomere direction)-D12S93-NTF3F8VWF-(ENO2-DRPLA-snRNAU7-PTPN6)-GAPD-SYB1-TPI1-CD4-C1R-CLTA-M6PR-A2 M-PZP-CD69-D12S77-(centromere direction) markers are situated in this order at 12p13.

A-18

EXPANDED DRPLA REPEATS ARE DERIVED FROM A UNIQUE ORIGIN. Hiroko YANAGISAWA $^{1,2}$, Shigeo NAGAFUCHI ${ }^{1}$, Tatsushi TODA ${ }^{2}$, Yutaka NAKAHORI $^{2}$ \& Masao YAMADA'. ('Natl. Children's Med. Res. Ctr., 3-35-31, Taishido, Setagaya-ku, Tokyo $154,{ }^{2}$ Dept. of Human Genetics, Univ. of Tokyo)

Dentatorubral and pallidoluysian atrophy (DRPLA) is a neurodegenerative disorder caused by expansion of triplet repeats on the short arm of chromosome 12. Based on genomic analyses around the DRPLA gene, we found new DNA polymorphisms suitable to study haplotypes. We analyzed the distribution of numbers of the repeat together with haplotypes in Japanese, Korean, Chinese, Caucasian \& African-American ethnic groups. All the expanded repeats found in Japanese as well as in Caucasian have a particular haplotype, which is otherwise associated with relatively longer repeats, and is commonly found in Asian populations. This indicates that expanded DRPLA repeats are derived from a unique origin, which seemed to created in an ancient Asian subpopulation. (In addition to authors described here, this is a collaborative work with a lot of researchers who made various DNA samples available in this analyses). 
A-19

Somatic mosaicism of CAG repeat expansion could be associated with brain shrinkage in DRPLA. Hiroki TAKANO ${ }^{1}$, Osamu ONODERA ${ }^{1}$, Hitoshi TAKAHASHI ${ }^{2}$,Mistunori YAMADA $^{2}$,Shuichi IGARASHI ${ }^{1}$, Mutsuo OYAKE ${ }^{1}$, Takeshi IKEUCHI ${ }^{1}$, Reiji KOIDE $^{1}$,Hajime TANAKA ${ }^{\dagger}$, Kiyoshi IWABUCHI ${ }^{3}$,Shoji TSUJI ${ }^{1}$ (Dept. of Neurology ${ }^{1}$ and Pathology 2 , Brain Res. Inst., Niigata Univ. Dept of Psychiatry ${ }^{3}$, Kanagawa Rehabilitation Center, Japan.)

Dentatorubral-pallidoluysian atrophy (DRPLA) is an autosomal dominant neurodegenerative disease caused by an unstable expansion of a CAG repeat in the DRPLA gene. We analyzed variation in size of the CAG repeat in neural and non-neural tissues from 8 autopsied DRPLA patients. Expanded alleles (AE) displayed various major band sizes of $A E$ and ranges of $A E$ in different tissues from the same patients, which indicated the presence of somatic mosaicism of $A E$, whereas normal alleles (AN) did not show somatic mosaicism. The cerebellar cortex showed 3 - 6 repeat smaller major band size of AE compared with the cerebellar white matter. The cerebral cortex also showed 1 - 4 repeat smaller major band size of AE than the cerebral white matter. It was suggested that smaller AE may be that of neuronal cells. The ranges of $A E$ in the cerebellar cortices were constant of 6 repeats among patients; however, those in the cerebral cortex, and the cerebral and cerebellar white matters seemed ot widen (8 - 22 repeat ranges) with patients' ages. The quite variable ranges of $A E$ in brains, which was

\section{CLONING OF A BREAKPOINT OF $\mathbf{t}(8 \mathrm{q} ; 13 q)$ IN A PATIENT WITH MULTIPLE CARTILAGINOUS EXOSTOSES}

EGASHIRA, M., SOEJIMA, H., YOSHIURA, K., NIIKAWA, N. (Dept. Hum. Genet., Nagasaki Univ. Sch. Med., Nagasaki), NAKAMURA, Y. (Inst. Med. Sci., Univ. Tokyo)

Multiple cartilaginous exostoses (EXT) is an autosomal dominant benign tumor in various bones. We previously isolated a cosmid clone corresponding to the $8 \mathrm{q}$ break point of a EXT patient. We then isolated a YAC covering the cosmid and constructed a cosmid contig. By exon trapping, we obtained two exon-like transcripts (K-37 and K219) from the break point region, and analyzed the clone $\mathrm{K} 37$ flanking the break point. Zoo blotting showed signals in human, rat, cow, pig and chicken. Although RT-PCR revealed the expression in cartilage tissues, no signals appeared by Northern hybridization in this tissue. We then tried to isolate the whole length of the cDNA by $3^{\prime}$ RACE/5' RACE. As a result, two products each probably due to alternative splicing were obtained by $3^{\prime} \mathrm{RACE}$, and a product consisting of repetitive sequences was obtained by 5'RACE. These sequences is being analyzed. 
A-21

ISOLATION OF COSMID CLONES, STSs, AND OVERLAPPING YACS FROM THE REGION OF THE HUMAN GENE (HYRC) COMPLEMENTING THE HYPERRADIOSENSITIVITY OF THE SCID MOUSE MUTATION

MATSUMOTO, N., WATANABE, Y., OHTA, T. TSUJTA, T., JINNO, Y. NIIKAWA, N. (Dept. Hum. Genet., Nagasaki Univ. Sch. Med.), KOMATSU, K. (Dept. Radiat. Biol., Res. Inst. Radiat. Biol. Med., Hiroshima Univ.)

We previously mapped the putative human $H Y R C$ (the hyper-radiosensitivity of the scid mutation, complementing gene) to human chromosome $8 \mathrm{q} 11.1$ by fluorescence in situ hybridization (FISH) using Alu-based PCR products from a mouse-human scid radiation cell hybrid (RD15/5) as probes. From a cosmid library constructed from RD15/5, 57 cosmid clones containing human DNA inserts were isolated, 18 of which were mapped at $8 \mathrm{q} 11$. Based on the sequences of the plasmid subclones of the 18 cosmids, five novel sequence-tagged-sites (STSs) were made. By a screening of the CEPH YAC library with these STSs, five YAC clones were isolated. All these YAC clones were confirmed not to be chimeric by FISH but to be overlapping each other by the Alu-PCR fingerprinting. The isolated cosmid clones, STSs and restriction map of a YAC contig are useful for a construction of a contig map for the positional cloning for HYRC.

A-22

RPS $4 X / R P S 4 Y, S M C X$, and $Z F X / Z F Y$ ARE POSSIBLY RULED OUT FROM CANDIDACY OF THE PUTATIVE KABUKI MAKE-UP SYNDROME GENE

MATSUMOTO. N., NIIKAWA. N, (Dept. Hum. Genet, Nagasaki Univ. Sch. Med.), FUKUSHIMA. Y. (Dept. Hyg., Shinshu Univ. Sch. Med.), OHASHI, H. (Div. Med. Genet., Saitama Child. Med. Ctr.), NAGAI. T. (Div. Pediatr. Kiyose Child. Hosp., Tokyo)

Kabuki make-up syndrome (KMS) is an MCA/MR syndrome of unknown cause, characterized by distinct facial changes, mild to moderate mental retardation, postnatal growth retardation, skeletal and dermatoglyphic anomalies. We previously hypothesized that KMS is caused by a mutation in a pseudoautosomal gene located to sex chromosomes.

We studied five KMS patients whether they have a mutation in such a gene. Reverse transcription - polymerase chain reaction (RT-PCR)-based single-strand conformational polymorphism (SSCP) analysis was performed using three pseudoautosomal genes such as RPS 4X/RPS4Y, SMCX and ZFX/ZFY), which escape X-inactivation and are mapped at around breakpoints of previously reported KMS-associated $X$ chromosome aberrations. The size of RT-PCR products from the patients for each gene corresponding to those as expected. There were no aberrant SSCP-patterns in any of the five patients. The findings suggested that these three genes may be ruled out from the candidacy for the putative KMS gene. 


\begin{abstract}
A-23
SEARCHING A GENE(S) RESPONSIBLE FOR ATAXIA TELANGIECTASIA BY POSITIONAL CLONING APPROACH.

Takashi IMAI ${ }^{1}$, Naohiko SEKI ${ }^{2}$, Takehiko SUGAWARA ${ }^{1}, 3$, Masatake YAMAUCHI $^{1}$, TOshiyuki SAITO ${ }^{1}$, Yoichi MATSUDA ${ }^{1}$, Hiroko ITOH $^{1}{ }^{1}$ Takahiro NAGASE ${ }^{2}$, Ken-ichi ISHIKAWA ${ }^{2}$, Kunio YAMANE ${ }^{3}$, Nobuo NOMURA $^{2}$ and Tada-aki HORI ${ }^{1}{ }^{1}{ }^{\text {Genome Res., Natl.Inst. Radiol. }}$ Sci., Chiba, ${ }^{2}$ Lab. Gene Str. I., Kazusa DNA Res. Inst., Chiba, ${ }^{3}$ Biological Sci. Univ. Tsukuba, Tsukuba)

Ataxia telangiectasia (AT) is an autosomal recessive disease and AT cells exhibit chromosomal instability, hypersensitivity to the killing effect of ionizing radiation, and defective $\mathrm{G}_{2} / M$ cell cycle checkpoint. Very recently, the candidate gene for AT, ATM, has been identified by Savitsky et a1. (Science 268:1749-1753, 1995). To analyze AT locus further, we constructed a long-range physical map of $\mathrm{YAC}$ clones spanning the AT region and identified two new house keeping genes by screening CDNA libraries with the YACs. Analysis of genomic structure showed that one of the new genes links closely to the ATM gene by head to head array. In order to clarify the role of the genes mapped in AT locus, we are attempting to analyze function of these genes as well as to search mutations of the genes in AT patients.
\end{abstract}

\title{
A-24 \\ COSMID ISOLATION FROM AN INV (21) BREAK POINT IN A PATIENT WITH TRANSIENT ABNORMAL MYELOPOIESIS (TAM)
}

NAKANO, M. OHTA, T. ABE, K. NIIKAWA, N. (Dept. Hum. Genet., Nagasaki Univ. Sch. Med., Nagasaki), and SOEDA, E. (Riken, Tsukuba)

Transient abnormal myelopoiesis (TAM) is a leukemoid reaction occurring occasionally in Down syndrome (DS) newborn infants. It has been hypothesized that "disomic homozygosity" in 21-trisomic cells plays a role for the genesis of TAM, and the putative TAM gene was suggested to be mapped at a $21 \mathrm{q} 11$ region. We encountered a DS-associated TAM infant with a 47,XY, inv(21)(q11.1q22.13), +inv(21)(q11.1q22.13) karyotype.

Based on another hypothesis that in this patient, the putative TAM gene is disrupted by the break, we tried to isolate a breakpoint DNA. FISH analysis with cosmid clones corresponding to various STS markers mapped at around 21q11.1-q11.2, we confirmed that the proximal breakpoint of the inv(21) was located between G51E07 and D21S215, the latter locus being consistent to the previous tentative mapping. After construction of a cosmid contig encompassing between the 2 markers, we have isolated a cosmid clone corresponding to the proximal breakpoint of the inversion. This breakpoint was located nearby the previously identified duplicated region that is homologous to the sequence at 21q22.1. The isolated cosmid clone is useful for analysis of other TAM patients and for a search for a transcript at or franking the breakpoint. 


\section{A-25}

\section{ISOLATION OF TRIPLET REPEATS FROM CHROMOSOME 21}

TSUJITA, T. OHTA, T. MATSUMOTO, N. NIKAWA, N. (Dept. Hum. Genet., Nagasaki Univ. Sch. Med.), OKAZAKI, Y. IMAMURA, A. (Dept. Psychiat., Nagasaki Univ. Sch. Med.), SOEDA, E. (Riken, Tsukuba)

In some genetic neuromuscular diseases showing expansion of triplet repeats, there is a relationship between the expansion and genetic anticipation or severity of symptoms. Since bipolar disorder and Unverricht-Lundborg disease have been located on chromosome 21, a study to isolate these genes has been started.

By a screening of a cosmid library with oligonucleotides such as $(\mathrm{AGC})_{20},(\mathrm{GGC})_{20}$ ? $(\mathrm{ACG})_{20}$, we isolated 3,2 and 9 clones consisting of the triplet repeats, respectively. They were mapped at either of 21q11.1-q11.2, q22.1, q22.2, or q22.3. By subcloning of these cosmids, we isolated 4 plasmid clones containing $(\mathrm{GGC})_{7},(\mathrm{GGC})_{7},(\mathrm{GCT})_{6}$, and $(\mathrm{GGA})_{7}$ repeats, respectively. Psychiatric disease families showing anticipation are analyzing by PCR whether patients have expansion of these triplet repeats.

\section{A-26}

ASSOCIATIONS OF AN INSERTION/DELETION POLYMORPHISM IN THE ANGIOTENSIN CONVERTING ENZYME GENE WITH BRAIN SUBSTANCE P CONTENTS AND WITH AFFECTIVE DISORDERS. Tadao ARINAMI, Liming LI, Hideo HAMAGUCHI (Dept. Med. Genet., Inst. Basic Med. Sciences, Univ.of Tsukuba, Tsukuba), Masanari ITOKAWA, Michio TORU (Dept Neuropsychat. Tokyo Med. and Dent. Univ, Tokyo), Hiroshi MITSUSHIO (Nat. Hosp. for Ment. Nerv. and Muscul. Disord., Tokyo)

Because of a potent action of angiotensin converting enzyme (ACE) to degrade substance $P(S P)$ and an association of the insertion/deletion $(I / D)$ polymorphism of the ACE gene with the ACE activity, an association between the SP level and the ACE I/D polymorphism were examined using 20 human postmortem brain samples. The results showed a significant association between the polymorphism and SP levels in the basal ganglia and substantia nigra, a higher SP level in the subjects with the DD genotype than in those with the II genotype and intermediate in heterozygotes. Associations of the polymorphism with schizophrenia and affective disorders were also investigated in 65 patients with affective disorders and 579 controls. The D allele was significantly more frequent in the patients with affective disorders than in the controls $(p<0.02)$, and the DD genotype was significantly more frequent in the patients with affective disorders than in the schizophrenics $(p<0.004)$ or controls $(p<0.002)$. These results suggest that the ACE I/D polymorphism is one of the genetic factors for an inter-individual variability of brain SP levels and that the ACE polymorphism may contribute to the susceptibility to affective disorders. 


\section{A-27}

NUCLEOTIDE SEQUENCE AND MAPPING OF HUMAN HISTAMINE-H 1-RECEPTOR AND HISTIDINE DECARBOKYLASE GENES AS A REGULATOR OF FOOD INTAKE AND OBESITY. Takashi IMAMURA, Hitoshi NAKASHIMA, Masako SAKAI, Rie INABA, Kenji IZUHARA (National Institute of Genetics, Mishima), and Tomoko HASEGHWA (Shizuoka Children's Hospital, Shizuoka)

It has been reported that neuronal histamine suppresses food intake through histamine-H1-receptor $(H 1 R)$, and that the histaminergic dysfunction may be involved in the development of obesity. The synthesis of this biogenic amine is catalyzed by the key enzyme histidine decarboxylase (HDC). Since the mutation of maternally imprinted genes mapped on the chromosome $15 q 11-13$ region results in morbid obesity as part of Pradar-Willi syndrome, we thought that either the $H 1 R$ gene or the HDC gene might be a candidate gene in this disorder. Thus, we determined the complete nucleotide sequence of $H I R$ gene, and then located this gene by the use of a PCA-mapping technique on the short arm of chromosome 3. Furthermore, we showed that HDC gene was fully expressed in patients with PWS syndrome. Although its map location may be in the PUS region on the chromosome 15, HDC gene does not appear to be maternally imprinted. our results suggest that both genes are not etiologically related to the abnormal behauior of food intake that results in the profound obesity in PWS syndrome.

A-28

BREAKPOINT ANALYSIS OF $\mathrm{t}(6 ; 18)$ IN A PATIENT WITH SITUS INVERSUS

KATO, R., OHTA, T., NIIKAWA,N. (Dept. Hum. Genet., Nagasaki Univ. Sch. Med.), and NAKAMURA, Y. (Inst. Med. Sci, Univ. Tokyo)

Situs inversus, a malformation resulting from a disturbance of laterality of visceral organs during embryogenesis, is often associated with cardiac, blood vessel and/or spleen anomalies. Thus, isolation and characterization of the putative laterality gene is important to understand the genesis of the anomalies. We are trying to isolate such a gene from a breakpoint of de novo $\mathrm{t}(6 ; 18)(\mathrm{q} 21 ; \mathrm{q} 21.3)$ in a patient with situs inversus. Using CEPH-YACs located at around 6q21 as probes, we identified a YAC that corresponded to the breakpoint. As we have subcloned this YAC into cosmids, clones to detect the breakpoint are searching.

In parallel, the connexin 43 gene which is responsible for right ventricular out-flow tract anomaly in the mouse was subjected to Southern blot analysis. However, any extra hybridization band was not detected in DNA from the patient, being ruled out from the candidacy for situs inversus in the patient. 


\begin{abstract}
A-29
Molecular cloning of the $11 \mathrm{q} 13$ inversion breakpoint of inv(11)(q13,q25) found in a patient with polysplenia syndrome.

Aritoshi IIDA(Uviv.of Tokyo, Tokyo, Nippon medical school, Kanagawa), Keioko OKUI(Uviv. of Tokyo, Tokyo), Takashi IMAI (Natl. Inst Rad.Sci.,Chiba), Yosimitsu FUKUSHIMA(Shinsyu Univ. ,Nagano), Mitsuru EMI (Nippon medical school, Kanagawa), Yusuke NAKAMURA (Uviv.of Tokyo, Tokyo)
\end{abstract}

We have cloned the chromosomal breakpoint of inv(11)(q13,q25) found in a patient with polysplenia. The breakpoint of the 11q13 was mapped between two loci defined by CZNE6 and CCI11-404 using FISH. Subsequently, a YAC covering the $11 \mathrm{q} 13$ breakpoint was isolated. We constructed a cosmid contig of this region and identified that one of these cosmids, cIH-21, recognized the rearrenge band in the patient by Southern hybridization. Using $1.8-\mathrm{Kb}$ BamHI fragment of CIH-21 as a probe, a cosmid containing the $11 \mathrm{q} 13$ breakpoint was isolated from a library constructed from the patient DNA. Sequence analysis revealed that chromosomal translocation occurred within the $L 1$ repeat sequences and we are inverstigating the transcriotional unit responsible for polysplenia syndrome.

A-30

DETAILED ANALYSIS OF A $t(2 ; 8 ; 3)(\mathrm{p} 11.2 ; \mathrm{p} 11.2 ; \mathrm{p} 23)$ OF A PATIENT WITH MENTAL RETARDATION, EPILEPSY AND AUTISM. ${ }^{1}$ Minoru ISOMURA, ${ }^{2}$ Yoshimitsu FUKUSHIMA and ${ }^{1}$ Yusuke NAKAMURA $\left({ }^{1}\right.$ Lab. Mol. Med., Inst. Med. Sci., Univ. Tokyo, ${ }^{2}$ Dept. Hyg., Shinshyu Univ. Med. Sch., Matsumoto)

We have analyzed a breakpoint of chromosomal translocation $t(2 ; 8 ; 3)(\mathrm{p} 11.2 ; \mathrm{p} 11.2 ; \mathrm{p} 23)$ of a patient with mental retardation, epilepsy and autism. Analyses of the patient's chromosomes with a linearly-ordered cosmid markers on 3p23 indicated that the breakpoint is located within two loci defined by cosmids cCI3-837 and CCI3-1444. Subsequently, a YAC clone containing both flanking loci was isolated and a cosmid library was constructed from the yeast DNA. To isolate the clone that contain the breakpoint, a cosmid contig was constructed. Among a contig from cosmid 19-52111-12-151-136-19, former four clones were mapped at centromeric side form the breakpoint, whereas the latter was at teromeric side by FISH analysis on patients chromosome These result suggested that cosmid 12 and/or 151 contain the breakpoint on $3 p$. 
$\mathbf{A - 3 1}$

POSSIBLE MAPPING OF A GENE FOR IDIOPATHIC ABSORPTIVE HYPERCALCIURIA TO 4q33-4q35.1 BY CYTOGENETIC ANALYSES. Hidefumi TONOKI, Keisaku IMAMURA, Satoshi SASAKI, Kazue YASUDA, and Hiroyuki TOCHIMARU (Dept. Pediatr. Hokkaido University, Sapporo)

Idiopathic hypercalciuria (IH) is a common cause for hypercalciuria and predisposes to urolithiasis. Although the pathogenesis is unclear, excess absorption of calcium from intestine with or without increased serum level of activated vitamin $D$ is known to account for the condition. We describe two patients with de novo deletions of the long arm of chromosome 4 who were disclosed to have IH along with multiple congenital anomalies. Patient 1, a four year old girl, had an interstitial deletion, del(4)(q33q35.1). The other patient had a terminal deletion of the long arm of chromosome 4 with the breakpoint at $\mathrm{q} 33$ as a result of de novo umbalanced translocation. Urinary excretion of calcium was increased in both patients as much as 0.7 and 1.0 (mg/mg of creatinin), respectively, but not in the parents. Serum levels of calciium, calcitonin, parathyloid hormone, and $1,25(\mathrm{OH}) 2 \mathrm{D} 3$ were normal in both patients. Further analyses revealed that they had idiopathic absorptive hypercalciuria. Since the chromosomal region of 4q33-q35.1 is commonly deleted in both patients, it is probable that hemizygosity of the region is responsible for the development of the absorptive hypercalciuria in our patients. This may result in overexpression of Vitamin D receptor in enterocyte, as suggested in rat. Alternatively, certain gene(s) involved in this region may have a suppressive effect on activation of Vitman D receptor in enterocyte.

A-32

STS ISOLATION VIA RDA AND MAPPING IN A YAC CONTIG AT AD3 LOCUS. Kouzin KAMINO, Yumiko NISHIWAKI, Aoi YOSHIIWA, Tetsuro MIKI, Toshio OGIHARA (Dept. Geriat. Med., Osaka Univ. Med. Sch., Osaka), Shinji SATOH, Koh-ichi KUROSE and Yoshiyuki SAKAKI ( Hum. Genome Center, Ins. Med. Sci., Univ. Tokyo, Tokyo)

We had reported the major locus of Japanese familial early-onset Alzheimer's disease (AD) at 14q24.3. To isolate its candidate genes, a contig was constructed by five YACs to cover the region between D14S61 and D14S77. A YAC clone, 797d11, was applied to representational difference analysis (RDA), and eleven STSs were successfully isolated and mapped in the contig. This method was effective to isolate STSs without any restrictions and to construct fine contigs. And we also reported a patient of TK-2 family to show a mutation of $\$ 182$ gene that was recently reported as a causative gene of familial early-onset AD. 
A-33

CONSTRUCTION OF COSMID/BAC CONTIGS FOR THE CAT EYE SYNDROME CHROMOSOME REGION (22q11)

Shinsei MINOSHIMA, Shuichi ASAKAWA, Jun KUDOH, Yimin WANG, Kazuhiko KAWASAKI and Nobuyoshi SHIMIZU (Dept. Mol. Biol., Keio Univ. Sch. Med.)

Cat eye syndrome (CES) is caused by tetrasomy (or trisomy) of the $22 \mathrm{q} 11$. The morphological anomalies in CES include coloboma of the eye, imperforate anus and characteristic heart malformation (totally anomalous pulmonary venous return). Most $(>90 \%)$ of the CES patient has a supernumerary bisatellited marker chromosome (mar) retaining two copies of the 22 pter-q11 region. We have constructed cosmid/BAC contigs of CES chromosomal region to isolate the disease-causing genes.

We previously prepared a CES region-specific cosmid library $(9,200$ clones, 10 times equivalent) with flow-sorted marker chromosomes of CH91-157 cell line established from a CES patient. Cosmid clones derived from the long arm were selected by fluorescence in situ hybridization (FISH) and 7 STS's were established to screen CEPH YAC library (35,000 clones). Twenty YAC clones were identified and arrayed in to a YAC contig. Using these YAC clones as probes we screened the CES region-specific cosmid library and a human genomic BAC library (70,000 clones, 2.3 times equivalent) that we recently constructed, and 1,131 cosmids and $18 \mathrm{BAC}$ clones were obtained. These cosmid/BAC clones were analyzed by finger printing and hybridization to build cosmid/BAC contigs. So far, 3 contigs including one with an approximate size of $350 \mathrm{~kb}$ have been made. These cosmid/BAC clones will be used for the large scale genomic sequencing.

\section{A-34}

\section{DELETION MAPPING OF 17p11.2 IN 8 PATIENTS WITH SMITH-} MAGENIS SYNDROME.

Toshiyuki KIMURA ${ }^{1}$, Yoshiki ARAKAWA ${ }^{1}$, Naoya HASHIMOTO ${ }^{1}$, Yoshimitu

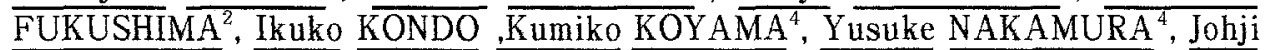
INAZAWA $^{1}$, Tatuo ABE ${ }^{1}{ }^{1}$ Dept. of Hyg., Kyoto Pref. Univ. of Med, ${ }^{2}$ Dept. of Hyg., Shinsyu Univ. of Med, ${ }^{3}$ Dept. of Hygene, Ehime Univ. of Med, ${ }^{4}$ Lab. of Mol. Med, Tokyo Univ. of Inst.. )

Smith-Magenis syndrome (SMS) is a contiguous gene syndrome associated with deletion of $17 \mathrm{p} 11.2$ and characterized by varying degress of development disability, self-destructive behavior, hyperactivity, and the other clinical manifestations. We have constructed a deletion map of $17 \mathrm{p} 11.2$ in eight unrelated patients with SMS by fluorescence in situ hybridization (FISH) with 24 cosmid markers and three novel genes recently mapped within this region. One patient was deleted for only three cosmids, although the other seven patients were deleted for 10 or 11 cosmids. All of three novel genes were retained in this patient, although at least two of them were deleted in the other patients. Major clinical manifestations are not different among eight patients. These results indicates that major genes responsible for SMS locate within a limited region deleted in this patient. 
A-35

HIGH RESOLUTION PHYSICAL MAPPING BY COMBINED ALUHYBRIDIZATION/STS CONTENT SCREENING: CONSTRUCTION OF A YAC CONTIG COVERING 25 CM IN 3p21-p14 REVEALS INVERSE DISTRIBUTION OF $(C A)_{n}$ AND ALU-PCR LOCI. Hiroyuki ABURATANI (3rd Dept. Internal Med., Univ. Tokyo, Tokyo) Vincent STANTON, Ir. and David E. HOUSMAN (M.I.T., Cambridge, MA, U.S.A.)

We present an integrated approach to large scale physical mapping that combines STS content mapping with a novel Alu PCR hybridization method. Intensive application of this combined approach enabled construction of a $\sim 25 \mathrm{mb}$ YAC physical map in 3p21-14 and allowed detailed comparison of the relative strengths of the two methods and the relative distribution of Alu-PCR vs. (CA)n loci. Analysis of the resulting contig, composed of 193 ordered loci connected by 538 YACs, reveals an inverse distribution of the two types of probes, suggesting that the two methods may be complementary over large regions of the genome and demonstrating that the use of Alu-PCR hybridization can speed the completion of high density contigs.

A-36

LINKAGE DISEQUILIBRIUM MAPPING OF A GENE FOR FUKUYAMA-TYPE CONGENITAL MUSCULAR DYSTROPHY. Tatsushi TODA, Masashi MIYAKE, Kunihiko MIZUNO, Yasuo NAKAGOME, Yutaka NAKAHORI (Dept. Hum. Genet., Univ. of Tokyo, Tokyo)

Fukuyama type congenital muscular dystrophy (FCMD) is an autosomal recessive severe muscular dystrophy associated with an anomaly of the brain. Following our initial mapping of the FCMD locus to chromosome 9q31-33, we had further defined the locus within a region of approximately $5 \mathrm{cM}$ between loci D9S127 and CA246 and also found evidence for linkage disequilibrium between FCMD and mfd220 on 9q31. Since FCMD is prevalent among the Japanese which is genetically isolated population, linkage disequilibrium mapping is feasible as in Finland. However, no markers have been discovered very close to $\mathrm{mfd} 220$. We developed new CA repeat markers from YAC contigs containing mfd220, determined their position on YACs, and allele-typed FCMD and normal individuals with these new markers. "P excess" values, representing the strength of linkage disequilibrium, were $0.32,0.75,0.81,0.95$, $0.81,0.60$, and 0.45 at $\mathrm{mfd} 220, \mathrm{XF9}, \mathrm{M} 8, \mathrm{~J} 12, \mathrm{D} 9 \mathrm{~S} 172$, GATA27, and A4, respectively. Distances between FCMD and each marker were presumed to be $1 \mathrm{Mb}$, $230 \mathrm{~kb}, 160 \mathrm{~kb}, 30 \mathrm{~kb}, 160 \mathrm{~kb}, 450 \mathrm{~kb}$, and $740 \mathrm{~kb}$, respectively. These putative distances were consistent with each marker's position on YACs. Thus, the FCMD gene could lie within a region of less than $100 \mathrm{~kb}$ containing $\mathrm{J} 12$ and we are able to perform highly-focused positional cloning. 
A-37

PHYSICAL MAP OF FUKUYAMA-TYPE CONGENITAL MUSCULAR DYSTROPHY CANDIDATE REGION BASED ON YACS AND COSMIDS.

Masashi MIYAKE, Tatsushi TODA, Kunihiko MIZUNO, Ikumi MATSUSHITA, Yasuo NAKAGOME, and Yutaka NAKAHORI (Dept. Hum. Genet., Univ. of Tokyo, Tokyo)

Fukuyama-type congenital muscular dystrophy (FCMD) is an autosomal recessive severe muscular dystrophy associated with an anomaly of the brain. We had localized the gene for this disorder between the markers D9S127 and CA246, a region of approximately $5 \mathrm{cM}$ on $9 \mathrm{q} 31-33$. From this region, we had found a marker, mfd220, which showed linkage disequilibrium with FCMD. Through further analysis, we have defined another marker, D9S172, which showed stronger linkage disequiribrium than mfd220. We constructed a YAC contig extending from $\operatorname{mfd} 220$ to D9S172, established restriction map, and constructed cosmid contig.

Total of 10 YAC clones containing either $\operatorname{mfd} 220$ or D9S172 were isolated using 3-D PCR. After analyzing the clones with FISH for chimeras, rough contig was constructed by Alu-PCR analysis. Then, restriction map was established for the clones that were nonchimeric, using the rare cutting enzymes. Also, detailed YAC contig was constructed by generating YAC end probes using vectrette PCR method in order to verify the overlapping of the YACs. Cosmid clones that were subcloned from YAC were also arranged into a contig, primarily in the vicinity of the D9S172. We are now utilizing other markers and the cosmids with NotI site as an anchor point for the purpose of construction of a cosmid contig. These physical maps will be a crucial source for the isolation of the FCMD gene.

A-38

Heteroallellic R94C/F97V missence mutations of GALNS gene in a late onset and mild Mucopolysaccharidosis IVA with residual activity. Seiji FUKUDA, Shunji TOMATSU, Kazuko SUKEGAWA, Naomi KONDO, Tadao ORII(Dept. Pediatr., Gifu Univ. Japan), David E.C.COLE (Dept. Clin.Biochem., Med. and Pediatr., Univ. Toronto, Canada) and B. A. Gordon (Dept. Pediatr. and Biochem., Univ. Western Ontario, Canada)

Mucopolysaccharidosis IVA is an autosomal recessive disorder caused by a deficiency of N-Acetylgalactosamine-6-sulfate sulfatase (GALNS). We report a patient with late onset and mild phenotype of the disease. Her bony changes were restricted largely to only the axial skelton and her vision were mildly impired. At age 22, keratan sufaturia was detected, an event that led to suspect the diagnosis of MPS IVA. $\beta$-galactosidase levels was normal but GALNS activity in her fibroblast homogenate was about $15 \%$ of controls. Her genotype of GALNS gene was F97V / R94C mutant alleles. Her father and mother had approxinately $75 \%$ and $25 \%$ GALNS activity and they were the carriers of F97V and R94C allele, respectively. In transfection experiment into GALNS deficient cells, R94C and F97V independently expressed as severe and mild GALNS deficiency, respectively. We interpret these findings to indicate that our patient bears heteroallelic missence mutations leading to GALNS deficiency and mild MPS IVA, but futher study of native and transfected mutant cell lines remains to be done to delineate the complete genotype phenotype relationship. 


\section{A-39}

MOLECULAR ANALYSIS OF MUCOPOLYSACCARIDOSIS IV A: MUTATION SCREENING OF THE COLOMBIAN PATIENTS WITH NON-RI SSCP-PCR. Zenichiro KATO, Shunji TOMATSU, Seiji FUKUDA, Naoto YAMADA, Atsushi YAMAGISHI , Kazuko SUKEGAWA, Naomi KONDO, Tadao ORII (Dept. of Pediatr., Gifu Univ. Sch. of Med., Gifu, JAPAN) and Hugo VEGA, L. A. BARRERA ( CIBI, Universidad de los Andes, Bogota, COLOMBIA)

Mucopolysaccharidosis IV A (MPS IV A) is an autosomal recessive disorder caused by a deficiency in $\mathrm{N}$-acetylgalactosamine-6-sulfate sulfatase (GALNS). In this study, we screened promoter region, 14 exons and exon-intron boundaries of GALNS gene of 12 Colombian severe type patients using non-RI SSCP-PCR method with silver staining. The results showed the presence of 3 kinds of novel missense mutations (F69V, S162F and G301C). F69V was found in unrelated one patient and S162F was found in both alleles of two sibling patients and in one allele of another unrelated patient. G301C was found in 12 of 24 alleles (50\%) and thought to be a common missense mutation. And also this mutation may correlate the severe phenotype of the disease. These new findings will help us for better understanding the genotype-phenotype correlation of MPS IV A.

\section{A-40}

Niemann-Pick disease type C (NPC) is a cholesterol-sphingomyelin storage disease that have a defect in cholesterol transport from the lysosome to other membrane sites. It has been reported that cystine transport defficiency is present in BALB/C model mice (Jean.D.Butler 1993). In this study we have shown that the defferences between infantile type and adult type of Niemann-Pick disease type $\mathrm{C}$ are intracelluler levels of cystine, sialic acid and gangliosides.

\begin{tabular}{|c|c|c|c|c|c|}
\hline & $\begin{array}{c}\text { Storage of } \\
\text { cholesterol }\end{array}$ & $\begin{array}{c}\text { Defficiency of } \\
\text { cholesterol } \\
\text { esterification }\end{array}$ & $\begin{array}{c}\text { Storage of } \\
\text { free cystine }\end{array}$ & $\begin{array}{c}\text { Storage of } \\
\text { sialic acid }\end{array}$ & $\begin{array}{l}\text { Storage of } \\
\text { ganglioside }\end{array}$ \\
\hline $\begin{array}{c}\text { NPC } \\
\text { (adult type) }\end{array}$ & mild & mild & normal & $\begin{array}{c}\text { increase } \\
\text { (free type) }\end{array}$ & normal \\
\hline $\begin{array}{c}\text { NPC } \\
\text { (infantile type) }\end{array}$ & severe & severe & increase & $\begin{array}{c}\text { increase } \\
\text { (bound type) }\end{array}$ & $\begin{array}{c}\text { increase } \\
\text { (GM2) }\end{array}$ \\
\hline
\end{tabular}

The severity in cholesterol accumulation and defective cholesterol esterification, and the heterogenity in the storage patterns of free cystine, free sialic acid and ganglioside may be closely associated with the severity of clinical symptoms. 
A-41

GENETICHETEROGENEITY OFNIEMANN-PICKDISEASETYPEC

Shinjiro AKABOSHI (Division of Child Neurology, Institute of Neurological Sciences, Faculty of Medicine, Tottori University) and Kousaku OHNO(Department of Neurobiology, School of Life Sciences, Faculty of Medicine, TottoriUniversity)

Niemann-Pick disease type C (NP-C) is considered to have a defect in intracellular transportof unesterified cholesterol, but the basic defecthas notbeenclarified. In this study we show that there is a genetic heterogeneity in NP-C and SPM-3T3 by complementation analysis. Cell line; Cultured skin fibroblasts were obtained from patients with NP-C (four chiolfhood type and one adult type) and I cell disease, and SPM-3T3 cell. Method; Two parental cell lines ( $4 \times 10^{5}$ cells each) were seeded in a $60 \mathrm{~mm}$ dish. Cell fusion were performed by Polyethylene glycol method. To evaluate the complementation, we have obtained the number of cholesterol nonaccumulating cells among mononuclear cells and the multinuclear cells. Result, The restored ratio of complemented group show 21.4 to $30.2 \%$ and that of noncomplemented grouop show 0 to $2.4 \%$. This result indicated that SPM-3T3 and four childhood type NP-C belong to the same complementation group and adult type NP$\mathrm{C}$ belong to another complementation group. SPM-3T3 cell is a authentic model of humanNiemann-Pick diseasetype $C$.

\section{A-42}

STRUCTURE AND SEQUENCE OF THE HUMAN GALACTOCEREBROSIDASE GENE.

Hisao FUKUSHIMA, Koji INUI, Norio SAKAI*, Keiichi OZONO* and Shintaro OKADA (Dept.Ped., Osaka Univ., Osaka and *Res.Inst., Osaka Medical Center for Maternal and Child Health,Osaka)

Krabbe disease (globoid ce11 leukadystrophy,) is an autosoma1 recessive neurodegenerative disorder that affects both the central and the peripheral nervous systems. The disease is caused by the deficiency of the galactocerebrosidase, which normally degrades galactocerebroside to ceramide and galactose. Recently we purified the enzyme from 1ymphocytes and cloned the cDNA. In this study, to understand further details of molecular lesions in this inherited disease and the mechanims regulating the expression of this enzyme activity, we characterized the entire structure of the human galactocerebrosidase gene including 5'-regulatory sequence. The gene is about $60 \mathrm{~Kb}$ and consists of 17 exons. The promoter activity of the 5'-flanking region was confirmed by a CAT assay. 
DIFFERENT ORIGIN OF THE 1448C MUTATION IN PATIENTS WITH GAUCHER'S DISEASE. Kyoko IWASAWA, Hiroyuki IDA, Yoshikatsu ETO, Kihei MAEKAWA (Dept. of Pediatrics, Jikei Univ, School of Medicine)

The 1448T to $\mathrm{C}$ mutation of the gene of the acid-betaglucocerebrosidase is found in patients with Gaucher's disease (GD) among all ethnic groups. The patients who are homozygous with the $1448 \mathrm{C}$ mutation are associated with the neuropathic form of GD in Askenazi Jews (AJ), but not in Japanese. We analyzed the haplotype, Pv1.1(+) or (-), of the 28 Japanese GD patients with the $1448 \mathrm{C}$ mutation and compared the results with other ethnic patients with the same genotypes to prove ethnic difference. The Pv1.1(+) alleles accounted for $84 \%$ and this rate was opposite to that reported in AJ and other Caucasian. The $1448 \mathrm{C}$ homozygote state did not show the apparent linkage to the Pvl.1 genotype in the Japanese patients. This result suggests that the origin of the $1448 \mathrm{C}$ mutation in Japanese patients with GD was different from that reported for other ethnic groups. This difference is postulated to be the basis of the different phenotype.

A-44

MOLECULAR ANALYSIS OF $\beta$-HEXOSAMINIDASE $\beta$ SUBUNIT GENE IN FOUR JAPANESE PATIENTS WITH INFANTILE SANDHOFF DISEASE. Akemi TANAKA, Mutsuko FUJIMARU, Gen ISSHIKI (Dept. Pediat., Osaka City Univ. School of Medicine, Osaka), Kyuchul CHOE (Eulji General Hospital, Taejon), Hitoshi SAKURABA (The Tokyo Metropolitan Institute of Medical Science, Tokyo)

Molecular analysis of $\beta$-subunit gene in four patients with infantile Sandhoff disease was performed. Cultured skin fibroblasts (cases 1,2 and 4) and lymphoblasts (case 3) were used for the analysis. Genomic DNAs were extracted by the standard method and mRNAs were purified by Quick Prep Micro mRNA Purification Kit (Pharmacia). The PCR and RT-PCR products were sequenced by an autosequencer after cloning by TA Cloning Kit (Invitrogen). A double mutation of Lys121Arg and Pro417Leu was found in cases 1 and 2 as the homozygote. In cases 3 and 4 , a transition of $A$ to $G$ at -17 of intron 10 was found as the homozygote. The mRNAs in cases 3 and 4 were abnormally spliced at -37 of intron 10 and an abnormal long fragment containing 3-prime end of intron 10 was generated by RT-PCR. An abnormally spliced short mRNA with missing by 112 bases of 5-prime end of exon 11 was found in all four cases. The reason was suggested that the mRNAs became unstable by the mutation(s) and the splice site score of the middle of exon 11 (72.1) is higher than that of normal splice site at the junction of intron 10 and exon $11(61.8)$. Wakamatsu et al. reported a Japanse patient with juvenile form of Sandhoff disease in 1992 who had the same genotype with cases 1 and 2 . The reason why the different clinical phenotypes appear among these patients is not known yet, though they have the same double mutation in their both alleles, which suggests that these mutant alleles have the same origin. 
$A-\mathbf{4 5}$

\author{
ENZYMATIC CONFIRMATION OF INBORN ERROR OF KETONE BODY \\ METABOLISM: CYTOSOLIC ACETOACETYL-COA THIOLASE ACTIVITY IN \\ HUMAN FIBROBLASTS. Toshiyuki FUKAO, Xiang-Qian SONG, Hiroh \\ WATANABE, Naomi KONDO (Dept. Pediatr. Gifu Univ.Sch. Med., Gifu), Seiji \\ YAMAGUCHI (Dept. Pediatr. Simane Med. Univ., Izumo), Takashi HASHIMOTO \\ (Dept. Biochem. Shinshu Univ. Sch. Med., Matsumoto), Tadao ORII (Chubu \\ Women's College, Seki)
}

We investigated the contribution of mitochondrial acetoacetyl-CoA thiolase(AACOAT) (T2), cytosolic AACoAT (CT), and mitochondrial 3-ketoacylCoA thiolase (T1) to the total AACoAT activitiy in human fibroblasts. Immunotitration of AACOAT activity with these antibodies was carried out in control fibroblasts, with the following results. Immunotitration with anti-CT antibody in 6 control fibroblasts revealed that CT activity ranges between $1.3-2.4 \mathrm{mU} / \mathrm{mg}$ protein. Because the normal range of total AACoAT activity is relatively wide, it is difficult to evaluate CT defects based on a decrease of total AACoAT activity. Immunotitration proved to be an accurate method to evaluate CT activity.

A-46

\title{
MOLYBDENUM COFACTOR DEFICIENCY: FAILURE TO RESTORE SULFITE OXIDASE AND XANTHINE DEHYDROGENASE ACTIVITIES in vivo WITH MOLYBDENUM SUPPLEMENTATION.
}

Makoto YOSHINO. Shoii YANO, Shinsaku ISHIIBASHI, Yasutoshi KOGA, Toyoiito MATSUISHI, Hirohisa KATO (The Department of Pediatrics and Child Health, Kurume Univ., Kurume), Satoshi SUMI, Satom OHBA, Kivoshi KIDOUCHI (Nagoya Higashi City Hospital, Nagoya)

\footnotetext{
Molybdenum cofactor deficiency is a syndrome that causes decrease in the activities of sulfite oxidase, xanthine dehydrogenase and aldehyde oxidase, to which molybdenum cofactor serves as the obligatory activator, and this disease is associated with severe neurological impairment and urolithiasis. The deficiency of molybdenum cofactor exhibits a unique metabolic profile; increases in S-sulfocysteine, taurine, thiosulfate and sulfite excretion as a consequence of sulfite oxidase deficiency, and hypouricemia, increased levels of xanthine and hypoxanthine in both urine and plasma due to xanthine dehydrogenase deficiency. We investigated whether or not a supplementation with molybdenum could normalize the metabolic profile to test the possible therapeutic effect of this trace metal. The metabolic profile did not show any substantial change at 7 days and 17 days of the oral supplementation with molybdenum ammonium $(10 \mu \mathrm{g} / \mathrm{kg} / \mathrm{day}$, ti.d.), in comparison with the pretreatment profile, and excretion of molybdenum in urine increased significantly in the first 24 -hour period after the supplementation. These observations indicate that intestinal molybdenum absorption is not impaired in this patient, and exclude a nutritional deficiency of molybdenum as the cause of molybdenum cofactor deficiency in this patient.
} 
A-47

PRENATAL DNA DIAGNOSIS OF PHENYLKETONURIA IN CHINESE POPULATION. Dian Chang HOU, Shigeo KURE, Kazutoshi TAKAHASHI, Yoich MATSUBARA, and Kuniaki NARISAWA (Dept. Biochem. Genet., Tohoku Univ. School of Medicine)

To establish the prenatal DNA diagnosis method in Chinese population, we examined 44 Chinese phenylketonuria (PKU) families by the mutation detection and the polymorphic marker analysis. First, we detected the presence of seven mutations with relatively-high prevalence, R243Q, Y204C, R111X, R261Q, Y356X, R413P, and IVS 4 nt- 1 by multiplex allele specific amplification method. As a result 12 out of 44 families $(40.9 \%)$ turned out to be susceptible of DNA prenatal diagnosis. Second, we examined two polymorphic markers, a short tandem repeat (STR) and a variable number of tandem repeat (VNTR), in phenylalanine hydroxylase gene locus. By using two polymorphic markers we could antenatally diagnose 23 out of 44 families $(52.2 \%)$. Twelve out of 44 families could be diagnosed by both the mutation detection and the polymorphic marker analysis. By a combination method of both analyses we could diagnose 33 out of 44 families (75\%) antenatally. These results suggests that the combination of mutation and polymorphic maker analyses is useful in performing the prenatal DNA diagnosis in Chinese population.

A-48

COMBINED MUTATIONS OF THE CARDIAC $\beta$-MYOSIN HEAVY CHAIN AND CARDIAC TROPONIN T GENES IN FAMILIAL HYPERTROPHIC CARDIOMYOPATHY.

Misa KIMURA, Tenkou OZAWA, Michiko FURUTANI, Yoshiyuki FURUTANI, Shoichi ARAI, Shin-ichiro IMAMURA, Atsuyoshi TAKAO, Saichi HOSODA, Kazuo MOMMA, Rumiko MATSUOKA (Tokyo Women's Medical College, Tokyo)

Cardiac troponin $\mathrm{T}(\mathrm{TnT})$ gene was studied in a family in which all affected members with hypertrophic cardiomyopathy had missense mutation of the cardiac $\beta$-myosin heavy chain (MHC) gene at exon 20 (Gly $741 \mathrm{Trp}$ ). A Lys 256 (AAG) to an Arg (AGG) transversion at exon 14 was detected in one affected son and his healthy father. His affected sister had the conversion of a Glu12 (GAG) to a Gly (GGG) at exon 2, and five or three deduced amino acids at exon 4 or exon 12 in the cardiac TnT gene, respectively. Furthermore, affected members with an combination of both cardiac $\beta-\mathrm{MHC}$ and TnT gene mutations had more sever clinical features, such as hypertrophic obstructive cardiomyopathy (HOCM), than affected members with a mutation of the cardiac $\beta-\mathrm{MHC}$ gene alone. The combination of the mutations of both genes may explain the anticipation of clinical features such as HOCM in this family. 
A-49

GLUCOSEPHOSPHATE ISOMERASE GENE MUTATIONS IN THREE JAPANESE FAMILIES ASSOCIATED WITH HEREDITARY HEMOLYTIC ANEMIA. Hitoshi KANNO, Akira HIRONO, Shiro MIWA (Okinaka Memorial Institute for Medical Research), Hisaichi FUJII (Tokyo Women's Medical College), Yoji ISHIDA, Shinichiro KURIYA, Takeo MADARAME (Iwate Medical University), Kenji MATSUZAWA (Maruko Central Hospital), Yasuhiko FUKUMOTO (Narita Red Cross Hospital)

Glucosephosphate isomerase (GPI) deficiency is a second most common hereditary hemolytic anemia due to glycolytic enzyme defect. Although this enzyme is considered to be expressed in virtually all tissues, clinical manifestations are generally limited to hemolysis with a few exceptions. We have analyzed reticulocyte GPI cDNA sequences of three GPI deficient families, GPI Narita, GPI Matsumoto and a new GPI variant, GPI Iwate. GPI Narita has been found to have a homozygous mutation at no. $1028 \mathrm{CAG} \rightarrow$ CGG (343 Gln $\rightarrow$ Arg). It was compatible with the fact that the variant enzyme moved faster than normal to the cathode in the electrophoresis. The substituted Gln is adjacent to the active site residue, $341 \mathrm{Asp}$. A homozygous missense mutation, $14 \mathrm{ACC} \rightarrow \mathrm{ATC}$ $(5 \mathrm{Thr} \rightarrow \mathrm{Ile}$ ) has been identified in GPI Matsumoto. Alteration in the protein secondary structure by the amino acid substitution may account for the thermal instability, which was shown in the previous enzymatic analysis. In GPI Iwate, a homozygous missense mutation, 671ACG $\rightarrow$ ATG $(224 \mathrm{Thr} \rightarrow$ Met) was identified. $671 \mathrm{~T}$ had been found in a Afro-American variant, suggesting that this may be occurred in a hot spot. Further studies may demonstrated the structure-function relationship of GPI as well as the relationship between clinical manifestations and the mutation.

\section{A-50}

MOLECULAR ANALYSIS OF PATIENTS WITH HOLOCARBOXYLASE SYNTHETASE DEFICIENCY BY FLUORESCENCE-BASED SINGLE-STRAND CONFORMATION POLYMORPHISM (SSCP) ANALYSIS.

Xue LI $^{1}$, Yoko AOKI ${ }^{1}$, Yoichi SUZUKI ${ }^{1}$, Osamu SAKAMOTO ${ }^{1}$, Terttu SOURMALA ${ }^{2}$, Regula BAUMGARTNER', and Kuniaki NARISAWA'. ('Department of Biochemical Genetics, Tohoku University School of Medicine, Sendai, ' 2 Children's Hospital, University of Basel)

Holocarboxylase synthetase (HCS) deficiency is an autosomal recessive disorder characterized by combined organic aciduria, metabolic ketoacidosis, and dermatitis. These clinical symptoms are dramatically improved by administration of biotin. We have previously identified two mutations (L237P and delG1067) that were frequent in Japanese patients. In order to detect mutations of three German patients and one French patient, we used fluorescence-based PCR-SSCP analysis on 12 overlapping HCS CDNA fragments. Two abnormal migration patterns were detected in fragments 5,6 , and 8 , and one abnormal pattern was detected in fragments 9 and 12. Sequencing analysis of cDNA revealed five new mutations; a $C$ to $T$ substitution at nt. position $1121(\mathrm{Ser} \rightarrow \mathrm{Ser})$ in patients 1 and 3, a $\mathrm{T}$ to A substitution at nt. position 1285 ( $\mathrm{Val} \rightarrow \mathrm{Glu}$ ) in patient 1 , a single $\mathrm{T}$ deletion at $\mathrm{nt}$. position 1876 resulting in a stop codon in patient 4,68 -base deletion between nt. positions 1740 and 1807 also in patient 4 , and a single $C$ deletion at nt. position 2279 followed by a stop codon in patient 2. No mutations were detected in 2 of 8 aberrant patterns. To identify other mutations, SSCP analysis on gels containing $5 \%$ glycerol is now in progress. 
MOLECULAR ANALYSIS OF GLYCOGEN STORAGE DISEASE TYPE Ia. Kazutoshi TAKAHASHI, Yoichi MATSUBARA, Yoichi SUZUKI, Shigeaki MIYABAYASHI* and Kuniaki NARISAWA (Department of Biochemical Genetics and *Department of Pediatrics, Tohoku University School of Medicine, Sendai)

Glycogen storage disease type Ia (GSD Ia) is an autosomal recessive disorder caused by deficiency of glucose-6-phosphatase (G6Pase). It is clinically characterized by hypoglycemia, hepatomegaly, short stature, hepatoma and renal insufficiency. Recently the G6Pase gene was isolated and genetic mutations among Caucasian patients have been reported. We studied three Japanese patients with GSD Ia and identified three novel mutations. Case 1 was a homozygote of Arg170-to-Ter mutation (R170X) in exon 4. An Arg83-to-His mutation (R83H) in exon 2 was identified in case 2 in heterozygous form. Case 3, a product of consanguineous marriage, was a homozygote of Pro257-to-Leu mutation (P257L). None of the three mutations exhibited residual G6Pase activity when expressed in COS7 cells. The results suggested genetic heterogeneity of GSD Ia in Japanese patients. This is in sharp contrast to a recent report which described remarkable homogeneity of mutations among Japanese patients (AJHG 57:549-555, 1995)

\section{A-52}

ESTABLISHMENT OF A CATEGORY OF PHOTOSENSITIVE DISORDER, UVS SYNDROME (CLINICAL FEATURES AND DIAGNOSIS).Toshiki ITOH, Tomomichi ONO (Dept. Dermatol., Kumamoto Univ., Kumamoto) and Masaru YAMAIMUMI (Dept. Ce11 Genet., Inst. Emby. Genet., Kumamoto Univ., Kumamoto)

By surveying other photosensitive patients whose fibroblasts showed similar biochemical phenotypes, we found another nonconsanguineous Japanese patient belonging to the same complementation group as our cases. Postreplication repair of the cells derived from these patients was normal, indicating that they cannot be classified as xeroderma pigmentosum variant (XPV). Although clinical manifestations of these patients-such as acute sunburn, dryness, freckling, pigmentation anomalies on sun-exposed skin, and teleangiectasia without nurological abnormalities or tumors-are similar to a mild XP phenotype, cellular characteristics such as UV sensitivity and defective RRS after UV irradiation with normal UDS are reminiscent of Cockayne syndrome (CS). On the basis of these results, we propose that these patients be included under a general category designated "UV-sensitive (UVS) syndrome". 
A-53

A NEW UV-SENSITIVE SYNDROME NOT BELONGING TO ANY COMPLEMENTATION GROUPS OF XERODERMA PIGMENTOSUM OR COCKAYNE SYNDROME. Masaru YAMAIZUMI(Inst. Molecular Embryo1. and Genetics, Kumamoto Univ. School of Med., Kumamoto), Toshiki Itoh and Tomomichi Ono (Dept. Dermatol., Kumamoto Univ. Schoo1 of Med., Kumamoto)

We report here on two siblings who show no clinical manifestations except for slight cutaneous photosensitivity and cutaneous pigmentation but have biochemical characteristics of Cockayne syndrome (CS). Fibroblasts derived from the patients (Kps2 and Kps3) were 3-4 times more sensitive to UV than normal cells. Although unscheduled DNA synthesis (UDS) in these cells was at a normal leve1, recovery of RNA synthesis (RRS) after UV irradiation was severely depressed. Microinjection of bacteriophage T4 endonuclease $V$ into the cells corrected RRS after UV irradiation to a level near normal. These results indicate that DNA repair of cyclobutane-type pyrimidine dimers is impaired in the cells and the biochemical characteristics are similar to those of CS cells. However, cell fusion complementation tests with CS group A and B ce11s resulted in correction of RRS after UV irradiation. Cell fusion with XP group A, B, D, F and $G$ cells also corrected RRS after UV irradiation, and microinjection of cell extracts prepared from Kps 3 cells corrected UDS in XP group $C$ and $E$ cells, indicating that the patients do not belong to any complementation group of XP or CS.

\section{A-54}

IN VITRO AND IN VIVO ANALYSIS OF THE XPA GENE

Kiyoji TANAKA, Yoshimichi NAKATSU, Masafumi SAIJO, Takehiro KOBAYASHI, Toshiro MATSUDA, Isao KURAOKA, Hiroaki MURAI, Hironobu NAKANE, Seiji TAKEUCHI,

Naohiko KODO, Masahiko NITTA

Institute for Molecular and Cellular Biology, Osaka University

1-3 Yamadaoka, Suita, Osaka 565, Japan.

Nucleotide excision repair (NER) is a versatile repair system capable of rectifying a broad spectrum of DNA damage. The importance of NER has been suggested by studies of the human inherited disease, xeroderma pigmentosum (XP), which is characterized by a high incidence of skin cancer in sun-exposed areas. Cells from XP patients are hypersensitive to killing by UVirradiation and have a defect in the early steps of NER processes. There are seven different complementation groups (groups A through G) in XP. We examined the roles of the group A XP $(X P A)$ gene and its product in NER and prevention of carcinogen-induced tumorigenesis.

The XPA gene encodes a protein of 273 amino acids with $\mathrm{C} 4$ type zinc finger motif, and the XPA protein preferentially bound to DNA damaged by UV, cisplatin or osmium tetroxide, indicating that the XPA protein is involved in the damage recognition step of NER processes. Moreover, the XPA protein has an ability to interact with other proteins. We found that the 34 $\mathrm{kDa}$ subunit of replication protein A (RPA) and DNA repair protein ERCC1 bound to the XPA protein. Biological significance of these interactions will be discussed.

To elucidate the in vivo function of the XPA gene and molecular basis of group A XP phenotype, we established XPA-deficient mice using mouse ES cell techniques. The XPAdeficient mice were defective in NER process and highly susceptible to UV-induced tumorigenesis. The XPA-deficient mice provide a good in vivo model to study UV-induced skin carcinogenesis in group A XP patients. 
A-55

A STUDY OF GENE THERAPY USING PERIPHERAL AND CORD BLOOD STEM CELLS . Michinori $T^{1} \mathrm{O}^{1}$, Yasuhiro OKAMOTO${ }^{1}$, Takanori $\mathrm{ABE}^{1}$, Yosifumi KAWANO ${ }^{1}$, Junko MATSUDA $^{1}$, Ichiro YOKOTA ${ }^{1}$, Etsuo NAITO ${ }^{1}$, Yoichi TAKAUE ${ }^{1}$, Takashi SHIMADA ${ }^{2}$ and Yasuhiro KURODA ${ }^{1}\left({ }^{1}\right.$ Dept. Pediatr., Sch. Med., Univ. Tokushima, Tokushima, ${ }^{2}$ Dept. Biochem. and Mol. Biol., Nippon Med. Sch., Tokyo)

Gene therapy for patients with inherited metabolic disease should be started as soon as possible after diagnosis. Peripheral blood (PB) and cord blood (CB) stem cells can be good candidates for target cells in gene therapy for these patients, because PB stem cells are obtainable from infants more safely and repeatedly than bone marrow cells and CB stem cells can be obtained at birth from patients diagnosed by prenatal diagnosis. In this study, to establish the efficient protocol for retrovirus-mediated gene therapy using $\mathrm{PB}$ and $\mathrm{CB}$ $\mathrm{CD} 4^{+}$cells, we examined the transduction efficiency of neomycin phosphotransferase (NeoR) gene into these cells using retroviral vector. The transduction efficiencies by methylcellulose assay and PCR were $54.1 \pm 11.6 \%$ (mean $\pm \mathrm{SD}$ ) and $83.3 \pm 14.7 \%$ with $\mathrm{PB} \mathrm{CD3} 4^{+}$cells, $53.4 \pm 16.8 \%$ and $79.2 \pm 10.8 \%$ with $\mathrm{CB} \mathrm{CD34}{ }^{+}$cells , respectively. Moreover, $74.1 \pm 9.7 \%$ and $64.4 \pm 17.1 \%$ of LTC-initiating cells from PB and CB were resistant to G418 and $87.9 \pm 4.3 \%$ and $87.5 \pm 5.9 \%$ were positive with PCR. These results indicate that PB and CB stem cells are good target cells for gene therapy in infant patients with inherited metabolic disease.

A-56

IN VIVO CORRECTION OF 4-HYDROXYPHENYLPYRUVIC ACID DIOXYGENASE DEFICIENCIES IN III MICE WITH RECOMBINANT ADENOVIRUS. Shuji KUBO, Kohji KIWAKI, Hisataka AWATA, Fumio ENDO, Ichiro MATSUDA (Dept. Pediatr., Kumamoto Univ. Sch. Med.), Yumi KANEGAE, Izumu SAITO (Lab. Mol. Genet., Inst. Med. Sci., Univ. Tokyo) and Hideki KATO (Central Lab. Exp. Animals., Kawasaki)

Tyrosinemia type III is caused by genetic deficiency of 4-hydroxyphenylpyruvic acid dioxygenase (HPD) in tyrosine catabolism, characterized by mental retardation, convulsion and ataxia. III mouse is a model for tyrosinemia type III in which HPD activity and protein are defective and its blood tyrosine levels are elevated $(20-30 \mathrm{mg} / \mathrm{dl})$. We constructed recombinant adenovirus vectors bearing the human HPD cDNA (AdexCAGhHPD) under control of the potent CAG promoter. III mice were injected with 1.0-10 $\times 10^{8} \mathrm{PFU}$ of AdexCAGhHPD from tail vein. When injected over $3.0 \times 10^{8} \mathrm{PFU}$, blood tyrosine level rapidly decreased (within 3 hours after injection), reached normal range (under $5 \mathrm{mg} / \mathrm{dl}$ ) and remained at low level until 2-6weeks. Hepatic HPD activity was $106.5,63.5$ and $11.0 \%$ of the control at 4,7 and 30 days, respectively after injection. Immunoblot analysis confirmed the hepatic HPD expression. Histological examination revealed no difference (gross or microscopic) between the liver injected with AdexCAGhHPD and control. No significant changes in blood tyrosine levels were observed after the second injection of $5.0 \times 10^{8}$ PFU of AdexCAGhHPD. 
A-57

A (TTTTA) REPEAT POLYMORPHISM IN THE 5'CONTROL REGION OF THE APO(A) GENE IS ASSOCIATED WITH PLASMA LIPOPROTEIN(A) LEVELS. Kimiko KOBAYASHI, Tadao ARINAMI, Shuichi KIKUCHI, Hisahiko IWAMOTO, Liming LI, Yiwen OU, and Hideo HAMAGUCHI ( Dept. Med. Genet., Inst. Basic Med. Sci., Univ. Tsukuba, Tsukuba )

Plasma Lp(a) levels are largely determined by variation at the apo(a) gene locus. It is estimated that the variation in the size of the apo(a) gene account for about $40-70 \%$ of the interindividual variation in plasma $L p(a)$ levels. Hence, other variations relating to $L p(a)$ levels must exist in the gene. The effects of (TTTTA)n repeat polymorphism in the $5^{\prime}$ control region of the apo(a) gene on plasma $\mathrm{Lp}$ (a) levels were analyzed in combination with the apo(a) protein size in 263 unrelated healthy Japanese. Six alleles containing 5, 6, 8, 9, 10 , or 11 TTTTA repeats were detected. The frequencies of the two common alleles with 8 and 9 repeats were 0.75 and 0.22 , respectively. Plasma Lp(a) levels were significantly higher in homozygotes for the 8 repeat alleles $(16.8 \pm 14.8 \mathrm{mg} / \mathrm{dl})$ than in those for the 9 repeats allele $(7.3 \pm 3.1 \mathrm{mg} / \mathrm{dl})(\mathrm{p}=0.03)$. In addition, more strongly negatively correlation between plasma $L p(a)$ levels and apo(a) protein size were observed in homozygotes for the 8 repeat alleles $(r=-0.73)$ than in those for the 9 repeats allele $(r=0.17)$. These data indicate that the (TTTTA)n repeat polymorphism affects plasma $\mathrm{Lp}$ (a) levels and the most common 8 repeats allele increases the effects of the size of the apo(a) protein on plasma Lp(a) levels compared to the second common 9 repeats allele.

\section{A-58}

Haplotypes of the Apo(a) gene associated with high plasma Lp(a) levels Liming Li, ${ }^{1}$ Hisako Yanagi ${ }^{2}$, Tadao Arinami', Kimik Kobayashi',Yoshimi Ijima', Shuichi Kikuchi', Shigeru Tsuchiya ${ }^{2}$, Hideo Hamaguchi' ('Dept.Med.Genet. and'Inst. Comm.Med. Univ.Tsukuba)

To determine the apo(a) haplotype associated with high plasma Lp(a) levels, the 40 school-age children with high plasma $\mathrm{Lp}(\mathrm{a})$ levels $(\geq 30 \mathrm{mg} / \mathrm{dl})$ and 35 school-age children with normal plasma $\mathrm{Lp}(\mathrm{a})$ levels $(<30 \mathrm{mg} / \mathrm{dl})$ were screened and family studies were conducted to examine the relation of high $\mathrm{Lp}$ (a) levels to apo(a) isoforms and a pentanucleatide repeat polymorphism (TTTTA)n in the 5 'control region of the apo(a) gene.The apo(a) allele frequency was $46 \%$ and $13 \%$ for small size apo(a) ( $\leq \mathrm{A} 12$ ), and $85 \%$ and $68 \%$ for (TTTTA) 8 in 40 probands with high plasma Lp(a) levels and 35 controls, respectively.The small size apo(a) and (TTTTA) 8 were significantly increased in the probands with high plasma Lp(a) levels. All the haplotype of the 40 probands with high plasma $L p(a)$ levels which were related with higher $L p(a)$ levels in families had (TTTTA) 8 and $82.5 \%$ of them had small size apo(a) (SA12). The ratio of subjects with high plasma $\mathrm{Lp}(\mathrm{a})$ levels $(\geq 30 \mathrm{mg} / \mathrm{dl})$ was 0.83 among the first-degree relatives who shared with one haplotype related with high Lp(a) levels. Nine of $35(26 \%)$ haplotypes from the probands with normal plasma $L p(a)$ levels had small size apo(a) ( $\leq \mathrm{A} 12)$, but all of them were linked to (TTTTA) 9 . These data indicated that the haplotypes consisting of small size apo(a) and (TTTTA) 8 are associated with high plasma $L p(a)$ levels. 
A-59

APOLIPOPROTEIN(A) HAPLOTYPE ASSOCIATED WITH CORONARY HEART

DISEASE. Hideo HAMAGUCHI, Shuichi KIKUCHI, Kimiko KOBAYASHI, Liming LI, Hisahiko IWAMOTO, and Tadao ARINAMI (Dept. Med. Genet., Inst. Basic Med. Sci., Univ. Tsukuba, Tsukuba )

This study was done to examine whether apo(a) haplotypes associated with high plasma $\mathrm{Lp}$ (a) levels are also associated with risk for coronary heart disease (CHD). In 369 patients with CHD examined, smaller size apo(a) was significantly increased as compared with 389 controls. As apo(a) size were becoming smaller, the odds ratio for CHD increased. The effects of (TTTTA) repeat polymorphism in the 5 ' control region of the apo(a) gene were examined in 223 patients and 195 controls in combination with the size polymorphism. Smaller sizes of the apo(a) protein were significantly associated with CHD in homozygotes for the 8 repeat allele but not in heterozygotes for the $8 / 9$ repeat alleles and homozygotes for the 9 repeat allele. The data suggest that apo(a) haplotypes consisting of smaller kringle 4 repeat numbers and (TTTTA) 8 are associated with CHD in Japanese. The data also support the notion that high plasma Lp(a) levels are an independent risk factor for CHD.

\section{A-60 \\ CHROMOSOMAL ASSIGNMENT AND TISSUE DISTRIBUTION OF NOVEL EXPRESSED SEQUENCE TAGS (EST) FROM HUMAN PANCREATIC ISLETS. Jun TAKEDA. (Lab. of Gene Engineering, Dept. of Molecular Medicine, Inst. for Molecular and Cellular Regulation, Gunma Univ., Maebashi, Japan)}

The pancreatic islets play a key role in glucose homeostasis by secreting the polypeptide hormones insulin and glucagon. Diabetes mellitus results from the specific loss or dysfunction of the insulin secreting B-cells which represent about $70 \%$ of the islet cells. Because of the central role of the pancreatic islets in the regulation of glucose homeostasis, we are preparing an EST database in this tissue. About 2,000 cDNA clones randomly isolated from a human pancreatic islet cDNA library and a subtracted library were partially sequenced. Database search indicated that $53 \%$ of the ESTs identified were not related to any known human genes or human homologs of genes identified in other species. In this study, one hundred novel EST clones from human pancreatic islets have been mapped using a human-rodent somatic cell hybrid mapping panel/PCR method and/or fluorescence in situ hybridization. In addition, the tissue distribution of 75 of these clones has been determined by RNA blotting. The analyses of chromosome and tissue distribution of novel human pancreatic islet ESTs will facilitate genetic studies of diabetes mellitus and better understanding of the functions of proteins encoded by these unknown genes in normal and diabetic sates. 
A-61

APOLIPOPROTEIN E PHENOTYPES AND AMYLOIDOSIS IN THE LONGTERM HEMODIALYSIS PATIENTS. Hisako YANAGI ${ }^{1)}$, Mituo OGURA ${ }^{3}$, Mari TANAKA ${ }^{1)}$, Shigeo TOMURA ${ }^{1}$, Shigeru TSUCHIYA ${ }^{1)}$ and Hideo HAMAGUCHI $^{2}$ (1) Inst. Comm Med, Univ Tsukuba 2) Inst Basic Med, Univ Tsukuba, 3) Tokyo Okubo Hosp]

We analyzed apolipoprotein E (APOE) phenotypes among 39 patients who have accepted hemodialysis therapy for 10 or more years. We also analyzed APOE phenotypes among 30 patients who would be or had been induced hemodialysis therapy within 2 years due to chronic renal failure as controls. Amyloidosis in the long-term hemodialysis patients was diagnosed by clinical status. APOE phenotypes in the patients with amyloidosis $(n=20)$ were $2 / 3-10 \%, 3 / 3-$ $85 \%, 3 / 4-0 \%$, others $-5 \%$, and APOE phenotypes in the patients without amyloidosis $(n=19)$ were $2 / 3-5.3 \%, 3 / 3-78.9 \%, 3 / 4-$ 15.8\%. APOE phenotypes in controls $(n=30)$ were $2 / 3-3.3 \%$, 3/4-60\%, 3/4-23.3\%, others-13.3\%. The frequency of $\mathrm{E} 4-$ positive was less in long-term hemodialysis patients than in controls. No differences were observed, however, in APOE phenotypes between with and without amyroidosis.

\section{A-62}

ANKYLOBLEPHARON FILIFORME ADNATUM WITH CLEFT LIP AND PALATE (MIM\#106250) ASSOCIATED WITH CONGENITAL HEART DEFECT (ENDOCARDIAL CUSHION DEFECT). Satoshi ISHIKIRIYAMA, Kohichi KADOMATSU, Akikazu UDAGAWA, Yoshitomo OKAJIMA, Hiroyuki AOTSUKA, Mariko ISOBE, Noriko KURODA, Tamaki NUMAZAWA, Tsuneho NAKAMURA (Chiba Children's Hospital, Chiba)

A female baby was born to healthy, unconsanguineous parents after an uneventful pregnancy. At birth, her father was 41 years old, her mother 37 years old, respectively. Her sister died at 2 years and 8 months. The sister had hydrocephalus and multiple cngenital arthroglyposis. Her birth weight was $3,200 \mathrm{~g}(+0.25 \mathrm{SD})$, height $50 \mathrm{~cm}(+0.58 \mathrm{SD})$, occipitofrontal circumference $33 \mathrm{~cm}(-0.43 \mathrm{SD})$, respectively. She had not only ankyloblepharon filiforme adnatum (AFA) but also bilateral cleft lip and palate. She suffered from heart failure due to endocardial cushion defect when she was a neonate. Her skin and hair were quite normal. Her karyotype was $46, \mathrm{XX}$.

This is the third case associated not only with AFA with cleft palate, which is supposed an autosomal dominant disorder, but also with congenital heart disease. Some cases with AFA with cleft palate had imperforate anus. The occurrence and temporal coincidence of AFA with cleft Iip and palate, imperforate anus, and congenital heart disease strongly suggest that they share a common pathogenesis, as Weiss et al. proposed in 1992 . 
A-63

\author{
A MUTATION OF ANGIOTENSINOGEN AND A POLYMORPHISM OF THE \\ ANGIOTENSIN II TYPE 1 RECEPTOR GENE IN PREGNANCY-INDUCED \\ HYPERTENSION IN JAPANESE. Gen KOBASHI ${ }^{1}$, Akira HATA ${ }^{1}$, Seiichiro \\ FUJIMOTO $^{2}$ and Kiyotaro KONDO ${ }^{1}$ (Dept.Public Health, ${ }^{2}$ Dept. Obstet. Gynecol., \\ Hokkaido Univ.School of Med., Sapporo)
}

A mutation of angiotensinogen (AGT), which replaces leucine by phenylalanine at position 10 of mature AGT (L10F), was reported in Caucasian preeclampsia. An association of angiotensin II type 1 receptor $\left(A \Pi{ }_{1} R\right)$ gene polymorphism $\left(A^{1166} \rightarrow C\right)$ and essential hypertension was also reported in Caucasian samples. To investigate the significance of these base substitutions in pregnancy-induced hypertension (PIH) in Japanese, 144 PIH samples and 315 controls were genotyped. We found a significant association between primiparous $\mathrm{PIH}$ and controls when comparing the frequency of $\mathrm{CC}+\mathrm{AC}$ vs. $\mathrm{AA}$ in $\mathrm{A} \Pi{ }_{1} \mathrm{R}$ gene $(20 \%$ vs. $9 \%, \mathrm{p}<0.05)$. On the other hand, we found no $\mathrm{L} 10 \mathrm{~F}$ mutation in our samples. Our result may suggest that the role of $\mathrm{A} \Pi_{1} \mathrm{R}$ in the pathogenesis of PIH.

A-64

ANGIOTENSIN CONVERTING ENZYME AS A GENETIC RISK FACTOR FOR CORONARY ARTERY SPASM: IMPLICATION IN THE PATHOGENESIS OF MYOCARDIAL INFARCTION. Akira HATA ${ }^{1}$, Yuichi OIKE ${ }^{2}$, Yasuhiro OGATA ${ }^{2}$, Yuichi NUMATA ${ }^{2}$, Koichi SHIDO ${ }^{1}$ and Kiyotaro KONDO ${ }^{1}$

$\left({ }^{1}\right.$ Dept. Public Health, Hokkaido Univ., Sapporo, ${ }^{2}$ Dept. Cardiol., Japanese Red Cross Kumamoto Hospital, Kumamoto)

It has been reported that individuals with the $D$ allele of an insertion/deletion $(I / D)$ polymorphism of the angiotensin converting enzyme (ACE) gene are at greater risk for myocardial infarction (MI), especially among subjects normally considered to be at low risk. However, little is known about the mechanism by which the ACE polymorphism affects the risk of MI. Coronary artery spasm (CAS) is considered to be one possible mechanism for developing MI. We therefore examined the ACE polymorphism relation to CAS to determine if this was the mechanism by which the $D D$ genotype influences MI. We studied 150 angiographically assessed Japanese males, all more than 60 years old. CASs were detected using intracoronary injection of ergonovine maleate. Subjects were divided into three groups, those with : 1 - CAS, 2 - no CAS, but with fixed organic stenosis, and 3 - no CAS and no organic stenosis. $D D$ subjects were significantly represented in group 1 when compared with group $2(p=0.002)$ and $3(p=0.026)$. These results suggest that the $D D$ genotype relates to the greater risk for $\mathrm{MI}$ in the patients with CAS. 
A-65

\title{
DELETION POLYMORPHISM DN THE GENE FOR ANGIOTENSIN CONVERTING BNZYME I IS ASSOCLATED WITH LOWER HDL- CHOLESTEROL. LEVELS IN HEALTHY YOUNG MALES. Eumie
} TAKAKUBO, Yuji MORIMOTO, Akira KUWANO, Osamu YOSHIMURA and Ikuko KONDO (Dept. of Hygiene, Ehime Univ. Sch. Med., Ehime)

A 287 base pair insertion(I)/deletion(D) polymorphism in the angiotensin-converting I enzyme( $A C E)$ gene has been suggested as a potent risk factor for myocardial infarction, restenosis and coronary artery disease(CAD) in the Japanese population. Low plasma concentrations of high density lipoproteins(HDL)-cholesterol are related with the risk for CAD. We have examined total and HDL-cholesterol levels and the ACE/ID polymorphism in 98 healthy Japanese males (21-30 years old). The mean HDLcholesterol level in DD subjects was significantly lower than those of II $(p<0.001)$ and ID subjects $(\mathrm{P}<0.02)$. The $\mathrm{D}$ allele frequency in subjects with higher HDL-cholesterol levels $(>75 \mathrm{mg} / \mathrm{dl})$ was significantly lower(8/36) than that in subjects with lower HDLcholesterol levels $(<50 \mathrm{mg} / \mathrm{d} 1)(29 / 60)(p<0.02)$. These findings suggest that the DD genotype of the ACE gene is associated with a lower HDL-cholesterol level in healthy young males. Late onset cardiovascular diseases, which are associated with ACE/ID polymorphism and HDL-cholesterol levels, might be in part due to the influence of the ACE genotype on HDL-cholesterol levels throughout their younger times.

\author{
A-66 \\ Detail deletion mapping of long arm of chromosome 16 in \\ breast cancer.
}

Aritoshi IIDA, Rie ISOBE(Nippon medical school, Kanagawa), Yusuke NAKAMURA (Univ. of Yokyo, Tokyo), Mitsuru Emi(Nippon medical school, Kanagawa)

Multiple genetic alterations have been documented in breast cancer. The highest frequency of LOH in primary breast cancer has been reported for chromosome $3,11,13,16$, and 17. These observation suggest that several type of tumor suppressor genes may influence the development and progression of breast cancer. To define common region of deletion on chromosomel6, we used 12 CA microsatellite markers to carry out detailed deletion mapping in 93 primary breast cancer. The results as follows.

1) Allelic loss study revealed on chromosome $16 \mathrm{q}$ in

$72 \%(67 / 93)$ of primary breast cancer

2) Two distinct, commonly deleted regions were

identified at $16 \mathrm{q} 22$ and $16 \mathrm{q} 24$. 
A- 67

MICROSATELLITE ANALYSIS OF CHROMOSOME 10q IN MALIGNANT GLIOMA . Hideo NAKAMURA Mitsuyoshi NAKAO, Hideyuki SAYA (Dept. Oncol. , Kumamto University School of Medicine, Kumamoto) and Jun-ichi KURATSU, Yukitaka USHIO ( Dept. Neurosurgery, Kumamoto University School of Medicine, Kumamoto)

Chromosome 10 is frequently deleted in malignant gliomas and the frequency of the deletion is known to be related to clinical and pathological malignancy of the tumor. Therefore, we expect that certain genes which is implicated in malignancy of glioma are located on chromosome 10. Here, we analyze the loss of heterozygosity (LOH) of microsatellite markers on chromosome $10 q$ by PCR using fluorescentry-labelled primer. D10S201, D10S200, D10S603, D10S192, D10S205, D10S222, D10S540, D10S566, D10S530, D10S597, D10S545, D10S587, D10S186, and D10S212 were used for this analysis. LOH of the markers were quantitatively analyzed by an automated DNA fragment analyzer and a software. Using this system, we found LOH in 19 of 43 cases of malignant gliomas, and the most frequent deletion was identified at D10S 566 region.

A-68

DETAILED DELETION MAPPING ON CHROMOSOME 13Q IN

SPORADIC BREAST CANCERS. Kazuhiro TSUKAMOTO ${ }^{1}$, Noriko ITO1, Yusuke NAKAMURA ${ }^{2}$ and Mitsuru EMI ${ }^{1}$ (1Division of Molecular Biology, Institute of Gerontology, Nippon Medical School, Kawasaki)(2Laboratory of Molecular Medicine, Institute of Medical Science, The University of Tokyo, Tokyo)

Frequent allelic losses at chromosome $13 q$ were shown in sporadic breast cancers and a second breast cancer susceptibility locus, $B R C A 2$, was localized to $13 \mathrm{q} 12-13$. To investigate the possible involvement of BRCA2 and the minimal area(s) of loss of heterozygosity ( $\mathrm{LOH})$ in sporadic breast cancers, 246 tumors were examined for LOH at 14 loci on chromosome $13 \mathrm{q}$ using polymorphic microsatellite markers. In $95(38.6 \%)$ of 246 cases we detected LOH for at least one locus on chromosome $13 \mathrm{q}$ and 44 revealed a partial or interstitial deletion. Deletion mapping of these 44 tumors indicated two separate common regions of deletion: one was identical with the region of the BRCA2 locus, flanked by the markers D13S289 and D13S267, and the other was located in the region including the RB1 gene, flanked by the D13S328 and D13S172. These findings suggest that the $B R C A 2$ gene is a tumor suppressor gene or possibly close to another tumor suppressor gene. 


\begin{abstract}
A-69
CONSTRUCTION OF COSMID CONTIG AND ISOLATION OF CANDIDATE TUMOR SUPPRESSOR GENES FROM A REGION ON CHROMOSOME 8p21.3-p22 WHICH IS COMMONLY DELETED IN CARCINOMAS OF THE COLON, LIVER AND LUNG. ${ }^{1},{ }^{3}$ Katsuhiko IZAWA, ${ }^{1}$ Katsuva CHINEN, ${ }^{2}$ Hirovuki OHATA, ${ }^{2}$ Yoshivuki EUJIWARA and 1,2 Yusuke NAKAMURA

$\left({ }^{1}\right.$ Dept.Mol.Med., Inst.of Med.Sci, Univ.of Tokyo, ${ }^{2}$ Dept.Biochem., Cancer Inst., 3 Mitsubishi KAGAKU.BCL, Ine.)

Frequent loss of heterozygosity at $8 \mathrm{p} 21.3-\mathrm{p} 22$ was observed in hepatocellular carcinoma(HCC), colorectal cancer(CRC) and non-small cell lung cancer(NSCLC), suggesting the presence of tumor suppressor gene(s) associated with development and/or progression of these types of tumors.

We constructed a cosmid contig map by means of southern hybridization and isolated 49 exon-like fragments by exon amplification method using cosmid clones derived from 3 yeast artificial chromosomes(YACs) covering the commonly deleted region in HCC, CRC and NSCLC.

Using one of the exon-like fragments, we have isolated a candidate tumor suppressor gene, PRLTS(platelet-derived growth factor receptor beta like tumor suppressor), which was mutated in two HCC and one CRC. Since this cosmid contig map covers the entire region of common deletion, it will be a useful resource for isolation of tumor suppressor gene(s) as well as other novel genes located in this region by means of exon amplification, direct sequencing, or other methods.
\end{abstract}

\title{
A-70
}

TCL1 ONCOGENE ACTIVATION IN PRELEUKEMIC T CELLS FROM A CASE OF ATAXIA-TELANGIECTASIA. Masaharu Isobe, Toyomasa Hatakeyama (Molecular and Cellular Biology Lab., Faculty of Engineering, Toyama University, Toyama) and GiandomenicoRusso (Raggio-Italgene, Roma, Italy)

The TCL1 locus on chromosome $14 \mathrm{q} 32.1$ is frequently involved in chromosomal translocations and inversions with one of the T-cell receptor loci in human T-cell leukemias and lymphomas. Recently we have identified putative TCL1 oncogene from this region. In cases of ataxia-telangiectasia (AT), similar chromosomal rearrangements occur also in the clonally expanded T cells in AT patients before the appearance of the overt leukemia. We have analyzed and the expression of TCL1 in peripheral blood lymphocytes (PBLs) from AT cases and from healthy controls. We found that the TCL1 gene was overexpressed in the PBLs of an AT patient with a large clonal T-cell population exhibiting the $t(14 ; 14)$ translocation but not in the lymphocytes of the other cases carrying no $t(14 ; 14)$. Fluorescence in situ hybridization of the TCL1 genomic locus to lymphocyte metaphase from the AT patient with the T-cell clonal expansion showed that the breakpoint of the $t(14 ; 14)$ translocation lies within the TCL1 locus and is accompanied by an inverted duplication of the distal part of chromosome 14 . These data indicate that TCL1 is activated in preleukemic clonal cells as a consequence of chromosome translocation involving sequences from the TCR locus at 14q11. 
A-71

REPRESENTATIONAL DIFFERENCE ANALYSIS: DETECTION OF GENETIC LESIONS IN CANCER. Hiroyuki ABURATANI, Yoshitaka HIPPO and Tatsuhiko KODAMA (3rd Dept. Internal Med., Univ. Tokyo, Tokyo)

To identify the possible location of a tumor suppressor gene (TSG), we have scanned the tumor DNAs for chromosomal deletion by Representational Difference Analysis (RDA). Matched pairs of tumor and normal DNA were restriction digested and PCR-amplified. The tumor DNA amplicon was used as a driver for subtraction to identify DNA fragments deleted in tumor DNA. Tumor specimen were derived from fresh tumors, tumor cell lines and tumors in nude mice. We analysed 16 cancer specimens: 6 cervical ( 5 cell lines, 1 fresh tumor), 2 renal ( 2 lines), 3 neuroblastoma ( 3 fresh), 1 hepatoblastoma (1 line), 1 gastric (1 line), 1 ovary (1 line) and 2 hepatocellular ( 1 fresh, 1 nude). Eleven out of 16 analyses produced difference products present only in normal DNA, which were either hemizygously or homozygously deleted in tumor DNA. The two cervical samples which failed to produce any difference products, were cell lines established from dysplasia patients, on which genetic lesions might be minimal. Another two were fresh specimens significantly contaminated with normal tissues. One cervical carcinoma cell line CC6 and a renal cancer cell line TK produced difference products deleted homozygously, which are localized in 3p12-13 and 9p21 region, respectively. The both region are known to have a high incidence of L.O.H. in a variety of carcinoma and may thus be a locus for TSG. RDA is an efficient method for identifying the genetic lesions in cancer and will be useful in positional candidate cloning.

\section{A-72}

EFFECTS OF ATOMIC BOMB RADIATION ON INSTABILITY OF MICROSATELLITES IN HUMAN GERM CELLS. Chiyoko SATOH, Kazuki YASUNAGA, Akiko MIURA (Dept. of Genetics, Radiation Effects Research Foundation, Hiroshima)

For the detection of effects of the atomic bomb radiation on human germ cell mutations, we have been examining instability of microsatellites. The microsatellites consist of around 10-50 copies of motifs from 2-6 nucleotides and are highly polymorphic in copy number of the motifs. The number of repeats is genetically determined. In this study, DNA samples were extracted from cell lines established from B-lymphocytes of members of 50 exposed families with 64 children and 50 control families with 60 children. Among 248 gametes producing 124 children, 65 gametes were derived from exposed parents and 183 gametes were derived from unexposed parents. The mean dose of the exposed gametes was $1.9 \mathrm{~Sv}$. When we examined a microsatellite composed of TATC repeats at locus DXS981 on the long arm of the X chromosome of members of 100 families, two mutations were detected in daughters who were produced from gametes from unexposed fathers of Hiroshima and Nagasaki. We have already examined three trinucleotide repeats in three genes controlling fragile $\mathrm{X}$ syndrome, myotonic dystrophy and spinobulbar muscular atrophy, respectively, with no mutations detected. Two mutations each were detected in two types of tetranucleotide repeats in a gene controlling colony stimulating factor- 1 receptor. In total, no mutations were detected in 363 alleles from the exposed gametes whereas six mutations were detected in 939 alleles from the unexposed gametes, mutation rate being $0.6 \%$ per locus per gamete. Thus, we could not detect any effects of radiation on the instability of these microsatellites. 


\section{A-73}

CGG REPEAT CONFIGURATION IN THE FMR1 GENE IN JAPANESE. Tadao ARINAMI, Hideo HAMAGUCHI(Dept. Med. Genet., Inst. Basic Med. Sciences, Univ of Tsukuba, Tsukuba), Mark C. HIRST (Inst. Mol. Med. John Radcliffe Hosp., Oxford)

The FMR1 trinucleotide repeats lies within the $5^{\prime}$ untranslated portion of the FMR1 gene. Its length varies within the normal population from 6-52 copies with a multimodal distribution. The repeats in most FMRI alleles consist of AGG(CGG) in Caucasians. The third common FMR1 allele in Japanese is 36 copies in length, that consist of as many as $8 \%$ of Japanese FMR1 alleles, whereas it is rarely found in Caucasians. As longer FMR1 repeats have been associated with high risk fragile $X$ haplotypes in some populations, these larger 36 copies in length could be the allele liable to fragile $\mathrm{X}$ mutation. Sequencing the trinucleotide repeats revealed the presence of (CGG) $)_{6}$ and $(\mathrm{CGG})_{16}$ blocks within the repeats, which is rarely present in Caucasians. The presence of a (CGG) $)_{16}$ block suggested that an ancestral event by which longer blocks of repeat are generated is more likely to be $\mathrm{A}$ to $\mathrm{C}$ transversion, not deletion of AGG. About $10 \%$ of the 36 repeats have $(\mathrm{CGG})_{26}$ blocks which might be associated with instability of the repeats.

\section{A-75}

GENETIC MAP AROUND THE WERNER SYNDROME REGION.

Lin YE, Jun NAKURA, Noriaki MITSUDA, Tohru OHTA\#, Norio NIIKAWA\#, Tetsuro MIKI and Toshio OGIHARA (Dept. Gerit. Med., Osaka Univ. Med. Sch.,Osaka; \#Dept. Hum. Genet., Nagasaki Univ., Sch. Med., Nagasaki )

Werner syndrome (WRN) is an autosomal recessive disorder characterized by premature aging which has been mapped to the short arm of chromosome 8, 8p11.2-p12. In order to refine the genetic map around the WRN region, we have isolated eight microsatellites for this region from a microdissection library. We typed members of Japanese families with WRN on the basis of homozygosity mapping analysis. There was no obligate recombination between the WRN locus and microsatellite clone, MS8-134 (D8S1055). The maximum lod score was 20.28 at theta $=0.00$. Alleles for MS8-134 showed association with WRN in a case-control study $(\mathrm{OR}=3.55, \quad 95 \% \quad \mathrm{Cl}$ 1.56-8.07, $\mathrm{P}<0.01)$. Such microsatellites from a microdissection library of the definite chromosome region may be useful for positional cloning of the WRN gene. 


\section{A-76}

A DETAILED PHYSICAL MAPPING OF A REGION CONTAINING A GENE RESPONSIBLE FOR WERNER'S SYNDROME ON THE SHORT ARM OF CHROMOSOME 8. 1,2 ${ }^{\text {Kumiko KOYAMA }}{ }^{2}$ Katsuya CHINEN, $2_{\text {Katsuhiko }}$ IZAWA, ${ }^{3}$ Makoto GOTO and 2 yusuke NAKAMURA $\left({ }^{1}\right.$ Dep. Gen. Anal. Cancer Ins., Tokyo, ${ }^{2}$ Lab. Mol. Med., Inst. Med. Sci., Univ. Tokyo, 3 Tokyo Metoropolitan otsuka Hospital, Tokyo)

Human chromosome 8 is approximately $135 \mathrm{Mbp}$ long and is thought to contain 4,500 genes. A gene responsible for Werner syndrome (WRN), an autosomal recessive disease associated with an early aging, has been mapped to chromosome 8p11.2-12. The recent genetic mapping has localized the major WRN locus within two lici defined by ANK and HEG. We have isolated a number of yeast artificial chromosomes (YAC) spanning the WEN region, and constructed a contig map with these YACs that cover about $10 \mathrm{Mb}$. Moreover, we have been generating a cosmid contig sppaning this region and begun a large scale genomic sequencing.

We also tried an exon-trapping method and isolated several expressed-sequences and one transcript was confirmed to be about $10 \mathrm{~kb}$ long. This gene may be a candidate for the gene responsible for WEN.

\section{A-77}

COMPUTER SOFTWARES FOR THE SEARCH AND ENTRY OF GENOME MAPPING DATA: GeneView ${ }^{P L U S}$, Locus-in AND Physical Mapper.

Shinsei MINOSHIMA, Susumu MITSUYAMA, Kazuhiko KAWASAKI and Nobuyoshi SHIMIZU (Dept. Mol. Biol., Keio Univ. Sch. Med., Tokyo)

Genome mapping data have been compiled into GDB (Genome Data Base) with international collaborative efforts. The GDB has become an indispensable international resource for human genome analysis. We have developed three new softwares which were designed for entry of raw mapping data, integration of various genome maps, and efficient use of GDB data. These systems have smooth graphical user interfaces and operate on a workstation with X-window.

GeneView ${ }^{P L U S}$ is able to quickly search GDB data with easy operation; to accept both English and Japanese; to show the search results on graphical chromosome ideograms; to zoom-in to an interested region; and to show supplementary information of each map object.

Locus-in is able to graphically display chromosome ideograms (800-band level) and zoom-in to a specific region of interest; to generate sub-windows regarding a specific region for entry and display of data including published data from GDB; to create new breakpoints to use as boundaries of sub-windows; to construct database by entering mapping objects into sub-windows; to show detailed information of each map object; and to manage the ownership of data.

Physical Mapper is designed to draw various physical maps including contig map, restriction map, and STS map with easy operation using mouse; to coordinate these various maps in the same window on the common scale; and to manage a wide range of scale from plasmid size $(\sim 5 \mathrm{~kb})$ to chromosome size $(\sim 250 \mathrm{Mb})$. 
A-78

ANALYSIS OF GROWTH GENE(S) ON THE Y CHROMOSOME Akiko HIDA, Keiko TOMITA, Tsutomu OGATA ${ }^{1}$, Ikumi MATSUSHITA, Tatsushi TODA, Yasuo NAKAGOME, and Yutaka NAKAHORI (Dept. Hum. Genet., Tokyo Univ., Tokyo., 1 Dept. Pediat., Keio Univ., Tokyo)

Stature is determined by various factors like parents' heights, races, and life styles. It is also widely accepted that growth hormone and male hormone affect stature. However, it was recently proposed that the growth gene(s) which have no relation to hormones exist on the human sex chromosomes. We correlated the genotype and the final height in patients with a partial Yq deletion. The results suggest that the growth gene(s) is on the Y chromosome in the region defined by DYS11 and DYS246.YAC clones spanning the region were picked out from the YAC contig by Page et al and CEPH YAC library to analyze the structure of this region and to isolate the gene(s). We constructed the restriction maps of four YAC clones. This shows that they contain one or two $\mathrm{CpG}$ islands. Cosmid library was established from one of the YAC clones. The direct cDNA selection strategy was used with two cosmids which contain the $\mathrm{CpG}$ island. Also, the human fetal brain cDNA library was screened with probe 87-28a which detects DYS140.As a result, two cDNA clones were isolated and are being analyzed in order to determine if they are the growth genes or not.

The analysis of deletion breakpoints of an azoospermic patient and of the fertile father on the Y chromosome long arm. Rie KOMAKI ${ }^{1}$, Kazuhiro KOBAYASHI $^{1}$, Yoko $\underline{\text { KUROKI }}^{1}$, Mikio NAMIKI ${ }^{2}$, Teruaki IWAMOTO $^{3}$, Tatsushi TODA ${ }^{1}, \underline{Y}$ asuo NAKAGOME ${ }^{1}$, Yutaka NAKAHORI ${ }^{1}\left({ }^{1}\right.$ Dept. Hum. Genet., Univ. of Tokyo, Tokyo, ${ }^{2}$ Dept. Urol., Osaka Univ., Osaka, ${ }^{3}$ Dept. Urol., St. Marianna Univ., Kanagawa)

We have previously reported that almost one tenth of the Japanese males with either azoospermia or severe oligospermia whose Y chromosomes were cytogenetically normal showed a common interstitial micro-deletion involving both DYS7C and DYS1 loci on the long arm of $\mathrm{Y}(\mathrm{Yq})$. The father of one of the patients also showed a deletion in what seemed to be the same region as his son. One of a few possible explanations for this fact was that the deletion in the fertile father was smaller than the sterile son and the additional loss around the breakpoints caused azoospermia. We have constructed cosmid libraries from YACs assembled by Foote et al. A contig of cosmids spanning around DYS7C was constructed focusing upon the proximal breakpoints. We also produced novel STSs in the vicinity of DYS7C. Though the breakpoint is still unclear, a probe derived from the region detecting both a Yp locus and a Yq locus showed a difference between the father and the son. Since the difference appeared to arise from Yp locus, we are now analyzing if this is the crucial event for azoospermia or it is just a coincidence. 
MOLECULAR ANALYSIS OF THE Y CHROMOSOME LONG ARM IN AZOOSPERMIC PATIENTS. Kazuhiro KOBAYASHI, Rie KOMAKI, Yoko KUROKI, Mikio MAMIKI ${ }^{1}$, Teruaki IWAMOTO ${ }^{2}$, Tatsushi TODA, Yasuo NAKAGOME and Yutaka NAKAHORI (Dept. Hum. Genet., Tokyo Univ., Tokyo., 'Dept. Urol., Osaka Univ., Osaka., ${ }^{2}$ Dept. Urol., St. Marianna Univ., Kanagawa.)

We analyzed DNA from 160 Japanese men with either azoospermia or severe oligozoospermia whose $Y$ chromosomes were cytogenetically normal. Each patient was examined for the presence of 14 loci between DYS7E and DYZ1. The SMCY (a candidate gene for HYA), YRRM1 (a candidate for AZF) and DAZ (another candidate for AZF) loci were also examined. Micro-deletions were detected in 18 of the 160 patients. YRRM1 was involved in only three of them. Two of the three lacked only this locus, indicating YRRM1 is causally related to azoospermia. No patient has deletion limited to SMCY, indicating that this gene may not be crucial for spermatogenesis. The remaining 15 patients showed deletion between DYS7C and DYS239 in common. All these cases involved the DAZ locus, suggesting that the deletion of the gene seems to cause azoospermia. However, these 15 patients exhibit a wide spectrum of clinical phenotype, ranging from Sertoli-cell-only syndrome (no germ cell) to oligozoospermia (small number of sperms). Moreover, the father of one of the patients with deletion of this region lacks the same area but has the normal ability of spermatogenesis. There are two models which may explain these facts. One is that this diversity of phenotypes might reflect variable expressivity of the DAZ gene or the other gene(s) in this region among the individuals. The other is that the deletion size is different among the patients so that the severity of the clinical phenotype of each patient is determined by the combination of deleted genes residing around breakpoints. We believe the latter model to be the most probable. Further analysis is now in progress focusing upon breakpoints.

\section{A-81}

\section{A CASE OF XX MALE TRANSLOCATED SRY TO THE TERMINAL END OF SHORT ARM OF A X CHROMOSOME DETECTED BY FLUORESCENCE IN SITU HYBRIDIZATION (FISH). Yasuko YAMANOUCHI (Dept. Hygiene \& Pub. Health, Teikyo Univ. School of Med., Tokyo), Shigeru OSHIO, Hiroshi TOMOMASA, Takashi UMEDA (Dept. Urology, Teikyo Univ. School of Med.), Yutaka NAKAHORI (Dept. Hum. Genet. School of Internat. Health, Tokyo Univ., Tokyo) and Takako TAKANO (Dept. Hygiene \& Pub. Health, Teikyo Univ. School of Med., Tokyo)}

A married XX male aged 25 years was studied to examine infertility and azoospermia. Assays revealed that $\mathrm{FSH}, \mathrm{LH}$, prolactin and testosterone were $19.7 \mathrm{mlU} / \mathrm{ml}, 10.3 \mathrm{mlU} /$ $\mathrm{ml}, 28.0 \mathrm{ng} / \mathrm{dl}$ and $428.6 \mathrm{ng} / \mathrm{dl}$,respectively. Testis capacity was small (right $5 \mathrm{ml}$, left $4 \mathrm{ml}$ ). The patient was $177 \mathrm{~cm}$ in height and $55 \mathrm{~kg}$ in weight. No abnormalities of external genitalia and sexual function were found. His karyotype was 46,XX. By using SRY probe (pHu 14; supplied by P.N.Goodfellow), clear twin spots were seen on Ypter in almost all metaphases of normal male controls by FISH. Twin spots were detected on Xpter of one X chromosome of the patient. The replication time in S phase can be determined by using the distribution of singlet signals (unreplicated DNA segments) and doublets (replicated) in interphase nuclei by FISH. SRY gene with this XX male seems to be replicated later than the CKT877 DNA segment which is located on Xq28. 
A-82

ANALYSIS OF 46,XY FEMALES WITH AND WITHOUT TURNER STIGMATA. Toshikatsu SHINKA ${ }^{1,2}$, Keiko TOMITA ${ }^{1}$, Reiko MATSUMOTO ${ }^{3}$, Taku IIDA ${ }^{4}$, Tatsushi TODA, Yasuo NAKAGOME ${ }^{1}$ and Yutaka NAKAHORI

('Dept.Hum., Tokyo Univ., Tokyo., ${ }^{2}$ Dept.Pediat., Tohoku Univ., Sendai., ${ }^{3}$ Dept.Gynecol., Chiba Municipal Kaihin Hosp., Chiba.,

${ }^{4}$ Dept.Obstet.Gynecol., Tokyo Univ., Tokyo.)

Several genes are found on both the human $\mathrm{X}$ and $\mathrm{Y}$ chromosomes in regions that do not recombine during male meiosis. In each case, nucleotide sequence analysis suggests that these $X-Y$ gene pairs encode similar but nonidentical proteins. The typical genotype for Turner syndrome is $45, \mathrm{XO}$ and the phenotype is thought to be caused by the lack of the genes activated even on the inactivated X chromosome. Since the discovery of the genes that escape $X$ inactivation and have homologue on the $\mathrm{Y}$ chromosome, there have been arguments that the gene(s) crucial for the Turner phenotype should be one of such X-Y homologous genes. Some scientists insisted on the RPS4X/RPS4Y as a candidate for the Turner gene from the possible role of the gene product while the other insisted on the ZFX/ZFY depending it's X chromosome location. We have experienced three cases of XY females who lack the SRY testis determining gene and correlated their phenotype to the deletions of the $Y$ chromosome. As a result, we concluded that neither RPS4X/RPS4Y nor ZFX/ZFY is the crucial gene for Turner syndrome.

B-1

INTERPHASE CYTOGENETICS USING BUCCAL MUCOSA. Hirofumi OHASHI, Keiko WAKUI, Yoshiaki KIN (Saitama Children's Med. Ctr., Iwatsuki), Yoshimitsu FUKUSHIMA (Shinshu Univ. Sch. Med., Matsumoto)

It has been demonstrated that FISH using chromosome-specific DNA probes may facilitate the detection of numerical chromosome aberration in mitotic cells and in interphase nuclei by counting the number of signals within the nucleus. This "interphase cytogenetics" allowed the detection of aneuploidy in various tissues not amenable to chromosome analysis. We presented here the following diagnostic applications of the interphase cytogenetics using buccal mucosa for chromosome aberrations. 1) Diagnosis of mosaic type chromosome anomalies: detection of supernumerary i(12p) in patients with Pallister-Killian syndrome; detection of monosomy $X$ cells in patients with mosaic Turner syndrome; detection of normal cells in a mild 18 trisomy patient who was initially diagnosed as full trisomy for chromosome 18 in peripheral blood lymphocytes. 2) Rapid diagnosis of 18 trisomy syndrome within $10 \mathrm{~h}$.

The most attractive advantage of using buccal mucosa is that buccal mucosa is easily obtainable without trauma even in the outpatient clinic or at bedside using only a tongue depressor. Interphase cytogenetics using buccal mucosa would be a useful diagnostic method especially for mosaic type chromosome anomalies. 


\section{B-2}

\section{DIAGNOSIS OF CHROMOSOME STRUCTURAL ABNORMALITIES OF UNKNOWN ORIGIN BY MEANS OF MICRODISSECTION AND CHROMOSOME PAINTING}

We diagnosed four cases of chromosome abnormalities of unknown origin by chromosome microdissection-mediated painting.

Case 1 , an add $(5 q)$ : An additional segment was removed by microdissection and DNA from the segment was amplified by PCR to generate a pool of probes for FISH. FISH revealed signals on normal chromosomes 5 and a double-size signal on the abnormal $5 q$, indicating that the $\operatorname{add}(5 q)$ was due to duplication of a distal $5 q$ segment.

Case 2, an add (3p): Likewise, FISH revealed signals at both distal $3 p$ and distal $7 q$ regions on normal cells, while reverse FISH showed signals at both the add( $3 p)$ and distal $7 \mathrm{q}$ regions, indicating that the patient had partial trisomy for $7 \mathrm{q}$.

Cases 3 and 4, both marker chromosomes: FISH using probes from each of the whole markers revealed signals on normal $15 \mathrm{p}$ and a paracentromeric region of normal chromosome 19, respectively. Thus, the marker of Case 3 was $i(15 p)$ or psu $\operatorname{dic}(15)(q 11)$ and that of Case 4 was $r(19)(\mathrm{p} 12 \mathrm{q} 12)$.

B-3

TECHNICAL EVALUATION OF THE FISH METHOD FOR EXTENDED CHROMATIN FIBER PREPARATIONS FROM INTERPHASE NUCLEI, WITH SOME MODIFICATIONS AND APPLICATIONS. Aiko HAYASHI ${ }^{1,2}, \underline{\text { Fumiko SAITO- }}$ OHARA $^{1}$, Sei-ichi KOHNO ${ }^{2}$, and Tatsuro IKEUCHI ${ }^{1}$ ('Dept. Cytogenet., Med. Res. Inst., Tokyo Med. Dent. Univ., ${ }^{2}$ Dept. Biol., Fac. Sci., Toho Univ.)

Recently, various methods have been described for releasing free extended chromatin fibers (ECF) from interphase nuclei, allowing detection of "linear" fluorescent signals with a DNA resolution much greater than the standard FISH on mitotic chromosomes. In this study, some reported methods for obtaining ECF preparations were evaluated in terms of DNA resolution and availability for routine use, and some improvements in the factors related to treatment of cell nuclei were also attempted. As DNA probes for FISH, $\mathrm{P} 1$ clones (75-80 kb in size) derived from human chromosome $21 \mathrm{q}$ (supplied by Dr. M. Ohki, Natl. Cancer Ctr.) were used. The cell samples used were fixed cells from peripheral lymphocyte cultures or living cells from B-lymphoblastoid cell lines. The resulting linear FISH signals on ECF showed a resolution corresponding to a DNA length of 3-30 $\mathrm{kb}$ per $1 \mathrm{um}$ under the microscope. The degrees of chromatin fiber extension varied among different methods, depending on the treatment conditions (duration, temperature and preparation techniques). These findings would make it possible to choose the methods or technical conditions on the basis of the differences in the size of DNA clones to be examined. Some examples were presented in which the methods were applied to refined analyses of closely adjacent or overlapping cosmid clones by two-color FISH. 


\section{B-4}

CHROMOSOME ANALYSIS BY FISH METHOD USING NOVEL FLUORESCENT SUBSTRATE(HNPP, 2Hydroxy-3-naphthoic acid-2'-phenylanilide phosphate). Ki ichi SHIMIZU, Takahiro MINESHITA, Kunio KOBAYASHI (Shionog i Biomed. Labs., Osaka)

We evaluated a novel fluorescent substrate(HNPP, 2-hydroxy-3-naphthoic acid2'-phenylanilide phosphate) for the chromosome analysis by FISH method. The evaluation was carried out using peripheral blood leukocytes from male with normal karyotype and Hybridization Kit(ONCOR) with $\alpha$-satellite probes(X and $Y$ chromosome-labeled biotins; DXZ1, DYZ3, ONCOR). The probes were hybridized to metaphase spreads, followed by incubation with anti-biotin-conjugated alkaline phosphatase, and then the biotinylated probes were fluorinated with INPP in the presence of Fast Red TR. The same chromosomes were simultaneously counterstained with Hoechst-33258 and quinacrine for the detection of Q-bands. Fluorescent signal with HNP/TR(orange fluorescence, Em:600nm) was compared with that(yellow fluorescence) obtained by FITC(fluorescein isothiocyanate) method. The signal with HNP/TR gave higher intensity than that with FITC, but reduced rapidly under visible light-inradiation for only 1 min. The HNPP method for required $3 \mathrm{hr}(12$ steps), whereas $2 \mathrm{hr}$ for FITC method(19 steps).

In conclusion, the HNPP method is highly sensitive (useful for the high resolutional analysis of chromosomal aberration). Moreover, this method using HNPP may be available for the chromosome analys is with Q-banding.

\section{B-5}

STANDERDIZATION OF BIVARIATE FLOW KARYOTYPING OF HUMAN CHROMOSOMES AND THE CLINICAL APPLICATIONS. Hideki KURIKI, Hakuo TAKAHASHI(Dept. Clinical Labo. Medi., Kansai Medical University, Osaka), $\underline{\text { Sadako }}$ YOSHIOKA, Norihiro NISHINO(Dept. Central Labo.,Kansai Medical University, Osaka) and Hiromitsu SHIMADA(Osaka Kessei Research Labo., Osaka)

Flow cytometry can be used for the detection of aberrations in DNA composition and DNA content of human chromosomes. We demonstrate here the magnitude of DNA content differences among normal chromosomes of 18 healthy individuals, and the clinical applications of the standardize bivariate flow karyogram.

Peak positions were determined from Hoechst33258(HO) vs Chromomycine A3(CA) flow karyograms, and the values of the relative chromosomal DNA content were normalized with respect to the position of the peak constituting chromosomes 9-12, to which a value of 100 arbitrary units(a.u.) was assigned. The mean values and SD of $\mathrm{HO}$ and $\mathrm{CA}$ fluorescence intensity for each chromosomes were calculated, the range of SD is 1.18 to $6.5(\mathrm{CA})$ and 1.24 to $4.69(\mathrm{HO})$. The standard deviations did not overlap for each chromosomes, therefore it was decided that the standardize bivariate flow karyogram can be used for clinical applications. Further study, fluorescence in situ hybridization with chromosome whole painting for chromosome 22 that was obscrved for extra peak position in the flow karyogram of clinical material, did not indicate the variant. This suggests that the peak-position difference between chromosome 22 homologues may be a result of a combination of satellite and heterochromatic-region size differences. 


\title{
B-6
}

\author{
OBSERVATIONS OF SMALL MARKER CHROMOSOMLS BY SCANNING \\ ELECTRON MICROSCOPE. Takenari NIINUMA, Masato SENOO, Youichi \\ TAKEYAMA, Shigeki UEHARA, Toshifumi TAKABAYASHI, Kunihiro \\ OKAMURA, Akira YAJIMA. (Dept. Obstet. Gynecol., Tohoku Univ. Sendai)
}

To study the fine structure of small marker chromosomes, we performed scanning electron microscopy (SEM) on samples isolated from two carriers (Case 1:46,XY / 47,XY,+mar / 48,XY,+mar,+mar; Case 2:47,XY, +mar). In both cases,light microscopic observation revealed marker chromosomes to lack a centromere and to be fragmented in appearance. However, SEM observation of the mataphasic cells from Case 1 showed two variations of the light-microscopic fragmentary marker chromosomes. One variation was a structure that seemed to be metacentric and the other was a structure that was fragmentary. Two types of marker chromosomes were observed in Case 2, one metacentric and the other fragmentary. Although no chromatid or centromere formation was observed in the metacentric-like structures in either case, the data suggest that these structures arose from chromosomal duplication. Therefore, it is indicated that SEM observation of the marker chromosomes is helpful in defining specific structures and in distinguishing them from those arise from chromosomal duplication.

\section{B-7}

COMPARATIVE GENOMIC HYBRIDIZATION (CGH): DETECTION OF CHROMOSOMAL ANOMALIES. Takazumi KOZAKI, Hiroshi SASAKI, Yasunobu YOKOYAMA, Tadash i KAJII (Genet ic Research Division, Center for Molecular Biology and Cytogenetics, SRL, Inc.)

Comparative genomic hybridization (CGH) is a recently developed, FISH based technique that allows detection of genomic imbalance from numerical or structual chromosome aberrations. Using the technique, we have detected imbalances in 5 cases of $X$ chromosome anomalies (numerical and structual), 3 cases each of trisomies $13,18,21$, and 15 cases of autosomal structural aberrations (umbalanced translocations, duplications and deletions), all in segment with standard cytogenetic or FISH analysis. Genomic DNA from a test individual and that from a reference individual, both differentially labeled, were comparatively hybridized to metaphases of a normal individual. CytoVision (JEOL, Inc.) was used for digital image processing.

CGH proved to be a useful tool for analysis of DNA sequence copy number changes not only in such as tumor samples, where conventional cytogenetic analysis is difficult but also in congenital chromosome aberrations. 
B-8

A MALE WITH THE FOLATE-SENSITIVE RARE FRAGILE SITEAT 12q24.1. Yoshiaki KIN, Hirofumi OHASHI, Keiko WAKUI, Tohru AOKI (Saitama Childre's Med. Ctr., Saitama), MasahiroIWAMA (Kodomo-no-Machi Clinic, Saitama), Yoshimitsu FUKUSHIMA (Shinshu Univ. Sch. Med., Nagano)

A fragile site on chromosome 12 at $12 \mathrm{q} 24.1$ was found in peripheral blood lymphocytes of an 8-year-old male with mental retardation during the study for suspected fragile X syndrome. The site was elucidated to be folate-sensitive and one of rare fragile sites.

This is the second report of rare fragile site at 12q24.1. (The first report (FRA 12D) was performed by Anthony P.Amarose et al in 1987.) Therefore the fragile site, FRA12D, can be confirmed by our report.

\section{B-9}

INTERSTITAL DELETION OF THE PROXIMAL LONG ARM OF CHROMOSOME 6: REPORT OF A PATIENT. Kazushige MATSUSHIMA, Keiko WAKUI, Akira YAMAGISHI, Takeshi ITO, Kibo YOSHIDA, Masato SATO (Saitama Children's' Med. Ctr., Iwatsuki), Yoshimitsu FUKUSHIMA (Shinshu Unv. Sch. Med., Matsumoto), Hirofumi OHASHI (Saitama Children's' Med. Ctr., Iwatsuki)

The patient was a 7-year-old boy with mental retardation and multiple anomalies. His features included astigmatism, anteversion of the femoral neck, dolicocephaly, a long nose, a wide nasal bridge, low set ears, short 5 th fingers and single palmer creases. Gbanded chromosome analysis revealed interstitial deletion of the proximal long arm of chromosome 6: 46,XY,del(6)(q13q15). Parental chromosome analyses were not granted. To our knowledge, nine patients with proximal $6 q$ deletions have been reported. Our patient had clinical features in common with previously reported patients, including mental retardation, a wide nasal bridge, low set ears and single palmer creases, and did not have several features commonly observed in previous patients, including short stature, downward slanting of the palpebral fissures, a long philtrum and a short neck.

Deletion of proximal $6 \mathrm{q}$ is a rare chromosomal anomaly. More cases would be needed to evaluate the phenotype-karyotype correlation in proximal $6 \mathrm{q}$ deletion patients. 
B-10

CHARACTERIZATIN OF AN INTERSTITIAL DELETION OF CHROMOSOME 4 [del(4)(q31.1q31.3 or q31.3q32.2] IN A MOTHER AND SON BY CHROMOSOME PAINTING. Keiko WAKUI, Akira YAMAGISHI, Takeshi ITO, Satohiko

IMAIZUMI (Saitama Child. Med. Ctr., Iwatsuki), Yoshimitsu FUKUSHIMA

(Shinshu Univ. Sch. Med., Mtsumoto), Hirofumi OHASHI (Saitama Child. Med.

Ctr., Iwatsuki).

Features of the proband, 14-month-old boy, included diaphragmatic hernia, funnel chest and facial abnormalities. G-banded chromosome analysis showed interstitial deletion of $4 \mathrm{q} 31.1-\mathrm{q} 31.3$ or $4 \mathrm{q} 31.3-\mathrm{q} 32.2$. His mother had the same $4 \mathrm{q}$ deletion as the patient. Because the mother was physically and intellectually normal, "half cryptic translocation " was considered. We performed FISH analyses on her chromosomes using chromosome 4 -specific painting probes to identify the cytogenetically undetectable translocated $4 \mathrm{q}$ segment. However, no additional chromosome region was painted other than chromosomes 4 which indicated that she was monosomic for $4 \mathrm{q}$ as was the patient. To date, 5 cases of $4 \mathrm{q}$ deletion involving the band $\mathrm{q} 31-\mathrm{q} 32$ have been described. Our patient had several features in common with these previous patients with $4 q$ deletion, while the mother had none. To explain this discordance between the mother and son in clinical features, we considered the following possibilities: 1) the translocated 4q segment in the mother was unidentifiable because it was below our detection sensitivity of FISH ;2) additional chromosome aberration was occurred in the del( $4 \mathrm{q})$ chromosome through its transmission from the mother to son; 3) genes at the deleted $4 q$ region were subject to genomic imprinting and 5) there were other factors causing manifestations in the patient than chromosome abnormality.

\section{B-12}

A Williams Syndrome Case with Balanced Translocation $t(7 ; 1)$ Hamao HIROTA, Atsuyoshi TAKAO, Misa KIMURA, Shin-ichiro IMAMURA, Rumiko MATSUOKA, Kazuo MOMMA (Dept.of Pediatric Cardiology, Tokyo Women's Medical College, Tokyo) and Makoto NAKAMURA, Junko KAMIMURA (Dept. of Pediatrics, National Minami kyushu chuoh Hospital, Kagoshima)

The case was a 10 month old girl. She had typical williams syndrome facial features, hoarse voice, small for dates and cardiovascular disease (supravalvular aortic stenosis, valvular pulmonary stenosis and peripheral pulmonary stenosis). She was examined by fluorescent in situ hybridization (FISH), using the williams syndrome Chromosome Region Probe and whole chromosome Painting DNA Probe

(Chromosome 1). Hemizygosity for a region of $7 q 11.23$, involving one entire elastin allele and balanced translocation $t(7 ; 1)$ were found. Her father did not have any williams syndrome features, but he had balanced translocation $t(7 ; 1)$. The relationship between hemizygosity for region of $7 q 11.23$ and balanced translocation $t(7 ; 1)$ is not known. Further investigation is necessary to clarify these relationship. 


\title{
B-14
}

\author{
A MALE CASE OF “CATCH 22" PRESENTING NEONATAL HYPOCALCEMIA \\ AND PANCYTOPENIA. Akemi HAZEYAMA Akira OHTAKE, Hiroshi NAKANO, \\ Yuko TAKAHASHI Kyoko MITSUBAYASHI Hiroshi SUZUKI Atsushi SHIBUYA \\ and Nozomu SASAKI (Department of Pediatrics, Saitama Medical School, Moroyama, \\ Saitama)
}

Hemizygosity for human chromosome region 22q11.2 (CATCH 22) is associated with a wide range of overlapping phenotype. We now describe a male case of "CATCH 22 " presenting neonatal hypocalcemia and pancytopenia, which has not been reported before. The proband was referred from a local hospital at the age of 10 days because of neonatal tetany. His face became gradually peculiar with small mouse, depressed nasal bridge, telecanthus and submucous cleft palate. VSD was found and spontaneously closed at 5 months. Immunological testing including $T$ cell subsets, Con-A and PHA were within normal range. Granulocytopenia was started at 7 months, followed by thrombocytopenia and anemia. There existed all kinds of immature cell lines in his bone marrow, so dysfunction of leukodiapedesis was considered to be a cause. He was examined by FISH using N25(D22S75) probe, and monosomy for a region of 22q11.2 was found.

A PATIENT WITH AN INTERSTITIAL DELETION IN THE LONG ARM OF CHROMOSOME 9. Mihoko NAKAMURA ${ }^{1}$ Toshihisa OKADA², Mitsuo MASUNO', Mutsuo HOSHINO ${ }^{3}$, Kiyoshi IMAIZUMI ${ }^{1}$ Yoshikazu KUROKI, ${ }^{1}$ (Division of Medical Genetics $^{1}$, Division of Endocrinology and Metabolism², Division of Neonatology ${ }^{3}$, Kanagawa Children's Medical Center, Yokohama )

We report a case of developmentally retarded girl with $46, X X$, del(9)(q32q34.1). She was the first child of a healthy 24-year-old mother and an unrelated 27-year-old father. The pregnancy was uncomplicated and delivery was breach presentation. She was born at 39 weeks of gestation. Birth weight was $1655 \mathrm{~g}$, lengh was $41 \mathrm{~cm}$ and head circumference was $29 \mathrm{~cm}$. She showed cleft lip and palate, hypertelorism, depressed nasal bridge, short fifth middle phalanx, and cutaneous syndactyly. X-ray findings revealed hemivertebrae of Th4 and Th7, and congenital hip dislocation. Serum examination showed hypothyroidism. She controlled her head at 4 months and rolled over at 11 months. At 12 months, She has short stature and does not sit. Eight cases of an interstitial deletion of the long arm of chromosome 9 have been described. Four patients showed chromosome deletion $9 \mathrm{q} 22 \mathrm{q} 32$, and deletion of $9 \mathrm{q} 32$ was observed in all patients. Clinical manifestations including brachycephaly, hypertelorism, epicanthus, dysmorphic ears, limb anomalies, short stature, and mental retardation were commonly seen. 


\section{B-16}

THE MAMMALIAN SINGLE-MINDED (SIM) GENE: MOUSE cDNA STRUCTURE AND SPECIFIC EXPRESSION IN DIENCEPHALON. Nobuyoshi SHIMIZU ${ }^{1}$, $\underline{\text { Akiko YAMAKI }}^{1,2}, \underline{\text { Setsuko NODA }}^{3}$, Nobuaki SHINDOH ${ }^{1}, \underline{\text { Hideto MAEDA }}^{1}$, Yoshiko SHIMIZU $^{2}$, Shinsei MINOSHIMA ${ }^{1}$ and Jun KUDOH $^{1}{ }^{1}$ Dept. Mol. Biol., Keio Univ. Sch. Med., 2 Dept. Clin. Genet., Sch. Health Sci., Kyorin Univ., ${ }^{3}$ Sch. Health Sci., Tokai Univ.)

To isolate genes potentially involved in the pathogenesis of Down syndrome, we recently performed exon trapping experiments using a series of cosmid clones derived from the DSCR (CBR-D21S55-ERG) and found six exons which have a striking sequence homology with the Drosophila single-minded (sim) gene [Nature Genetics, 10: 9-10 (1995)]. The Drosophila sim gene encodes a transcription factor which regulates the development of central nervous system midline cell lineage, and thus the identification of a human homolog (hSIM) from the DSCR is quite intriguing. We have now isolated SIM cDNA clones from a mouse embryo cDNA library. Mouse SIM protein is highly homologous to human SIM and Drosophila Sim proteins, all contain the basic-helix-loop-helix (bHLH) domain and the PAS domain. In situ hybridization analysis indicated that SIM is expressed in the diencephalon of mouse embryos at the age of 8-9.5 days postcoitum. These results strongly suggest that the newly isolated mammalian SIM homolog functions as a transcriptional regulator which plays a critical role in the development of the central nervous system. The hSIM gene may potentially be involved in the pathogenesis of Down syndrome.

\section{B-17}

REEVALUATION OF THE DOWN SYNDROME (DS) CHROMOSOME REGION (DCR) BY FISH AND PFGE ANALYSES OF THE DS-ASSOCIATED 4;21 TRANSLOCATION BREAKPOINT. Tatsuro IKEUCHI ${ }^{1}$, Fumiko SAITO-OHARA ${ }^{1}, \underline{\text { Hiroko }}$ KAWASHIMA $^{3}$, Kohtaro YAMAMOTO $^{2}$, Miki OHIRA $^{4}, \underline{\text { Hitoshi ICHIKAWA }}^{4}$, and Misao OHKI ${ }^{4}$ ('Dept. Cytogenet., ${ }^{2}$ Dept. Virol., Med. Res. Inst., Tokyo Med. Dent. Univ., ${ }^{3}$ Ishikawa Pref. Nanao Health Ctr., ${ }^{4}$ Radibiol. Div., Natl. Cancer Ctr. Res. Inst.)

Chromosome and molecular studies of the Down syndrome (DS) chromosome region (DCR), responsible for the main clinical features of DS patients have been conducted in rare $21 \mathrm{q}$ partial trisomy cases. Currently, the minimum DCR is defined as the region between the DNA markers D21S17 (proximal) and ERG (distal border) (Delabar et al., 1993), located on subband 21q22.2, spanning approximately $2.5 \mathrm{Mb}$. We previously reported a DS family with an associated reciprocal translocation $t(4 ; 21)$. In this study, the translocation breakpoint of the healthy carrier father was localized on the Not I restriction map of 2lq (Ichikawa et al., 1993). FISH analysis using Not I site-containing PI clones as probes revealed that the breakpoint was located between the LA68 and LB23T Not I sites, and thus the trisomic region of his DS children was distal to LA68. PFGE analysis using the same probes confirmed the FISH findings, and further detected the P1 clone S599 containing the breakpoint, located more than $160 \mathrm{~kb}$ distant from LA68. Thus, the DCR was restricted to the region between the $t(4 ; 21)$ breakpoint and $E R G$, and was estimated to be approximately $1.6 \mathrm{Mb}$ in length. The present findings will be useful for efficient screening of candidate genes involved in the pathogenesis of DS. 


\section{B-19}

MOLECULAR DIAGNOSIS FOR PROTEOLIPID PROTEIN GENE IN A FAMILY WITH PELIZAEUS-MERZBACHER DISEASE. Toshiyuki YAMAMOTO, Eiji NANBA (Gene Research Center, Tottori University, Yonago), Ichiro SUZAKI, Kenzo TAKESHITA (Division of Child Neurology, Institute of Neurological Sciences, Tottori University Faculty of Medicine, Yonago)

Pelizaeus-Merzbacher disease (PMD) is an X-liked dysmyelinating disorder of the central nervous system. Recently, some investigators reported that proteolipid protein (PLP) gene would be causative for PMD. We studied PLP gene on a family with PMD. The patient was a 5-month old male infant whose maternal uncle died for quadriplegia with unknown etiology. He showed developmental delay, pendular nystagmus and absence of light reflex. Brainstem auditory evoked response (BAER) showed bilateral absence of the following waves after III. Brain magnetic resonance imaging (MRI) showed dysmyelination. PLP gene was analyzed by genome DNA from the patient and the parents. PCR primers were made according to R. Doll et al. (Am J Med Genet 51: 161169,1992). We detected different patterns of SSCP(Single-strand conformational polymorphism)-PCR on the samples of the families using $20 \%$ polyacrylamide gel electrophoresis and silver staining. Although the sequence data on exon 4 at 166 position showed $T$ on the patient's sample instead of $C$ on the father's, it should not result in an amino acid change. Therefore these data showed known polymorphism on exon 4. Now we are studying other exons of PLP gene.

\section{B-20}

\section{NEW MUTATIONS IN THE PROTEOLIPID PROTEIN GENE IN}

PATIENTS WITH PELIZAEUS-MERZBACHER DISEASE.

Chiaki KAWANISHI, Ken INOUE, Naoya SUGIYAMA, Tomohiro MIYAKAWA, Hideki ONISHI, Kyoko SUZUKI, Tokiil HANIHARA, Yoshiteru YAMADA, Kenji KOSAKA (Dept. of Psychiatr., Yokohama City Univ., Yokohama), Hitoshi OSAKA, Atsuo NEZU, Seiji KIMURA (Dept. of Pediatr., Yokohama City Univ.), Katsuo SUGITA (Dept. of Pediatr., Chiba Univ.) and Kenii OWA (Dept. of Pediatr., Saiseikai Nakatsu Hp.)

Pelizaeus-Merzbacher disease (PMD) is an X-linked recessive inherited disorder with dysmyelination restricted to the central nervous system. Thus far, molecular analyses have revealed various gene defects in proteolipid protein (PLP) in patients with $P M D$, and mutations in the coding region of the PLP gene are observed in 10-30\% of PMD patients. We analyzed the PLP gene in 11 patients with PMD, 9 with classical form and 2 (twin males) with atypical form who clinically meet the criteria of $\mathrm{X}$-linked spastic paraplesia. Four new point mutations $-\mathrm{C} \rightarrow \mathrm{T}$ at $\mathrm{nt} . \mathrm{-34} ; \mathrm{T} \rightarrow \mathrm{A}$ at nt. 623 $(\mathrm{V} 208 \mathrm{~N}) ; \mathrm{C} \rightarrow \mathrm{T}$ at nt. $629(\mathrm{P} 210 \mathrm{~L})$ and $\mathrm{G} \rightarrow \mathrm{C}$ at $\mathrm{nt} .721$ (A241P) — were observed in patients with classical form. The patient with a transition at $\mathrm{nt} .-34$ is the first PMD case with a mutation in the $5^{\prime}-$ UTR of the PLP gene. Ala ${ }^{241}$ is the neighboring residue of $\mathrm{Ala}^{242}$ which is substituted by $\mathrm{Val}$ in the jimpy mouse, and the patient with A241P exhibits a severe dysmyelinating pattern and clinical manifestations. Concerning the atypical patients, we identified the $G \rightarrow A$ transition at $n t .431$ resulting $W 144 X$. These atypical patients could be classified into $X$-linked spastic paraplesia type 2 which links to Xq 21 and is allelic to PMD (Saugier-Veber et al., 1994). 


\section{B-21}

Mutations in the proteolipid protein gene in Pelizaeus-Merzbacher disease. Akiko IWAKI, Kenji KUROSAWA and Yasuyuki FUKUMAKI

(Inst. Gen. Infor., Kyushu Univ. 18, Fukuoka)

Pelizaeus-Merzbacher disease (PMD) is an X-linked dysmyelinating disorder of the central nervous system, characterized by an early onset of nystagmus and spastic quadriplegia and caused by point mutations, insertion/deletion, complete deletion, and duplication of the myelin proteolipid protein (PLP) gene. We examined the PLP locus in the patients in 18 families diagnosed as PMD by clinical feature and magnetic resonance imaging (MRI) . In typical infantile cases we detected three missense mutations and one insertion leading to truncated PLP/DM20 proteins. In atypical juvenile case there was a $\mathrm{C}$ to $G$ transversion, which creates a new splicing acceptor site upstream of the boundary of the intron 4 and exon 5 of the PLP gene, leading to truncated PLP gene products with altered carboxyl terminal amino acid sequences, while the normal acceptor site was intact. It seems likely that retaining of a certain amount of the normal splicing products decreases severity of illness in this milder form of PMD. No exon mutation was found in the remaining 13 families except polymorphism at exon 4 in 4 families. Further analysis of the region outside of exon, the duplication event of this gene and linkage study is required for understanding molecular defects of the PMD families.

\section{B-22}

FOUNDER EFFECTS OBSERVED IN THE JAPANESE PATIENTS WITH HEREDITARY SPINOCEREBELLAR DEGENERATION. Akemi WAKISAKA, Hidenao SASAKI, Akio TAKADA, Tohru MATSUURA, Yoshihiro SUZUKI, Kiyoshi IWABUCHI, Takeshi HAMADA and Kunio TASHIRO.

(Dept. Pathol. and Neurol., Hokkaido Univ., Sch., Med., Dept. Med., Yamagata Univ., Sch. Med., Dept. Neurol. Psych., Kanagawa Rehabil. Center, Hokuyukai Neurol. Hosp.)

The haplotypes which co-segregated with the disease were determined in 12 pedigrees with spinocerebellar ataxia 1 (SCA1), 8 with spinocerebellar ataxia 2 (SCA2) and 22 with Machado-Joseph disease (MJD). Although the alleles of SCA1 haplotype varied from pedigree to pedigree, depending on the distance from the SCA1 locus, the affected and pre symptomatic individuals carried the same alleles at D6S288 and D6S274 loci. Furthermore, all the SCA1 family are found to be originated from either Miyagi or Yamagata Prefectures reflecting a founder effect. This is also true in MJD haplotypes. The most MJD patients carried the same alleles at the closest locus of AFM343 and a half of the MJD family are originated from either Toyama or Niigata. On the other hand, no deviation of ancestral residence and not statistical level of association were observed in case of SCA2. It seems highly likely that SCA1 and MJD in the Japanese derives from the single common ancestry. 


\section{B-23}

Gene analysis of early age onset Charcot-Marie-Tooth disease. Naoki KOZUKA, Nobutada TACHI(Sch. of Health Sci., Sapporo Med. Univ., Sapporo), Kazuhiro OHYA, Shunzo CHIBA(Dept. of Pediatr., Sapporo Med. Univ., Sapporo), Masahiko YAMAMOTO, Gen SOBUE(Dept. of Neurol., Nagoya Univ., Nagoya)and Kiyoshi HAYASAKA(Dept. of Pediatr., Yamagata Univ., Yamagata)

CMT1A is caused by DNA duplication on chromosome 17p11.2 encompassing peripheral myelin protain(PMP22). CMT1B has point mutations within the myelin Po gene on chromosome 1. By Southern blot analysis, single-stranded conformation polymorphism(SSCP) analysis, heteroduplex analysis, we analysed Po and PMP22 genes in patients with early onset CMT1 and CMT3(Dejerine-Sottas disease;DS). 5 cases from 3 families with CMT1 had duplication. On 6 cases without duplication, we examined the six Po exons to detect point mutations by heteroduplex analysis and perfomed direct sequence determination of amplified PCR products. Heteroduplex analysis showed an abnormal band pattern in exon 3 on 4 of 6 cases.Sequence analysis in exon3 showed a point mutation $A$ to $G$ substitution of nucleotide 389 . For the analysis of 7 cases with DS, we examined Po and PMP22 genes.1 case of the patients showed an abnormal band pattern in electrophoresis by SSCP and heteroduplex analysis in Po exon4. Sequence analysis in Po exon 4 showed a point mutation $G$ to $C$ substitution of nucleotide 499 . However, we could not disclose any mutation of other cases. These results suggest that DS may be heterogenious disorder.

B-24

INTERACTING GENES AND LIFESTYLES IN PARKINSON'S DISEASE. Kiyotaro Kondo (Dept. Publ Hlth, Hokkaido U, Sapporo) and Masao Kanamori (Dept. Hygiene, Toho U, Tokyo)

This study analyzes interplay of genes and lifestyles in Parkinson's disease (PD), and compares results between Japan and western countries in which the disease shows different clinical, epidemiological and pharmacodynamic features.

Lifestyle-gene interactions in $\mathrm{PD}$ are being investigated in which a few universities collaborated. Blood samples from a total of 44 cases disclosed no associations with CYP2D6 and MAO-B, unlike reports from the western countries. A weak negative protective association with EpoE2 was preliminarily identified.

A general segregation model (Elston-Elverton, 1975) is applied to the Swedish family data and in future will be to those from US and Japan, as an attempt to evaluate possible Mongoloid / Caucasian difference in the genetic background in PD. Additive co-dominance model showed the best fitness with the Swedish data. 
A CASE OF CEREBELLAR ATROPHY AND ATAXIA, PANCYTOPENIA, DELAYED MYELINATION AND PSYCHOMOTOR RETARDATION

Shinjiro AKABOSHI, Masaki YOSHIMURA, Toshiro HARA (Division of Child Neurology, Institute of Neurological Sciences, Faculty of Medicine, Tottori University) and Atsushi IESHIMA (Department of Pediatrics, Tottori Prefectural Kaike Rehabilitation Center for Dysabled Children)

Case report; She was born of uneventful pregnacy from unrelated healthy parents. At 4 months of age, titubation, delayed postural reflexes and hand deformity of first finger were noted. Head CT showed severe cerebellar atrophy. From 1 year of age, pancytopenia appeared. She shows a gradual psychomotor development and has no telangiectasia and immune deficiency. Laboratory data showed a decrease of $B$ cell $(0.4$ $\%)$, an increase of $\gamma \delta \mathrm{T}$ cell $(19.1 \%)$, and normal level of immunoglobulin $G, A, M, \alpha$ fetoprotein. Chromosome karyotypes of peripheral blood and bone marrow were normal. Breakage of chormosome by bleomycin (BLE) and mitomycin $C$ (MMC) was normal. Sensitivities of colony formation to BLE and MMC were not different from that of normal controls. This case have some features consistant to those of ataxia telangiectasia or Fanconi anemia. However, breakage of chromosome was not evident. This case might represent a distinct genetic disorder with involvment of central nervous, hematopietic and immune systems.

B-26

GENOMIC STUDY FOR X-LINKED HYDROCEPHALUS : A DELETION OF 5 NUCLEOTIDES IN THE LICAM GENE IN A JAPANESE FAMILY WITH X-LINKED HYDROCEPHALUS. Tomoki TAKECHI ${ }^{1,2}$ Jun TOHYAMA ${ }^{2}$, Kyohko MARUTA $^{3}$ Keiichi UYEMURA ${ }^{4}$ and Norio SAKURAGAWA ${ }^{2}$. ( ${ }^{1}$ Dept. Pediatrics, Kochi Medical School, Kochi, ${ }^{2}$ Dept. Inherited Metabolic Disease, National Institute of Neuroscience, National Center of Neurology and Psychiatry, Tokyo, ${ }^{3}$ Dept. Neurology, Nichinan Hospital, Miyazaki and ${ }^{4}$ Dept. Physiology, Keio University School of Medicine, Tokyo )

X-linked hydrocephalus (HSAS, hydrocephalus due to congenital stenosis of aqueduct of Sylvius) is the most common form of inherited hydrocephalus. MASA syndrome (mental retardation, aphasia, shuffling gait and adducted thumbs) and SPG1 (X-linked spastic paraplegia) are also $\mathrm{X}$-linked disorders overlapping clinical signs. Several mutations in the gene for the neural cell adhesion molecule L1 (LICAM) were found in families with these disorders in Europe and America. We have performed genetic study for LICAM gene in a Japanese family with HSAS patients and found a deletion of 5 nucleotides in exon 8 in the LICAM gene. This 5 nucleotide deletion causes a shift of the reading frame and introduces a premature stop codon, which might result in a truncated protein. Screening by Bgll digestion of PCR products revealed that two siblings have the same mutation and a sister is identified as a heterozygous carrier. 


\section{B-27}

AN ASSOCIATION STUDY BETWEEN THE ALCOHOL DEHYDROGENASE 2(ADH2) GENE, THE ALDEHYDE DEHYDROGENASE 2(ALDH2) GENE AND ALCOHOLISM.

Yoshihi ro KONO, Hiroshi YONEDA, Taku OGAWA, Hi royuki ASABA, Toshiaki SAKAI

(Dept. Neuropsychiatry, Osaka Medical College, Takatsuki, Osaka),

Atsuko UCHIDA, Koichi SUZUKI, Yasuhiko MIZOI (Dept. Legal Medicine, Osaka

Medical College, Takatsuki, Osaka) and Hiroyuki IMAMICHI (Shin-abuyama

Hospital, Takatsuki, Osaka )

We examined the allelic association of the alcohol dehydrogenase 2(ADH2) gene and aldehyde dehydrogenase 2 (ALDH2) gene wi th alcohol ism in 99 unrelated Japanese alcoholics and 157 unrelated controls. Genomic DNAs were prepared from peripheral white blood cells. We investigated ADH2 and ALDH2 polymorphisms by using PCR-RFLP methods. We found an apparent excess of the ADH2 heterozygote in the normal controls when we used primer sets reported by Harada and Xu for PCR-RFLP assay of ADH2 polymorphism. Therefore we designed a new palr of primers for amplification of ADH2. The alcoholics had significantly higher frequencies of $\mathrm{ADH}^{*} 1$ and $\mathrm{ALDH} 2 * 1$ alleles than the controls. These results suggest that genetic variation in both ADH and ALDH, by modulating the rate of metabolism of ethanol and acetaldehyde, influences drinking behavior and the risk of developing alcohol ism.

\section{B-28}

ANTICIPATION IN MOOD DISORDER AND SCHIZOPHRENIA. Akira IMAMURA, Yuji OKAZAKI, Kosuke FUJMARU, Takahiro FUKUSAKO, Akira HAMADA, Yoshibumi NAKANE (Dept. Neuropsychiatr., Nagasaki Univ. Sch. Med.), Sumitaka MATSUMOTO (Michinoo Hospital, Nagasaki), Takahiro TSUUITA, Norio NIIKAWA (Dept. Genet., Nagasaki Univ. Sch. Med.)

To test the hypothesis of anticipation, we compared ages of onset between the two generations in 19 parent-offspring pairs with DSM-IIL(-R) mood disorder(MD) and 22 parent-offspring pairs with DSM- III (-R) schizophrenia(S), each of which includes a proband being admitted to the Nagasaki University Hospital or Michinoo Hospital between 1986-1994. Statistically significant decrease in age of onset in offspring generation was observed for both of the disorders (MD: Wilcoxon $t=7.0, d f=18, p<.0001$; $\mathrm{S}$ : Wilcoxon $\mathrm{t}=2.5, \mathrm{df}=21, \mathrm{p}<.0001$; one tailed). Although ascertainment bias could not be thoroughly ruled out in this sample, these findings suggested that the expansion of unstable DNA sequence, such as that of triplet repeats, was a possible mode of transmission in a part of patients with these disorders. 


\section{B-29}

Mitochondrial DNA (mtDNA) diagnosis of Leber's hereditary optic neuropathy. Keiko FUJIKI, Yoshihiro HOTTA, Mutsuko HAYAKAWA, Toshiyuki YOKOYAMA, Misako TAKEDA, Hiroo HAYATSU, Hiroshi TOSHIDA, Koichi TAMAKI, Masao ISHIDA, Nobuou ISHIDA, Syunsuke UEDA, Takurou FUJIMAKI, Atsushi KANAI (Dept. Ophthalmol., Juntendo Univ., Tokyo)

Leber's hereditary optic neuropathy (LHON) is a maternally inherited disease which causes permanent visual loss. The most prevalent mtDNA mutation is a $G$ to A substitution at nucleotide position 11778 (11778 mutation). In our department, the 11778 mutation in 30 members of 18 LHON families, were detected by restriction enzymes and/or dot blot hybridization with allele specific oligonucleotides. Heteroplasmy of mtDNA was found in 1 of 4 affected females and in 3 of 8 female carriers. The male to female ratio was $17: 4$ ( $81.0 \%$ male). Fifteen patients of LHON have been maternally inherited (12 have maternal lineage ; 2 have affected sibs and 1 isolated case whose mothers have 11778 mutation). Two sisters aged 9 and 14 years old had an early onset. Their optic discs were observed as slightly pale and they were diagnosed then as optic atrophy of unknown cause. The mtDNA analysis disclosed that they have 11778 mutation. Their mother's physical examination was normal but was found to have $100 \%$ mutant mtDNA. Their maternal grandmother was found to have heteroplasmy with $9 \%$ mutation.

Almost all LHON patients with 11778 mutation are males and have very poor visual acuity. The 3 female cases including their sisters have relatively good remaining visual acuity. One could see that females with LHON have relatively mild affection compared to males.

\section{B-30}

A POINT MUTATION AT POSITION 8363 IN MITOCHONDRIAL DNA AMONG JAPANESE PATIENTS WITH MITOCHONDRIAL ENCEPHALOMYOPATHY. Matsuko OZAWA, Ichizo NISHINO, Yu-ichi GOTO, Ikuya NONAKA (Dept. Ultrastructral Res., Natl. Inst. Neuroscience., NCNP, Tokyo), Motoki SANO (Dept Neurol, Showa General Hosp., Tokyo)

Myoclonus epilepsy with ragged-red fiber (MERRF) is one of the mitochondrial encephalomyopathies, in which a point mutation at position 8344 has been described. In 1992 , a second point mutation at position 8356 located in the tRNA-Lys gene similar to 8344 mutation, was reported in Caucasion families. To investigate the possibility of this mutation in other racial groups, we examined 80 Japanese patients with various mitochondrial encephalomyopathies; 35 MELAS, 20 MERRF and CPEO 25, respectively. None but one family with MERRF phenotype had this mutation, suggesting that tRNA-Lys alterations are closely related to the MERRF phenotype. 
B-31

An $A$ to $G$ transition at nt3243 of mitochondrial tRNALeu(UUR) gene associated with clinico-pathologically defined Leigh's disease. Yasutoshi KOGA, Toyojirou MATSUISHI, Makoto YOSHINO, Hirohisa KATO. (Dep. Pediatrics and Child Health, Kurume University School of Medicine, Kurume, Japan)

Leigh disease is a clinico-pathologically defined syndrome, associated with various defects in oxidative phosphorylation (OXPHOS). There are three mitochondrial point mutations reported to cause this disease including T8993G and T8993C in mitochondrial ATPase 6, and A8344G in tRNALys. We analyzed a three year-old floppy infant who was diagnosed as Leigh disease, pathologically, showing bilateral necrosis and gliosis of the mid brain. Muscle biopsy at 3 years of age showed ragged-red fibers (5\% of total muscle fibers), scattered COX negative fibers and SSVs, pathologically, and complex I (15\% of the control) plus IV (10\% of the control) deficiency, biochemically. Mitochondrial genomes analysis in various tissues including skeletal muscle, liver, heart, kidney and brain obtained at autopsy showed high percentage (>90\%) of an A3243G mutation in the mitochondrial tRNALeu(UUR) gene in all tissues examined. RNA analysis showed consistent increase in the steady-state levels of an RNA 19. Single fiber PCR analysis of COX-positive and COX-negative fibers using muscle specimen showed high point mutation $(>90 \%)$ in both groups. Above findings indicate that the Leigh's disease phenotype is a final common outcome for severe defects in OXPHOS genes.

B-32

STUDY ON DUPLICATION OF MITOCHONDRIAL DNA. Yu-ichi GOTO, Ichizo NISHINO, Ikuya NONAKA (Dept. of Ultrastructural Res., Natl. Inst. of Neuroscience, NCNP, Tokyo) and Satoshi HORAI (Dept. of Hum. Genet., Natl. Inst. of Genetics, Mishima, Japan)

Duplication of mitochondrial (mt) DNA has been reported to be detected in some chronic progressive external ophthalmoplegia (CPEO) patients. We thus examined muscle biopsies from 25 Japanese patients with CPEO including 6 with Kearns-Sayre syndrome (KSS) and found that none of them had duplicated $\mathrm{mt}$ DNA. This result suggested that duplication was very rare or did not take an important role in pathogenesis of CPEO or KSS. Southern blot analyses using a restriction enzyme SnaBI, which cut the DNA within the deleted region, showed in some cases the probability of different structural forms other than duplication as well as deletion monomer. 
B-34

OXYGEN STRESS INDUCES CELL DEATH ASSOCIATED WITH

MITOCHONDRIAL DNA DAMAGE. Makoto YONEDA, Kazumi KATSUMATA, Mika HAYAKAWA Masashi TANAKA and Takayuki OZAWA (Dept. of Biomed.

Chem., Faculty of Med., Univ. of Nagoya, Nagoya)

We have investigated the role of mitochondria on an active cell death, a feature of apoptosis, under oxygen stress. An immortalized human fibroblast cell line $\left(p^{+}\right)$ carrying normal mitochondrial genome (mtDNA) underwent an active cell death in $95 \%$ oxygen. By contrast, its derivative lacking mtDNA $\left(\rho^{0}\right)$ exhibited a marked resistance to the cell death. PCR analyses using 180 primer pairs covering the entire regions of the $\mathrm{mtDNA}$ revealed extensive fragmentation of the $\mathrm{mLDNA}$; the number of different type deletions increased from 49 to 187 on the 3 rd day.

We further compared the cell death induced by the oxygen stress among an osteosarcoma cell line lacking mtDNA $\left(\rho^{0}\right)$, its parental cell line carrying normal mtDNA $\left(\rho^{+}\right)$, and the cybrids harboring the mutations in the tRNA genes of mtDNA (syn-), which are responsible for MERRF or MELAS syndrome. The cybrids showed markedly rapid cell death, compared with those in the $\rho^{+}$or $\rho^{\circ}$ cell lines in $95 \%$ oxygen.

These results indicate that the mtDNA fragmentation, accelerated by mtDNA mutations, is an underlying molecular lesion in the cell death pathway induced by the oxygen stress, and suggest that the oxidative damage to the mtDNA plays a crucial role in the cell death in mitochondrial diseases.

\section{B-35}

Y CHROMOSOMAL DNA VARIATION AND THE PEOPLING OF JAPAN. Michael F. HAMMER (Univ. Arizona, Tucson) and Satoshi HORAI (Dept. Human Genetics, National Institute of Genetics, Mishima)

Four loci mapping to the nonrecombining portion of the $\mathrm{Y}$ chromosome were genotyped in three Japanese populations (Okinawa, Shizuoka and Aomori) and Taiwanese. The Y Alu polymorphic (YAP) element is present in $42 \%$ of the Japanese and absent in the Taiwanese, confirming the irregular distribution of this polymorphism in Asia. Data from the four loci were used to determine genetic distances among populations, construct $Y$ chromosome haplotypes, and estimate the degree of genetic diversity in each population. Evolutionary analysis of $Y$ haplotypes suggests that polymorphisms at the YAP (DYS287) and DXYS5Y loci originated a single time, whereas restriction patterns at the DYS1 locus and microsatellite alleles at the DYS19 locus arose more than once. Genetic distance analysis indicated that the Okinawans are differentiated from Japanese living on Honshu. The data support the hypotheses that modern Japanese populations have resulted from distinctive genetic contributions involving the ancient Jomon people and Yayoi immigrants from Korea or mainland China, with Okinawans experiencing the least amount of admixture with the Yayoi. It is suggested that $\mathrm{YAP}(+)$ chromosomes migrated to Japan with the Jomon people $>10,000$ years ago and that a large infusion of YAP(-) chromosomes entered Japan with the Yayoi migration starting 2,300 years ago. Different degrees of genetic diversity carried by these two ancient lineages may be explained by the different lifestyles of the migrant groups, the size of the founding populations, and the antiquities of the founding events. 
B-36

\section{EXTENSIVE POLYMORPHISM OF ABO BLOOD GROUP GENE: SPECIFIC MUTATIONS FOR VARIANT ABO PHENOTYPES}

Kenichi OGASAWARA ${ }^{1}$, Makoto BANNAI ${ }^{1}$, Ryuichi YABE ${ }^{1}$, Kenichi NAKATA', Toshio MAZDA $^{1}$, Michiko TAKENAKA ${ }^{1}$, Kivoshi FUJISAWA ${ }^{1}$ Naruya SAITOU' ${ }^{2}$, Makoto UCHIKAWA $^{3}$, Yoshihide ISHIKAWA ${ }^{3}$, Takeo JU $^{3}{ }^{3}$ and Katsushi TOKUNAGA ${ }^{3,4}$ ('Japanese Red Cross Tokyo Metropol. Blood Center, Tokyo, "2National Institute of Genetics, Mishima, ${ }^{3}$ Japanese Red Cross Central Blood Center, Tokyo, ${ }^{4}$ Dept. Human Genetics, Univ. Tokyo, Tokyo)

We have identified 13 different $A B O$ alleles from blood donors possessing common $A B O$ phenotypes by means of PCR-SSCP and sequence analysis, and clarified the existence of several alleles for single phenotypes. These alleles were classified into three major lineages, ${ }^{*} A /{ }^{*} O 1,{ }^{*} B$ and ${ }^{*} O 2$, in terms of their evolution. By the PCR-SSCP, we identified 14 additional alleles from the donors possessing variant $A B O$ phenotypes. Nine out of 11 sequenced alleles were presumed to be generated from common $\mathrm{ABO}$ alleles by single nucleotide mutations. Two other alleles may have originated by recombination or gene conversion-like event rather than point mutations. Analyses of the phenotypes and the corresponding nucleotide sequences revealed that the amino acid residues at positions 266 and 268 may be crucial for transferase specificity, whereas $214,216,223,291$ and 352 may be critical for the activity level.

\section{B-37}

HIGH INCIDENCE OF A POLYMORPHIC VARIANT OF ERYTHROCYTE MEMBRANE PROTEIN, BAND 3-MEMPHIS, ON A WESTERN JAPANESE ISLAND. Takeshi OTSUKA, Kenji IZUHARA, Tomonori OGO, Yoshiyuki NIHO (Dept. 1st Int. Med., Kyushu Univ., Fukuoka), Hiroshi IDEGUCHI (Dept. Clin. Chem. and Lab. Med., Fukuoka Univ., Fukuoka) and Kenshi OKUBO, Naotaka HAMASAKI (Dept. Clin. Chem. and Lab. Med., Kyushu Univ., Fukuoka)

Band 3 is the major membrane protein of erythrocytes, which binds membrane skeletal proteins, glycolytic enzymes, and hemoglobin and transports various kinds of anions. Band 3-Memphis is a variant of Band 3, the amino terminal fragment of which depicts a slow electrophoretic mobility on sodium dodecyl sulfate-polyacrylamide gel. The frequency of Band 3-Memphis varies among populations, with a higher frequency among the Japanese. We investigated the frequency of Band 3-Memphis in a western Japanese island which is relatively isolated from the main islands, finding that the frequency of Band 3-Memphis of the inhabitants of this island is significantly higher than the frequency of the Japanese based on the survey in Kyushu Island. This indicates that there may be differences of population in the frequency of Band 3-Memphis in Japan and that Band 3Memphis may be a good marker to genetically differentiate each population. 
B-38

MOLECULAR BASIS OF TRANSFERRIN POLYMORPHISM

Shuichi TSUCHIDA, Shigenori IKEMOTO and Eiji KAJII(Dept. Hum. Genet. and Legal Med.)

Transferrin(TF) polymorphism is one of the most useful markers in human genetics and forensic science. Three common phenotypes, TF C1, TF C2-1 and TF C2, are determined by two autosomal codominant alleles, $T F^{*} C I$ and $T F^{*} C 2$. We have analyzed the TF polymorphism at the nucleic acid level. The molecular basis for the TF polymorphism is determined by a single base pair mutation $(\mathrm{C} 1765 \mathrm{~T})$ that results in a Pro570Ser amino acid substitution. $T F^{*} D c h i$ allele is a variant which is a marker of Mongoloid population. The His300Arg amino acid substitution in TF Dchi variant has been determined by amino acid sequencing. The molecular analysis that showed an Ato-G base exchange at position 956 in $T F^{*} D c h i$ allele confirmed the amino acid substitution in TF Dchi variant and indicated that $T F^{*} D c h i$ allele was derived from $T F^{*} \mathrm{Cl}$ allele.

B-39

DETECTION OF VARIATIONS IN DNA AND MRNA BY DENATURING GRADIENT GEL ELECTROPHORESIS - REPORT 5. STUDY OF VARIATIONS OBSERVED IN VARIOUS GENES.

Norio TAKAHASHI, Hideo OHMINE, Akiko MIURA, Junko KANEKO, Chiyoko SATOH (Dept. of Genetics, Radiation Effects Research Foundation, Hiroshima)

Denaturing gradient gel electrophoresis (DGGE) is an efficient method for detecting small variations (e.g., single base substitutions or deletions and insertions of one to dozens of base pairs). DGGE in which DNAs amplified from genomic DNAs or DNAs amplified from cDNAs reverse-transcribed from mRNAs are used as samples, is termed as PCR-DGGE or RT-PCR-DGGE. Using these methods, we examined genes encoding factor IX, p53, phosphoglucomutase-1 and phosphoglycerate kinase, and retinoblastoma susceptibility gene. Former two genes were examined by PCR-DGGE and latter three by RT-PCR-DGGE. As samples, we used genomic DNAs or mRNAs obtained from B-cell lines established from peripheral lymphocytes of 100 unrelated individuals each from Hiroshima and Nagasaki. Twenty one types of polymorphic variations and 13 types of rare variants were observed. Among the 21 types of polymorphic variations, a significant difference was observed in frequencies between Hiroshima and Nagasaki of two variations in p53 genes. Frequency of variations observed in the exon regions of $\mathrm{X}$-chromosome is much lower than that detected in other regions such as introns on $\mathrm{X}$-chromosome and both exons and introns on autosomes. 
B-40

SYNERGISTIC EFFECT OF CYTOCHROME IA1 INDUCIBILITY AND NACETYLTRANSFERASE POLYMORPHISM ON AGE AT ONSET OF COLORECTAL CANCER. Masako ABE, Kenji SHIBUTA and Tomokazu SUZUKI (Dept..Clin. Genet., Med. Inst. Bioregulation., Kyushu University, Oita)

Polycyclic aromatic hydrocarbon, contained in tabacco and barbecued meat, and heterocyclic amines are considered to be associated with colorectal cancer. These compounds are metabolized by many enzymes, conjugated and excreted from the body. The effects of combination of the cytochrome IA1 (CYP1A1) inducibility and polymorphic $\mathrm{N}$-acetyltransferase (NAT2) polymorphism have been investigated. There was no difference in the distribution of CYPIA1 genotype between 220 patients with colorencatal cancer and 238 healty subjects. When the inducible CYPIA1 genotype was combined with the NAT2 phenotype, however, homozygotes for induclible CYPIA1 were more frequently found among intermediate + slow than fast acetylator, although there was no statistical difference. Further the effect of the combination of CYPIA1 inducibility and NAT2 polymorphism on age at onset was different with statistical significance. It seems that these two xenobiotic enzymes have synergistic effect on the age at onset of colorectal cancer in Japanese population.

B-41

NINE-BP REPEAT POLYMORPHISM IN EXON 1 OF THE hMSH3 GENE. Eiitsu NAKAJIMA, Hideo ORIMO,Atsushi WATANABE, Miyoko IKEJIMA, Takashi SHIMADA (Dept. Biochem. Molec. Biol., Nippon Medical School, Tokyo)

The hMSH3 gene encodes a protein highly homologous to a bacterial mismatch protein MutS. The number of the consensus sequence (GC)CPy( GC)CAGCG which encodes alanine or proline differs depend on the cells. We analyzed Japanese 58 individuals and 11 families to investigate a length polymorphism due to a variable number of tandem repeat. PCR amplification of the corresponding region of the genomic DNA was performed and comparison with the sequencing ladder revealed that the length of each fragment was a function of the number of copies of 9 nucleotide repeating unit. As a result, 3 to 7 repeats were observed, and 6 repeats showed the highest frequency,70/116 alleles (frequency,0.603), and the heterozygosity was found to be 0.57 . Mendelian inheritance was observed in all families. Recently, microsatellite instability due to mutations of $\mathrm{hMSH} 2$ has been reported among some familial cancers.To analyze genetic diseases and cancers probably related to this gene, this marker should be useful. 
B-42

EFEECTS OF CYTOCHROME P4501A1 GENE POLYMORPHISMS ON SMOKING STATUS AND HEMATOLOGICAL FINDINGS. Sumio Iijima (Dept. Health Sciences, Yamanashi Medical Univ.), Zentaro Yamagata (Health Care Center, Yamanashi Univ.), Shinichi Shinozaki, Yingning Zhang, Akio Asaka

Measures to control smoking is an important field of preventive medicine. To clarify methods for primary prevention of lung cancer applicable to individual differences in the susceptibility, effects of genotypes of CYP1A1, which are considered to be related to lung carcinogenesis, on the smoking status and hematological findings were evaluated in 391 healthy males. (1) No correlation was observed between the genotype of CYP1Al and the smoking status. (2) The white blood cell count in smokers with a Val allele was significantly higher than in those without a Val allele. (3) Multiple regression analysis showed that the genotype of CYP1A1 and daily cigarette consumption had significant effects on the white blood cell count in smokers. In consideration of the epidemiologic findings that many individuals with increased white blood cell counts have cancer or cardiac diseases, and reports that the increase in the white blood count was associated with poor respiratory function, the white blood cell count may contribute to prevention of these diseases as a risk marker.

B-43

Est ablishment of $\mathrm{H1} 9$ functional imprint ing in human developing placent ae and met hylation pat tern of the promoter and upstream regions. Yoshihiro JINNO Norio NIKAWA (Dept . Hum. Genet , Nagas aki Univ, Nagasaki), Yuichiro IKEDA, Hideaki MASUZAK, His anobu FUKUDA (Dept. Obst et. Gynecol, Nagas aki Univ, Nagas aki) and Kankat su YN(Dept . Pat hol, Ot ago Univ., Otago)

We have found that the imprinted $\mathrm{H} 19$ gene can be expressed either biallelically or monoallelically in the developing human placent ae. H19 biallelic expression is confined to the placent a unt il 10 weeks of gestation, after which it becomes exclusively maternal, and does not affect allele-specificity or levels of IGF2 expression. The promoter region of $\mathrm{Hl} 9$ is hypomethylated at all stages of placent al development, while a $1.8 \mathrm{~kb}$ BamHI fragment (spanning from - $1.6 \mathrm{~kb}$ relative to the $\mathrm{start}$ of transcript ion to $-3.4 \mathrm{~kb}$ ) were hypermethylated in sperm and mole DNAs and partially (about 50\%) met hylat ed in placent a, leukocytes and liver DNAs. These results indicate that epigenetic modificat ions responsible for establishment of $\mathrm{H} 19$ funct ional imprinting, if present, reside in ot her region or that switching of trans-acting fact ors must correspond to this process. 
B-44

Imprinted regulation in the region of Prader-Willi and Angelman syndromes. Mitsuyoshi NAKAO, Tadashi ANAN, Hideyuki SAYA(Dept. Oncology, Kumamoto University School of Medicine, Kumamoto), James S. SUTCLIFFE, Preethi H. GUNARATNE and Arthur L. BEAUDET (Dept. Molecular and Human Genetics, Bayor College of Medicine, Houston)

Prader-Willi syndrome(PWS) and Angelman syndrome(AS) are distinct clinical phenotypes resulting from patemal and maternal deficiencies respectively in human chromosome $15 \mathrm{q} 11-\mathrm{q} 13$, and are caused by deletion, uniparental disomy, or other mutations.

Three paternally expressed transcripts containing small nuclear ribonucleoproteinassociated polypeptide N(SNRPN), PAR-5 and PAR-1 were absent in cultured cells from PWS patients with a small deletion that involve a differentially methylated $\mathrm{CpG}$ island around a $5^{\prime}$ untranslated exon alpha of SNRPN gene. Methylation of the CpG island is specific for the maternal chromosome consistent with paternal expression of the imprinted domain. The small deletion, which is benign when maternally transmitted, extends upstream $50 \mathrm{~kb}$ from the $\mathrm{CpG}$ island, and results in the loss of expression of the three imprinted transcripts, altered methylation and replication timing around SNRPN gene, implying the presence of an imprinting control element.

B-45

THE ORIGIN AND X-CHROMOSOME INACTIVATION OF PARTHENOGENIC NEOPLASM

Taku IIDA $^{1,2}$, Osamu TSUTSUMI ${ }^{2}$, Yuji TAKETANI ${ }^{2}$, Yasuo NAKAGOME ${ }^{1}$, Yutaka NAKAHORI ${ }^{1}$, ('Dept. Hum. Genet., Tokyo Univ., Tokyo, ${ }^{2}$ Dept. Obstet. and Gynecol., Tokyo Univ., Tokyo)

We analyzed five families in which there was a patient of cystic teratoma, the benign ovarian tumors. The diagnosis for each patient was made macroscopically and confirmed with histopathology. Using three locus of CA repeat polymorphisms on the $\mathrm{X}$-chromosome, we could classify the origin of the tumor. There were three kinds of combinations: there were only paternal alleles, only maternal, and both alleles.

Afterwards, Southern hybridization using FMR-1 probe was performed following digestion using two restriction enzymes, EcoRI and BssHII, to detect the methylation status of the gene on X-chromosome. We found that half of the allele pairs of any parental origins were methylated just like somatic cells.

Our research confirms the multiple origins of ovarian cystic teratoma including abnormal cell division in various stages, meiosis I, or II, or other abnormal cell behavior, such as cell fusion. As there are no differences in methylation status between paternal and maternal parthenogenesis, we can conclude that there must be no "genomic imprinting" of the gene on X-chromosome prior to fertilization. 
Human ESP1/CRP2, a Member of the LIM Domain Protein Family: Characterization of the cDNA and Assignment of the Gene Locus to Chromosome 14q32.3.

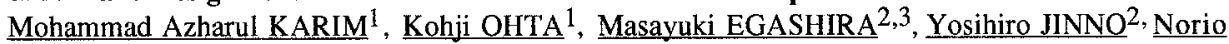
NIIKAWA $^{2}$, Ichiro MATSUDA ${ }^{1}$ and Yasuhiro INDO ${ }^{1}$

${ }^{1}$ Dept.of Pediatrics, Kumamoto University School of Medicine, Kumamoto. ${ }^{2}$ Dept. of Human Genetics and ${ }^{3}$ Orthopedics, Nagasaki University School of Medicine, Nagasaki.

The LIM is a cysteine-rich motif with a cosensus sequence of $\mathrm{C}-\mathrm{X}_{2}-\mathrm{C}-\mathrm{X}_{16-23}-\mathrm{H}-\mathrm{X}_{2}-\mathrm{C}-\mathrm{X}_{2}-$ $\mathrm{C}-\mathrm{X}_{2}-\mathrm{C}-\mathrm{X}_{16}-21-\mathrm{C}-\mathrm{X}_{2}-3-\mathrm{C} / \mathrm{H} / \mathrm{D}$, present in a number of proteins with diverse functions and subcellular distributions including transcription factors, components of cytoskeleton, proto-oncogene products and regulators of tissue specification during embryogenesis. A human cDNA encoding two tandemly arrayed LIM domains have been isolated through successive screening of the human intestinal cDNA library with a single LIM domain rat cysteine-rich intestinal protein (rCRIP) cDNA probe under the conditions of low stringency. We termed the isolated cDNA as human ESP1/CRP2 as $93 \%$ of its amino acid residues are found to be identical with that of its murine counterparts. Human ESP1/CRP2 encompasses a 1,171 bases region including 26, 624 and 521 bases in the $5^{\prime}$ noncoding, coding and $3^{\prime}$ noncoding regions respectively, and encodes a protein product of about $22.5 \mathrm{kD}$. In northern blot analysis, a widely expressed RNA transcript was found in multiple adult human tissues: significantly highest in the heart with a relative restrictions in the lymphoid tissues,- suggests its specific role in tissue organization or function. Human ESP1/CRP2 gene has been mapped on a somatic cell hybrid panel blot to chromosome 14 and by fluorescence in-situ hybridization (FISH) to chromosome $14 \mathrm{q} 32.3$; the region of immunoglobulin heavy chain locus. It is of our provocative speculation that ESP1/CRP2 could be involved in gene regulation, cell growth and somatic cell differentiation,- likely myocardiogenesis.

\section{B-47}

Isolation of a novel Duffy cDNA which is the predominant transcript in erythroid. Sadahiko IWAMOTO, Shigenori IKEMOTO, Eiji KAJII (Dept. Legal Med. and Human Genet., Jichi Medical School, Tochigi)

The Duffy gene has been shown not to be split by introns, even in its 5'untranslated region and to be expressed not only in erythroid but in postcapillary venule endothelium. To further investigate the transcriptional start position in erythroid, we performed 5'-rapid amplification of cDNA ends ( $5^{\prime} \mathrm{RACE}$ ) procedure. While every positive clones of 5'RACE encoded the identical sequence of previously identified cDNA in the downstream from nucleotide 203, the upstreams were different from that. The upstream sequences were regarded as novel exon. This novel exon encoded 7 residues initiated with a methionine, and linked to nucleotide 203 in frame and in agreement with GT-AG splicing rule. A major transcriptional start position in erythroid was identified 34 base upstream from the first ATG codon. Both Northern blotting and reverse transcription-PCR followed by Southern analysis indicated the predominancy of the novel spliced form mRNA in about 50 to 200 -fold comparing to the unspliced form. The spliced form cDNA has been transfected into $\mathrm{K} 562$, and the expressed protein reacted with Duffy specific murine monoclonal antibody. These studies indicate that the product from the spliced form mRNA is the major product of the Duffy gene in erythroid lineage. 
B-48

CLONING OF THE RABBIT CORNEAL FKBP25 cDNA.

Hitoshi KITAGAWA, Yoshihiro HOTTA, Keiko FUJIKI, Fumino IWATA, Takurou FUJIMAKI, Hisashi OHNUKI, Nobuyuki HONDA, Yoshiki KUDOH, Naohiro OHTA, Misako TAKEDA, Michifumi WATANABE, Toshiyuki YOKOYAMA, Atsushi KANAI (Department of Ophthalmology, Juntendo University School of Medicine, Tokyo)

We have isolated corneal endothelial cDNA clones to try the candidate gene approach for the corneal dystrophy, and we have reported a clone that has been suggested to be the cDNA of B22 subunit of rabbit mitochondrial NADH: ubiquinone oxidoreductase. We report here further investigation. We isolated and sequenced rabbit $25 \mathrm{kDa}$ FK -506 binding protein (FKBP25) cDNA clone. The cDNA clone was a 955 bp fragment with a $670 \mathrm{bp}$ open reading frame, and a 285 bp 3' non - coding region. The first two bases of the start codon were lacking. The cDNA and deduced amino acid sequences were 91.7 and $96.4 \%$ identical, respectively, to previously reported human FKBP25B sequences. The lysine rich region $\mathrm{KK}(\mathrm{X})_{7} \mathrm{KK}(\mathrm{X})_{26} \mathrm{KKKK}$, which plays a great role in nuclear translocation in rabbit FKBP25 was recognized. Although corneal tissue has less of mRNA than the other tissues, RT - PCR analysis showed that more FKBP25 and FKBP12 were found in the cornea compared to the other tissues. FKBP25 and FKBP12 expression were detected in cultured corneal epithelial and endothelial cells. Higher expression of FKBP25 and FKBP12 in the rabbit cornea than the other tissues suggests a greater role of FKBPs in the cornea.

CLONING, EXPRESSION AND MAPPING OF HUMAN CATIONIC AMINO ACID TRANSPORTER 2. Ryuuji HOSHIDE, Toshinobu MATSUURA, Fumio ENDO, Ichiro MATSUDA (Dept. Pediatr., Kumamoto Univ., Kumamoto), Tatsuya KISHINO, Yoshihiro JINNO, Norio NIIKAWA, (Dept. Hum. Genetics, Nagasaki Univ., Nagasaki) and Kenichi MIYAMOTO, Eiji TAKEDA (Clinical Nutrition, Tokushima Univ., Tokushima)

Human cationic amino acid transporter2 (HCAT2), the homologue of mouse cationic amino acid transporter2 (MCAT2), was isolated from human intestine cDNA library using low stringency hybridization method. The nucleotide sequence of the coding region predicts a 658 amino acid protein with a calculated molecular weight of 71,669. Many tissues including intestine and kidney demonstrate gene expression. Transport activity was confirmed by arginine uptake using Xenopus oocyte. The chromosomal position of HCAT2 was assigned to $8 \mathrm{p} 21.3-22$. 
B-50

ANALYSIS OF THE ARGINASE GENE ENHANCER. Tomomi GOTOH, Masaki

TAKIGUCHI, and Masataka MORI (Dept. of Mol. Genet., Kumamoto Univ. School of Med., Kumamoto)

Liver-type arginase catalyzes the last step of the urea cycle (ornithine cycle). The major clinical manifestations of arginase deficiency are neurological symptoms, and the prominent laboratory finding is high arginine concentration in plasma and cerebrospinal fluid. Arginase is selectively expressed in the liver. Arginase mRNA and protein are induced by starvation or high protein uptake. This induction is thought to be mediated by glucocorticoid and glucagon. We looked for the hormone responsive element of this gene.

Human and rat arginase genes are about $12 \mathrm{~kb}$ long, and consist of 8 exons. We found an enhancer element that is located $11 \mathrm{~kb}$ downstream from the transcription start site of the rat gene and that spans the junction of intron 7 and exon 8 with a transient transfection assay using hepatoma cell lines. This enhancer was hepatoma cell-selective and showed a delayed glucocorticoidresponse. Footprint analysis revealed four protein-binding sites. Gel shift analysis demonstrated that two of the four sites are recognized by members of the CCAAT/enhancer binding protein (C/EBP) family. Studies on the relationship between glucocorticoid responsiveness and the C/EBP family are underway.

B-51

ERYTHROPOIETIN GENE REGULATION IN RESPONSE TO HYPOXIA. Terumasa TSUCHIYA, Mitsuhiro OKADA, Wei ZHANG, and Yukio YASUKOCHI (Department of Molecular Genetics, Medical Research Institute, Tokyo Medical and Dental University, Tokyo)

A molecular basis for hypoxia signaling and erythropoietin (Epo) gene regulation was studied. Reporter assays showed that Epo gene expression in response to hypoxia was controlled by the complex of the promoter and enhancer located in the 5'- and 3'-flanking regions, respectively. Systematic electrophoretic mobility shift assays using competitors and antibodies indicated that tissue-specific transcription factors (HNF-4 etc.) bound the regulatory elements in the Epo promoter and enhancer. Transactivation assays showed that the transcription factors could not affect Epo gene expression under normoxia. In contrast they activated Epo gene expression under hypoxia. 
B-52

CELL CYCLE-DEPENDENT REGULATION OF THE RNA POLYMERASE II BASAL TRANSCRIPTION ACTIVITY. Masatomo YONAHA, Taku CHIBAZAKURA, Shigetaka KITAJIMA*, and Yukio YASUKOCHI(Dept. Mol. Genet., Tokyo Med. \& Den. Univ., Tokyo * Dept. Clin. Lab., Fac of Med., Kyushu Univ. Sch. Med., Fukuoka)

Regulation of transcroption by RNA polymerase(Pol II) in eukaryotic cells requires both basal and regulatory transcription factors. In this report, we have investigated in vitro Pol II basal transcription activity during the cell cycle by using nuclear extracts from synchronized HeLa cells. It is shown that Pol II basal transcription activity is low in $S / G 2$ phases and high in early G1 phase, and TF IID is the rate-limiting component of Pol II basal transcription activity during the cell cycle. Further analyses reveal that TF IID exists as a less-active form in the G2/M phases and nuclear extracts from G2/M-phase cells contain a heatsensitive repressor(s) of TATA box-binding protein(TBP). These results suggest that $P o l$ II basal transcription activity is regulated by a qualitative change in the TF IID complex, which could involve repression of TBP, during the cell cycle.

\section{B-53}

MOLECULAR CLONING OF HEART-TYPE AMP DEAMINASE GENE. Takayuki MORISAKI, Keiko TOYAMA, Hiroko MORISAKI, *Ikuo MINEO, Tsunehiro MUKAI (Dept. Bioscience, Natl. Cardiovasc. Ctr. Res. Inst., Osaka, *Ohtemae Hospital, Osaka)

AMP deaminase (AMPD) plays a central role in purine nucleotide interconversion and can be a determinant of energy metabolism in eukaryotic cells. Myoadenylate deaminase deficiency has been reported in patients with metabolic myopathy. The molecular analysis of AMPD deficiency have revealed that one mutant AMPD1 allele is extremely common in Caucasians. This suggests that there must be a mechanism for phenotypic rescue of this common inherited defect through alternative splicing of AMPD1 or expression of other AMPD genes. Since the gene for heart-type AMPD isoform could play an important role in this mecahnism, we have cloned and analyzed cDNA for mouse heart-type AMPD gene. We have isolated cDNA clones which are homologous to human AMPD3. RNA analysis shows that this gene is highly expressed in heart, spleen or lung, but lower in liver. Red skeletal muscle expresses this gene more abundantly than white muscle. Based on the fact that we have isolated several clones containing partly different sequences, this gene could be regulated by alternative splicing as well as AMPD1. These results suggest that heart-type AMPD may play an important role in the energy metablism of red skeletal muscle as well as in that of heart or nonmuscle tissues. Therefore, the regulatory mechanism of this gene may account for the metabolism in the individuals with AMPD1 deficiency. 


\section{B-54}

A LARGE SCALE CDNA SEQUENCING OF A NORMALIZED DIRECTIONALLY-CLONED CDNA LIBRARY FROM ADULT HEART.

1,2 Toshihiro TANAKA, $1_{\text {Yusuke NAKAMURA }}\left({ }^{1}\right.$ Lab. Mol. Med., Inst. Med. Sci., Univ. Tokyo, Tokyo, 23 rd Dept. Int Med, Univ. Tokyo, Tokyo)

In the heart that is a continuously contracting and relaxing organ, muscle contractile and mitochondrial genes are highly expressed. To identify novel genes expressed in the heart efficiently, genes abundantly expressed should be reduced. We constructed a normalized directionally-cloned CDNA library from adult heart and determined the 5' partial sequences by an automated DNA sequencer. DNA sequences of these 3040 clones were compared with known DNA sequences in the database and we found that $58.3 \%$ of them were identical to the genes already known, $23.4 \%$ of them were human ESTs, and $14.2 \%$ of them were unknown. The remaining $4.1 \%$ of the clones were highly homologous to known genes; for example, dog calsequestrin gene, and Drosophila bendless gene. Northern blot analyses of some of these clones revealed that most of them were highly expressed in the heart and skeletal muscle. Hence we suggest that this method is useful to isolate novel genes expressed in the heart.

\section{B-55}

MOLECULAR GENETIC AND METABOLIC ASPECTS OF HPH-1,A MOUSE MUTANT DEFICIENT IN GTP CYCLOHYDROLASE I ACTIVITY Shigehiko HAENO Toyoki MAEDA, Masako ABE Kazumi ODA, Tomokazu SUZUKI (Dept. Clin. Genet., Med. Inst. of Bioregulation, Kyushu Univ., Beppu) and Hiroshi ICHINOSE, Toshiharu NAGATSU (Inst. for Comprehensive Medical Science, Fujita Health Univ., Toyoake)

GTP cyclohydrolase I (GTP-CH) catalyzes the initial and rate limiting step of the biosynthesis of tetrahydrobiopterin, the cofactor of three aromatic amino acid hydroxylases. Deficiency of this enzyme causes atypical phenylketonuria and hereditary progressive dystonia with marked diurnal fluctuation. To clarify the pathogenesis of the disorder, we analyzed urinary organic acids in adult $h p h-1$, using gas chromatography/mass spectrometry, and found that compared with control mice there were significant increase in phenyl pyruvic acid and decrease in homovanillic acid, although the disappearance of phenylketonuria in $h p h-1$ older than 20 days was previously reported. On the other hand, the structural analysis of the GTP-CH gene from the hph-1 revealed that the sequence of the open reading frame and a part of 5 'flanking region is identical with that of wild type. Further analysis is mandatory to explain the characteristic metabolic abnormality. 
B-56

MUTATION OF THE $h t s$ GENE, THE RAT HOMOLOGUE OF THE HUMAN WILSON DISEASE (WND) GENE, IN THE LEC RAT. Takao ONO, Risaku FUKUMOTO, and M.C. YOSHIDA (Cytogenet.Lab.,Grad. School of Environmental Earth Sci., and Chromosome Res. Unit, Fac. of Sci., Hokkaido Univ., Sapporo)

The LEC rat is a mutant strain which develops hereditary hepatitis and subsequently liver cancer. The LEC rat shares many clinical and biochemical features with Wilson disease, such as a low level of serum ceruloplasmin and an excess copper accumulation in the liver. An autosomal recessive gene, hts, responsible for the hepatic disease of the LEC. We have previously reported that the $h t s$ is the rat homologue of the human WND which encodes a copper transporting P-type ATPase by cloning cDNAs for the rat gene. We also found a partial deletion of the $h t s$ in the LEC. In this report, we analyzed extensively the deleted region of the hts gene. Southern hybridization and PCR analyses demonstrated that the deletion breakpoint was between the 3 'end of the exon-18 and the proximal region of intron between exon-18 and exon-19 of the hts gene and that the deletion extended to a termination codon of the hts cDNA. This indicates that the deletion removed at least $470 \mathrm{bp}$ of cDNA of the coding region at the $3^{\prime}$ end, includes the two transmembrane sites adjacent to the ATP binding site. Although the deleted region in the LEC was not identical to that of the human WND of Wilson disease, the LEC rat provides an animal model for Wilson disease and the better understanding the copper metabolism.

B-57

INTRODUCTION OF WILSON DISEASE GENE INTO THE LEC RATS AND CULTURED HEPATOCYTES DERIVED FROM THE RATS. Kimitoshi NAKAMURA, Koji NAGANO, Fumio ENDO, Ichiro Matsuda (Dept. Ped. Kumamoto Univ. School of Medicine)

Wilson disease is an autosomal recessive disorder of copper transport, resulting in copper accumulation and toxicity to the liver and brain. The gene for Wilson disease (ATP7B) was cloned and its product is a copper binding P-type ATPase protein. The Long-Evans Cinnamon (LEC) rat shows similarity to Wilson disease in many clinical and biochemical features. The gene for the rat (Atp7b) homologous to the Wilson disease gene was also cloned and found a partial deletion in the LEC rat. Therefor the LEC rat is defined as an animal model for Wilson disease.

We established a series of hepatic cell lines from the liver of LEC rats. The hepatocytes accumulated larger amounts of copper than hepatocytes from normal control rats. There was no differences between the LEC and control hepatocytes in amounts of $\mathrm{CP}$ secreted into culture medium. The ATP7B cDNA was ligated into an expression vector. We made monoclonal antibodies against the ATP7B product. A membrane fraction from human liver was analyzed by SDS-PAGE and immunoblot analysis using these antibodies, and a band at $155 \mathrm{kDa}$ was detected. The expression vector containing ATP7B cDNA was injected into rat with liposome. After a week, the ATP7B was detected in the liver by means of PCR analysis. 
B-58

MOLECULAR CLONING OF MURINE HOMOLOGUE CDNA FOR

DENTATORUBRAL-PALLIDOLUYSIAN ATROPHY (DRPLA) GENE. Mutsuo

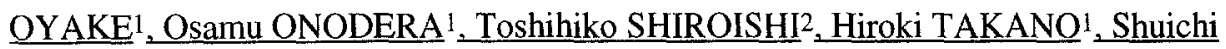

IGARASHI ${ }^{1}$, Hajime TANAKA ${ }^{1}$ Kazuro MORIWAKI ${ }^{2}$, Shoji TSUJI ${ }^{1}$ ( 1 Dept Neurol., Brain Res.Inst.,Niigata Univ., Niigata) (2 Mam. Animal Lab., Nat.Inst.Genet. Mishima)

Dentatorubral-pallidoluysian atrophy (DRPLA) is an autosomal dominant neurodegenerative disease caused by expansion of an unstable CAG repeat in a novel gene mapped to chromosome $12 \mathrm{p}$. Nucleotide sequence of this gene transcript and its expession in both normal and affected individuals are determined, however, the function of this gene product and the mechanism responsible for selective neuronal death remain to be elucidated. As a first step to develop an amimal model for DRPLA, we isolated murine homolouge cDNA for DRPLA. The consensus cDNA spanned $4103 \mathrm{bp}$. encoding 1175 amino acid protein. The murine homolouge exhibited $86 \%$ nucleotide and $92 \%$ amino acid identity to the human sequence. Sequece analysis revealed that murine cDNA contained shorter but polymorphic CAG repeat ranging from three to eight repeat . The numbers of CAG repeat varied among differnt phylogenetic mice but were constant within same phylogenetic ones. Northern blot analysis revealed that a single $4.5 \mathrm{~kb}$. transcript was widely expressed in all tissues examined and most abundant in brain. During embryonal stages, DRPLA mRNA was expressed with little variation.

\section{B-59}

MAPPING THE MOUSE GENE FOR CARNITINE DEFICIENCY. Kohei OKITA ${ }^{1}, 3$, Takashi TOKINO ${ }^{1}$, Hirovuki NISHIMORI ${ }^{1}$, Hiroko NIKAIDO ${ }^{2}$, Jun-ichro HAYAKAWA ${ }^{2}$, Akira OHNO $^{3}$, Masamichi KUWAJIMA ${ }^{3}$, YUji MATSUZAWA $^{3}$ and Yusuke NAKAMURA ${ }^{1}$. (1Lab. Mol. Med., Inst. Med. Sci., Univ. Tokyo, ${ }^{2}$ Inst. Exp. Ani., Sch. Med., Kanazawa Univ., 32nd Dep. Int. Med., Osaka Univ. Med. Sch.)

Carnitine is an essential cofactor for mitochondrial fatty acid oxidation by transporting long-chain fatty acids. Carnitine deficiency results in failure of energy production and accumulation of triglyceride in tissues, and leads to recurrent episodes of coma and hypoglycemia, chronic skeletal muscle weakness and cardiomyopathy. Juvenile visceral steatosis (JVS) mouse is an animal model of systemic carnitine deficiency, and jvs is inherited in an autosomal recessive mode. For a positional cloning of a gene responsible for JVS, we have performed linkage analysis on 190 back cross progeny, using microsatellite markers. We were able to map the jvs gene to a region of approximately $1.6 \mathrm{~cm}$ on mouse chromosome 11 . Furthermore, we have identified three YAC clones covering this region. 


\begin{abstract}
B-60
RESCUE OF ALBINO-LETHAL MICE (c14Cos) BY MUTANT 4-HYDROXYPHENYLPYRUVATE DIOXYGENASE DERIVED FROM TYROSINEMIC MOUSE STRAIN III.

Fumio ENDO, Shuji KUBO, Hisataka AWATA, Hideki KATOH, Ichiro MATSUDA

(Department of Pediatrics, Kumamoto University, School of Medicine, Kumamoto, Jaopan, Division of Genetics, The Central Labpratory for Experimantal Animals, Kawasaki, Japan)
\end{abstract}

A mouse strain c $14 \mathrm{Cos}$ is characterized by a large deletion on chromosome 7 and perinatal death due to failure of expression of hepatocytes specific and development specific genes. Recently gene for fumarylacetoacetate hydrolase (Fah) is disrupted in c14Cos mice. We attempted to rescue the lethal phenotype of the mice by introducing a mutant 4-hydroxyphenylpyruvate dioxygenase gene derived from a mouse strain III, a naturally occurring mouse strain with hypertyrosinemia. The new mutant combination with albino deletion on chromosome 7 and inactivating mutation of Hpd gene on chromosome 12 is able to survive with no apparent abnormality of the liver. These observations suggest that lethal phenotype of c14Cos mouse is due to metabolite(s) derived from tyrosine catabolism.

\title{
B-61
}

AN ATTEMPT TO GENERATE SERUM AMYLOID P COMPONENT-DEFICIENT MICE THROUGH GENE TARGETING. Shuichiro MAEDA, Sadahiro ITO, Nongying WU, Kyoko YOKOI, Shin NAKANO, Shinji TOGASHI (Dept. Biochem., Yamanashi Med. Univ., Yamanashi), Ken-ichi YAMAMURA (Inst. Mol. Embryol. and Genet., Kumamoto Univ., Kumamoto), Kyoji HORIE and Kazunori SHIMADA (Dept. Med. Gent., Res. Inst. Microbial Diseases, Osaka Univ., Osaka)

Several observations support the possibility that serum amyloid $\mathrm{P}$ component (SAP) plays some role in cases of amyloid deposition. To investigate the relationship between SAP and amyloid deposition, we attempted to disrupt the sap gene in mice. We used a positive-negative selection strategy to introduce an inactivating neor marker into the endogenous sap gene in mouse CCE ES cells. The targeting vector consisted of a short $(1.6 \mathrm{~kb})$ and a long $(8.7 \mathrm{~kb})$ regions of homology of the mouse sap genomic locus separated by the $1.6 \mathrm{~kb}$ neo ${ }^{\mathrm{r}}$ gene from $\mathrm{pGKNeo}$. A counterselectable HSV-tk gene was placed at the end of the long region of homology. This vector was electroporated into mouse ES cells, which were subsequently selected with G418 and FIAU. Among the 250 colonies obtained, 6 homologous recombinants were identified by Southern blotting and PCR. After injection of four of the six targeted ES cell clones into C57BL/6 host blastocysts, twelve male chimeric mice were obtained. The coat colors of the males varied from 40 to $70 \%$ chimeric. These male chimeric mice are now being bred with C57BL/6 females. 
Developmental genetic analysis of mouse quaking locus Kuniya $\underline{A b e}^{1}$, Tokiko Furuta ${ }^{1}$, Tadashi Kaname ${ }^{1}$, Ken-ichi Yamamura ${ }^{1}$, Tom Ebersole ${ }^{2}$, Karen Artzt', ( ${ }^{1}$ Inst. of Molecular Embryology \& Genetics, Kumamoto Univ. School of Medicine, Kumamoto 862, Japan, ${ }^{2}$ Dept. of Zoology., Univ. of Texas at Austin, Tx78712, USA)

Mouse quaking ( $q k$ ) locus locates within the $T / t$ complex of mouse, where a number of developmental mutations are mapped. We are attempting to identify and isolate gene responsible for $q k$ mutation by positional cloning approach. There are at least two alleles in the $q k$ locus, i.e. $q k^{\circ}$ (viable) and $q k^{e}$ (ENU-induced). $q k^{v} / q k^{\prime}$ or $q k^{v /} q k^{e}$ show dysmyelinating phenotype, resulting in body tremor, while $q k^{\ell}$ homozygotes die during embryogenesis. It was recently found that $q k^{v}$ genome had a relatively large deletion. We thus isolated a series of YAC clones to cover the deletion break points and the deleted genomic region, and detailed structural analysis of this region has been carried out. We have found novel genes adjacent to the deletion break points. In addition to such 'genome' analysis approach, we are also attempting to rescue the $q k$ phenotype by YAC transgenesis.

\section{B-64}

Detection of aneuploidy rate of spermatozoa from a male heterozygous for a $t(14 \mathrm{q} 21 \mathrm{q})$ Robertsonian translocation by FISH. Hu He, Norio MIHARU, Osamu SAMURA, Satoshi HAYASHI, Koso OHAMA (Dept. of Obstet.and Gynecol., Hiroshima Univ. of School of Medicine)

In order to quantify the relative proportion of sperm with unbalanced chromosomes resulting from the meiotic segregation of Robertsonian translocation, cytogenetic analysis was done with sperm from a man heterozygous for a $(14 q 21 q)$ Robertsonian traslocation using fluorescence in situ hybridization (FSH). Semen samples were obtained from a man with a karyotype of $45, X Y, t(14 q 21 q)$ and normal man. Two color FISH was performed with DNA probes (digoxigenin labeled chromosome 21 22 specific probe and biotin labeled alpha-satellite D17Z1 probe ). A total of 6233 sperm were scored with double blind study. The frequency of disomic sperm for chromosome 21 was $1.5 \%$ which was higher than those of a control man $(0.22 \%)$ and lower than those of theoretical frequency $(16.7 \%)$. For chromosome 17, the frequency of disomy and diploid sperm in a man of $45, X Y, t(14 q 21 q)$ were $0.22 \%$ and $0.28 \%$ respectively as previously described. These data indicate that there is some selection during or after meiotic segregation, with no evidence for an interchromosomal effect on chromosome \#17 aneuploidy in the Robertsonian traslocation carrier. 
B-65

VILLOUS TISSUES OBTAINED FROM SPONTANEOUS ABORTIONS CONTAIN TRIPROID CELLS AT A LOW FREQUENCY

Isao HORIUCHI, Yoshiyuki TSUJI, Koji KOYAMA (Dept. Obstet. Gynecol., Hyogo Coll. Med., Nishinomiya) and Tomoko HASHIMOTO, Hiromitsu SHIMADA, Jun-ichi FURUYAMA (Dept. Genet., Hyogo Coll. Med., Nishinomiya)

One of major causes of spontaneous abortion is chromosomal abnormalities. To examine spontaneous abortions caused by polyploidy, we analyzed the number of chromosomes by FISH (fluorescence in situ hybridization) using interphase nuclei of villous cells. Since trisomies 4 and 17 in villous samples obtained from spontaneous abortions have been rarely reported, we used alpha-satellite DNA probe, D4Z1 and D17 Z1 to detect centromeric regions of chromosome 4 and 17, respectively. Villous cells of each 30 cases of spontaneous and artificial abortions were analyzed.

By using both probes, three signals were found in 2 to $12 \%$ of nuclei from 4 cases with spontancous abortions. Moreover, 0.2 to $0.3 \%$ of cells with 6 signals were observed in 3 cases out of the 4 cases, suggesting that there may exist dividing triplod cells in these samples. On the other hand, no such increase of the frequency of nuclei with 3 signals was found in the cases of artificial abortions. These results indicate that the mosaic state of triploid cells existing at a low frequency may cause spontaneous abortion.

\section{B-66}

MECHANISM OF TRISOMY INDUCTION: PRECOCIOUS DIVISION. Shin-ichi SONTA and Noriko KOHMURA (Department of Genetics, Institute for Developmental Research, Aichi Human Service Center, Kasugai, Aichi)

Using female Chinese hamsters, we investigated meiotic segregation by performing chromosomal analyses of oocytes obtained from spontaneous ovulation and from ovulation stimulated by pregnant mare serum gonadotropin (PMSG) and human chorionic gonadotropin (hCG). Of a total of 919 and 566 oocytes from 41 mature females and 29 immature females stimulated with PMSG-hCG, cells with single chromatids and centromereseparating MII chromosomes were seen in $2.5 \%$ and $5.4 \%$ of these oocytes, respectively. Compared with the non-treated females, the frequency of cells with single chromatids and centromere-separating chromosomes was significantly greater in oocytes from both mature and immature females stimulated with PMSG-hCG. The frequencies of hyperhaploid cells from mature and immature females, respectively, were $2.2 \%$ and $4.7 \%$. These cells mostly had extra whole chromosomes but a few oocytes from mature and immature females had an extra single chromatid. The frequency of hyperhaploid oocytes in both mature and immature stimulated females was significantly greater than that in non-treated females. The findings suggest that such hormonal stimulation induces centromere separation of MII chromosomes and precocious division at anaphase I which can be assumed by the presence of MII cells with extra single chromatids. 
ANALYSIS OF THE BREAK POINT OF AN INTERSTITIAL DELETION OF THE LONG ARM OF CHROMOSOME 1 BY FISH (FLUORESCENCE IN SITU HYBRIDIZATION) AND GENE DOSAGE EFFECT OF THE NEIGHBORING GENES. Takako TAKANO, Yasuko YAMANOUCHI (Dept. Hygiene \& Pub. Health, Teikyo Univ. School of Med., Tokyo), Yosuke MORI, Satoshi KUDO, Toyoaki NAKAYAMA, Masatoshi SUGIURA, Shintaro HASHIRA and Toshiaki ABE (Dept. Pediat. Teikyo Univ. School of Med., Tokyo)

A patient with an interstitial deletion of the long arm of chromosome 1 is reported. He had multiple congenital anomalies, including meningomyelocele, hydrocephalus, atresia ani, atrial septal defect, left renal agenesis, bilateral retentio testis and talipes equinovarus. His karyotype was 46,XY, del(1)(q23.1q24.2) by conventional Gbanding. We examined the break points using many cosmid clones of chromosome 1 by fluorescence in situ hybridization (FISH) and diagnosed the karyotype as 46,XY.ish del(1)(q24q25.3). Assays for apolipoprotein A-II (1q21-q23, Human Gene Mapping 1994), coagulation factor $V(1 q 21-q 25)$ and antithrombin III (1q23-q25.1) revealed that the first two showed normal activity and the last showed low activity. The gene dosage effect suggests that the gene of coagulation factor $V$ is located to 1q21-23 and the gene of antithrombin III is located to $1 \mathrm{q} 24-\mathrm{q} 25.1$.

\section{B-68}

NONRANDOMNESS OF RADIATION-INDUCED CHROMOSOME ABERRATIONS IS REVEALED BY ANALYSIS USING CHROMOSOME PAINTING METHOD. Kiyomi YAMADA (Dept. Genetics, Res. Inst.) and Jun ITAMI (Dept. Radiation Therapy, Hospital, The International Medical Center of Japan, Tokyo)

It is an important problem for radiation dosimetry whether frequncies of radiation-induced aberrations in individual chromosomes are strictly dependent on their DNA content or not. We studied frequencies of chromosome aberrations in lymphocytes experimentally exposed to X-rays in 2-5 grey doses with FISH method using chromosome painting probes. Results were the followings: 1) There were 'hotspots' of chromosome breaks in individual chromosomes (i.e., in R-band-rich regions). 2) These 'hotspots' were fairly coincident with leukemia-specific translocation breakpoints. 3) Frequencies of breakpoints in individual chromosomes were not always relative to their DNA content (e.g., 15 chromosomes are more sensitive than 13). 4) Radiation sensitivity between homologs was slightly different by their parental origin (i.e., more sensitive in the paternally derived chromosomes). 5) Estimated chromosome aberrations per cell using different single probe for nos. $1,4,5,9,11$, or $13 \mathrm{ch}$ romosome showed a range of $1.8-2.5(t+$ dic, only) in 3-grey-exposed cells. The present study revealed that chromosome painting method is rapid and convenient for aberration scorings, and suggests that if the method is generally used, target chromosomes for painting must be fixed for comparison and evaluation of data obtained by different investigators. 
B-69

MOUSE A9 CELLS CONTAINING A SINGLE HUMAN CHROMOSOME 2 TAGGED WITH A DOMINANT SELECTABLE MARKER GENE IN DIFFERENT REGIONS.

Hiroshi UEJIMA ${ }^{1}$, Tokuyuki SHINOHARA ${ }^{1}$, Hitoshi YOSHIDA ${ }^{2}$, Kazuma TOMIZUKA ${ }^{2}$, Isao ISHIDA ${ }^{2}$, Mitsuo OSHIMURA' ('Department of Molecular and Cell Genetics, School of Life Sciences, Faculty of Medicine, Tottori University, Yonago, ${ }^{2}$ Central Laboratories for Key Technology, KIRIN Brewery Co.,Ltd., Yokohama)

Mouse A9 cells containing a single human chromosome have been used for the hybrid-panel, isolation of chromosome-specific DNA markers and the donor cells of microcell-mediated chromosome transfer (MMCT), to map the tumor suppressor genes and genes responsible for recessive genetic disorders. To clone these genes efficiently, isolation of region-specific DNA markers is required and thus, mouse A9 cells containing subchromosomal fragments can be constructed by irradiating the A9 microcell hybrids. However, the fragments obtained through this method tend to be derived from the integration site of a dominant selectable marker gene.

To conquer the problem, we constructed the library of mouse A9 cells containing a single human chromosome 2 tagged with a dominant selectable marker gene in different regions, because MMCT and RFLP analyses recently showed the presence of a tumor suppressor gene(s) and a senescence gene(s) on human chromosome 2 . The dominant selectable marker genes, neo or $b s r$, were transfected to normal human fibroblasts, the transfectants were fused to mouse A9 cells, and microcells derived from the whole cell hybrids were again fused to mouse A9 cells. Seven independent clones were obtained, and the integration sites identified by FISH were $2 \mathrm{p} 21-23,2 \mathrm{p} 16-22,2 \mathrm{p} 11-12,2 \mathrm{q} 31$, $2 q 31-35,2 q 33-36$ and $2 q 34-37$.

B-70

DELETED GENETIC DISTANCE AT 7q11.23 IN WILLIAMS SYNDROME Yuji MORIMOTO (Dept. Pediatr, Zentsuji National Hosp, Kagawa), Akira KUWANO, Fumie TAKAKUBO, Ikuko KONDO (Dept. Hyg, Ehime Univ. Sch. Med., Ehime), Katsuko KUWAJIMA (Dept. Pediatr, Ibaraki Pref hand Capped Cild Center, Ibaraki), Yoshimitsu FUKUSHIMA, Hirofumi OHASHI (Dept Genet, Saitama chil Med center, Saitama), Kiyotaka TOMIWA (Dept Pediatr, Osaka City General Hosp, Osaka), Hidefumi TONOKI (Dept Pediat, Hokkaido Univ. Sch Med, Hokkaido

Williams syndrome (WS) is a contiguous gene syndrome including mental retardation (MR), short stature, dysmorphic facies, characteristic personalities, and supravalvular aortic stenosis. The elastin gene was deleted in 38 patients with typical clinical features of WS by the fluorescence in situ hybridization.To ascertain the expansion of the detetion in WS, we studied the genetic distance among the markers of the elastin gene (ELN), D7S653, and D7S1870 in 42 families. All patients with WS not heterozygous for ELN and D7S1870, and the origin of deletion were detected (Paternal 10, maternal 10). Furthermore, the linkage analysis showed one recombinant in ELN and D7S1870 (O=0.03, maximum lod score 4.390), but no recombinant in ELN and D7S653 $(\mathrm{O}=0.00,6.019)$. These data suggested that the expansion of the deleted region in WS might be $3 \mathrm{Mb}$ including the several genes, and the genetic order, 7qcen-D7S653- ELN-D7S1870-D7S675-7qter. 
B-71

MAPPING OF GENES BY FISH METHOD USING MAINLY CDNA PROBES. Setsuo TAKAI ${ }^{1}, 2$, Kiyomi YAMADA ${ }^{1}$ (1 Dept.Genet.,

Res.Inst., Internatl. Med. Centr of Japan, ${ }^{2}$ Dept.

Experimental Pathol., Cancer Res. Inst.)

We have mapped about 50 genes on chromosomes by fluorescence in situ hybridization (FISH) method using mainly human cDNAs. Experimental findings through FISH method in our labolatory are as follows so far. 1) Even probes of CDNA that have only about $0.7 \mathrm{~kb}$ insert size could be mapped by our system. 2) Some probes of CDNA (about 10\%) may not used for FISH because of their having repetitive sequences. In such cases, after amplification procedure of signals, Alu-like signals were observed all over the human chromosomes. 3 ) Some probes of CDNA can be hybridized not only to real chromosomal locations of genes but also to locations of pseudogene(s) or family gene(s) at high rate, up to about 50\% of symmetrical double spots. In such cases, we had to determine the real location of the gene among mainly two locations using a genomic DNA probe later that was hybridized to only one location of them in the end. 4)Even probes of genomic DNA that have $A l u$ family sequence( $s$ ) and also only about $7-8 \mathrm{~kb}$ insert size could be mapped on human chromosmes.

\section{B-72}

STRUCTURE OF STRETCHED CHROMATIN FIBER ANALYZED BY ATOMIC FORCE. MICROSCOPY.

Momoki HIRAI, Mari KASAHARA (Dept. Biol. Sci., Grad. Sch. Sci., Univ. Tokyo, Tokyo), Satoshi KAWASAKI, Tetsuo KOBAYASHI (01ympus Inc., Tokyo) and Yumiko SUT0 (Red Cross Central Blood Center, Tokyo)

The atomic force microscope(AMF) can image the surface of uncoated chromatin at resolution comparable to that obtained by electron microscopy (EM). Specially sharpened AFM tips give images with reporoducible features several nanometers in size along the specimen. High resolution AFM imaging performed in air using chromatin from cultured lymphocytes has revealed that the DNA is organized into nodular subunits, which vary in diameter between 30 and $200 \mathrm{~nm}$. Decondensed chromatin preparations obtained by SDS treatment showed that thick bundles of DNA fibers looped out away from the nuclei. These fibers appeared to stretch or unrave1, generating narrow smooth fibers with approximately $30-\mathrm{nm}$ width and 2-nm thickness. Images obtained by AFM revealed details that improve the understanding of the structure of the chromosomal DNA for the visual mapping of stretched chromatin by fluorescence in situ hybridization (FISH). 
B-73

THE HUMAN HS1 GENE IS ASSIGNED TO 3q13.3

MIYOSHI, O., EGASHIRA, M. NIIKAWA, N. (Dept. Hum. Genet., Nagasaki Univ. Sch. Med., Nagasaki), KITAMURA, D., WATANABE, T. (Dept. Prevent. Med., Med. Inst. Bioregul., Kyushu Univ., Fukuoka)

The HS1 protein is a $75-\mathrm{kD}$ intracellular protein, $\mathrm{p} 75^{\mathrm{HS} 1}$, recognized only in blood cells, and its N-terminal has a DNA binding site similar to that in the Jun-Fos-Myc family and C-terminal represents $\alpha$-helix structure similar to other transcription factors. Recent studies showed that the HS1 protein plays an important role in signal transduction in an antigen receptor on the surface of B and T lymphocytes. The human HS1 gene has been isolated by Kitamura et al (1989).

We report here the assignment of the HS1 gene. An 8-kb pUC19 insert, p411G, that corresponded to the genomic DNA of the HS1 gene and a 2-kb HS1-cDNA were probed for fluorescence in situ hybridization (FISH) on normal metaphase chromosomes. Both probes gave FISH signals at 3q13.3. Thus, The HS1 gene is assigned to this chromosomal region.

\section{B-74}

\section{MAPPING OF THE MSP GENE BY FISH}

SASAKI, T. SAKAI, H., KANETAKE, H. SAITO Y. (Dept. Urol., Nagasaki Univ. Sch. Med.), MATSUMOTO, N. JINNO, Y., and NIIKAWA, N. (Dept. Hum. Genet., Nagasaki Univ.)

$\beta$-microseminoprotein (MSP) is one of major proteins secreted by the prostate gland, and its biological function has remained unknown. We previously reported that MSP was strongly expressed in both the normal and hyperplastic prostate tissues, while its expression was decreased in prostate cancer tissues. These findings suggested that the decreased MSP expression may play a role in the process of prostate cancer. The MSP gene was tentatively mapped on chromosome 10 by hybrid cell analysis. Since $\mathrm{LOH}$ at $10 \mathrm{q}$ (or 10q24) has been observed in prostate cancer, a more accurate mapping of the MSP gene is necessary. Here, we report the assignment of the gene.

By screening of a phage library with a partial sequence of the MSP gene, a phage corresponding to the gene was isolated. FISH using the phage as a probe revealed that the MSP gene was assigned to $10 \mathrm{q} 11.2$. Since the mapped region was outside the previously identified LOH regions, the result indicated that the MSP gene can be ruled out from candidacy for a tumor suppressor gene located to the regions of prostate cancer. 


\section{B-75}

\section{CHROMOSOME MAPPING OF THE HUMAN TBP (TATA BOX-BINDING PROTEIN)} GENE TO 6q27 BY FISH. Fumiko SAITO-OHARA, Tatsuro IKEUCHI (Med. Res. Inst., Tokyo Med. Dent. Univ.) Tohru YAMAMOTO and Masami HORIKOSHI (Inst. Mol. Cell. Biosci., Univ. Tokyo)

TBP (TATA box-binding protein) plays an essential role in both basal and regulated transcription directed by RNA polymerase I, II and III. In the present study, to determine directly the chromosomal location of the human TBP gene by FISH, we used cDNA fragment (H10) containing the entire coding region of the TBP to hybridize to the R-banded prometaphase chromosomes of healthy donors. A total of 39 doublet signals were observed, and 15 of them (38.5\%) were exclusively detected on the terminal region of chromosome $6 \mathrm{q}$, more precisely on the distal half of the band $6 \mathrm{q} 27$. The other signals were distributed randomly along the chromosomes. As the possibility remains that the observed signals are due to hybridization of trinucleotide (CAG)n repeat in the N-terminal region of the TBP to a similar repeat on unrelated chromosome DNA, we prepared a cDNA fragment probe (M14; 718bp) encoding only the $\mathrm{C}$-terminal region without (CAG)n repeat. Since this M14 clone also gave signals on chromosome 6q27, we concluded that human TBP gene is unequivocally located on the chromosome region $6 \mathrm{q} 2705->\mathrm{qter}$.

\section{B-76}

CHROMOSOME MAPPING OF THE HUMAN NFATX GENE TO 16q21->q22 BY FISH. Fumiko SAITO-OHARA, Tatsuro IKEUCHI (Med. Res. Inst., Tokyo Med. Dent. Univ.), Esteban S. MASUDA. Naoko ARAI (DNAX Res. Inst., USA)

The nuclear factor of activated $\mathrm{T}$ cells (NFAT) regulates cytokine gene expression in $\mathrm{T}$ cells through cis-acting elements located in the promoters of cytokine genes. A novel member of the NFAT, designated NFATx, exhibits in its middle a region very similar to the Rel homology domain in NFATc and NFATp. NFATx can reconstitute binding to the NFAT binding site from the interleukin 2 (IL2) promoter with AP1 polypeptides to activate transcription of the IL.2 promoter in COS-7 cells when stimulated with phorbol ester and calcium ionophore. NFATx mRNA is preferentially and remarkably found in the thymus and at lower levels in peripheral blood leukocytes. For FISH analysis, two cDNA fragments for NFATx (fragment A[positions 1 to 1396] and B [positions 1575 to 3699]) were used. As we located the majority of the doublet signals on chromosome $16 \mathrm{q} 21->\mathrm{q} 22$ and obtained similar results when two different fragments were used as probes, we concluded that NFATx gene mapped to $16 q 21->q 22$. NFATc and NFATp have mapped by FISH to chromosomes 18 and 20 , respectively. Thus, the three genes encoding different members of the NFAT family are located in different chromosomes of the human genome. 
C-1

THE GENE STRUCTURE OF THE 100-kDa COMPLEMENT-ACTIVATING COMPONENT OF Ra-REACTIVE FACTOR Fumio TAKADA $,{ }^{*}, \dagger$ Naohiko SEKI,${ }^{\dagger}$ Yoh-ichi MATSUDA, $\$$ Yoshinaga TAKAYAMA, ${ }^{\dagger}$ Masaya KAWAKAMI ${ }^{\dagger}$ and

Nobuo MATSU-URA*. Depts. *Pediatr. and TMol. Biol., Kitasato Univ. Sch. Med., Sagamihara; $¥$ Lab. Gene Structure I, Kazusa DNA Res. Inst., Kisarazu; and §Div. Genet., Natl. Inst. Radiol. Sci., Chiba

Ra-reactive factor (RaRF) is a serum bactericidal factor that activates the C4 and C2 components of complement after binding to polysaccharides which are shared by many strains of microorganisms. The human gene for the $100-\mathrm{kDa}$ complement-activating serine protease component, called P100, of RaRF (CRARF) has been cloned from a $\lambda$ human genomic library. Sixteen exons and 15 introns were isolated, and the size of this gene is more than $35 \mathrm{~kb}$. However the domain constitution of P100 component is the same to those of $\mathrm{C} 1 \mathrm{r} / \mathrm{s}$ components of complement, the exon-intron constructions of serine protease domain were different. The genome of the protease domains of $\mathrm{C} 1 \mathrm{r} / \mathrm{s}$ is constructed with only one exon, intronless, but that of P100 has 6 exons. Our results suggest that the exon-shuffling was occurred after P100 gene branched from $\mathrm{C} 1 \mathrm{r} / \mathrm{s}$ in their evolutional tree.

C-2

SIGNAL TRANSDUCTION PATHWAY OF INTERLEUKIN-4 AND INTERLEUKIN-13 IN HUMAN B CELLS DERIVED FROM X-LINKED SEVERE COMBINED IMMUNODEFICIENCY PATIENTS. Kenji IZUHARA, Masako SAKAI, Rie INABA, Takashi IMAMURA(Dept. Hum. Genet., Natl. Inst. Genet., Mishima), Takeshi OTSUKA, Yoshiyuki NIHO(First Dept. Int. Med., Kyushu Univ., Fukuoka), Toshio HEIKE, Mituhumi MAYUMI(Dept. Ped., Kyoto Univ., Kyoto) and Nobuyuki HARADA(First Res. Dept., Res. Inst. Tub., Kiyose)

X-linked severe combined immunodeficiency (XSCID) is an inherited immunodeficiency disease characterized by absent or markedly reduced numbers of $\mathrm{T}$ cells and $\mathrm{B}$ cells which function abnormally. XSCID has recently turned out to be occured by mutations of the $1 \mathrm{~L}-2$ receotor (IL-2R) $\gamma$ chain $\left(\gamma_{c}\right)$ gene. The $\gamma_{c}$ is known to be shared by not only the IL-2R, but also the IL-4, IL-7, IL-9, and IL-15Rs. In this study, we have analyzed activation of members of the Jak family and STAT 6 induced by IL-4 and IL-13 which has similar effects as IL-4, in EBV-transformed B cells derived from two patients of XSCID. In these B cells, IL-4 failed to induce tyrosine phosphorylation of Jak 3 and activation of STAT6. In contrast, IL-13 activated STAT6 in these cells as well as normal $\mathbf{B}$ cells. These results clearly indicated that $\gamma_{c}$ is essential for activation of Jak3 and STAT6 in the signal transduction pathway of IL-4 in human $B$ cells, and that IL-13 does not utilize $\gamma_{c}$ but activates STAT6 through an alternative pathway, which is not impaired in B cells of XSCID patients. 
DQA $1 * 0302$ SPLITS BY A NUCLEOTIDE SUBSTITUTION IN EXON 1. Shin'ichiro YASUNAGA, Takehiko SASAZUKI (Dept. Genet., Med. Inst. Bioreg, Kyushu univ.) and Akinori KIMURA (Dept. Tissue Phisiol., Div. Adult Diseases, Med. Reserch Inst., Tokyo Med. Dent. Univ.)

We reported in the last JAHG meeting that DQA $1 * 0301$ was different from DQB $1 * 0302$ only at codon 160 (GCT vs GAT). We also reported that DQA ${ }^{*} 0301$ links to DRB1* $0403, * 0406, *(0407$ and $* 08() 2-\mathrm{DQB} 1 * 0302$ haplotypes and DQA $1 * 0302$ links to DRB 1 *0405-DQB $1 * 0401$, DRB $1 * 0410-\mathrm{DQB} 1 * 0402$ and DRB1*0901-DQB $1 * 0303$ haplotypes in the Japanese population. This time we determined nucleotide sequences in exon 1 of DQA1 alleles and developed a typing system for DQA 1 exon 1 by PCR-SSOP method. It should be noted that DQA $1 * 0302$ which links to DRB $1 * 0405$ or $* 0410$ and DQA $1 * 0301$ have ATG at codon -6 (codon 18 in exon 1), on the other hand DQA $1 * 0302$ which links to DRB $1 * 0901$ has ACG at codon -6 . This observations correspond to the polymorphism of DQA1 promorter region (QAP) that we previously reported. That is DR4 links to QAP3.1 and DR9 links to QAP3.2. These facts suggest that QAP and DQA1 exon 1 may have passed a different evolutional pathway from DQA1 exon 2, 3 and 4 reflecting the about $3.5 \mathrm{~kb}$ long intron 1 .

C-4

GENETIC CONTROL OF THE IMMUNE RESPONSE TO HEPATITIS B SURFACE ANTIGEN IN HUMANS. Mari MINETA, Masako TANIMURA (Natl. Children's Hosp., Tokyo), Takeshi TANA, Wei-Ping MIN, Nobuhiro KAMIKAWAJI, Akinori KIMURA and Takehiko SASAZUKI (Dept. Genet., Med. Inst. Bioreg., Kyushu Univ., Fukuoka)

To investigate the HLA-linked genetic control of the human immune response, we immunized 339 healthy Japanese medical students with recombinant hepatitis B surface antigen and determined the HLA types by PCR-SSOP method. The anti-HBs antibody titers showed a log normal distribution, suggesting that the immune response to $\mathrm{HBsAg}$ in humans is a multifactorial and continuous trait. A stepwise multiple regression analysis demonstrated quantitatively how all loci of the HLA-class I (HLA-A and B) and class II (HLA-DRB1, DQA 1, DQB1, DPA1, and DPB1) genes contributed to anti-HBs antibody production. The multiple correlation coefficient of antibody production to HBsAg with the DRB1 locus was 0.34, and it was highest among all the HLA loci. The incorporated correlation coefficients of class I and class II with the antibody production were 0.36 and 0.44 , respectively, and that of the presence of entire HLA genes was 0.50 , suggesting that the class I and class II loci within the HLA multigene family are dynamically involved in the regulation of the immune response to $\mathrm{HBsAg}$. The predicting equation for anti-HBs antibody levels for the individuals with any HLA types was proposed by multiple regression analysis. Thus, we can predict anti-HBs titers of individuals by the HLA typing prior to immunization. 
C-5

Differences in the naturally bound MHC Class I peptide repertoires among a colon carcinoma cell line, an activated Ki-Ras gene-targeted progeny cell line and a EBV transformed B-cell line. Clistopher.J. SAVOIE, Nobuhiro. KAMIKAWAJI, Tohru. SUDO, Takehiko. SASAZUKI. (Dept. Genetics, Med.Inst. Bioreg., Kyushu University,Fukuoka).

To elucidate the relative genetic influence of $\mathrm{Ki}-\mathrm{Ras}$ on the MHC class I-bound peptide repertoire in colon cancer, and the differences in class I peptide repertoires among cells from different tissues, we isolated the peptides bound to HLA A.2.1 molecules from a colon carcinoma cell line (HTC116), a Ki-Ras gene-targeted progeny cell line (Hke-3) and an EBVtransformed B-cell line. We then analyzed the eluted peptides by tandem mass spectrometry. Although the two colon carcinoma cell lines have very different metabolisms and morphologies, due to the presence or absence of activated Ki-Ras, there were no observed differences in the MHC class I peptide repertoires between these cells. However, there were profound differences between the repertoires of the colon cancer cell lines and the Bcell line. 3 of 7 peptide CID spectra were different between B-cells and colon cancer cells, indicating that tissue differences have more influence on MHC class I repertoire than mctabolic changes due to the influence of the Ki-Ras oncogene.

C-6

Analysis of $\mathbf{T}$ cell response using motif aided peptide epitope liblary. Nobuhiro. KAMIKAWAJI, Tohru. SUDO, Takehiko. SASAZUKI. (Dept. Genetics, Med.Inst. Bioreg., Kyushu University,Fukuoka).

We describe a novel method to investigate variability of $\mathrm{T}$ cell responses of PBLs using large libraries of synthetic peptides. Motif aided peptide epitope library for DRB $1 * 0405$ restricted $T$ cell response was synthesized, containing fixed amino acids representing the major histocompatibility complex (MHC) class II anchor residues for HLADRB $1 * 0405$ (YXXLXAXXD). We synthesized 135 sets of peptide libraries, each of which contains 729 peptide species. T cell responses of PBLs were examined for two HLA-DR identical donors (DRB1*0405/1502) and one non identical donors (DRB $1 * 0406 / 0901$ ). Appreciable $T$ cell responses were observed in both donors. The response pattern of PBLs against two HLA-DR identical donors were similar while that between HLA-DR non identical donors were different, suggesting the strong HLA restriction of $T$ cell response. The library will be useful tool to investigate the pathogenic $T$ cell response such as auto immune diseases. 
ANALYSIS OF CLASS II HLA-BINDING PEPTIDE MOTIFS USING A PHAGE fUSE5 PEPTIDE LIBRARY. She MATSUSHITA, Shoji FUJISAO, Masatake OISQ, and Yasuharu NISHIMURA (Div. Immunogenet., Kumamoto Univ. Grad. Sch. Med. Sci., Kumamoto)

Our previous studies on DR4-binding peptide motifs allowed us to identify a T cell epitope on insulin molecule in insulin autoimmune syndrome. With the same strategy, we analyzed: (a) DQ4 (DQB1*0401) associated with rheumatoid arthritis (RA); (b) DR9 (DRB1*0901) associated with juvenileonset myasthenia gravis and SLE with anti-phospholipid syndrome; and (c) DQ9 (DQB1*0303) vs DQ8 (DQB1*0302) with difference in ${ }^{57} \beta$ alone. Peptide motif analyses by using a phage fUSE5 random 15-mer peptide library revealed that: (a) DQ4 motifs are distinct from known DR motifs, and type II collagen, the most likely autoantigen in RA, has as many as 94 DQ4-binding motifs; (b) no significant differences were observed between the affinities of the collagen-derived peptides with DR or DQ molecules of RA-susceptible DR4-DQ4 and with those of non-susceptible DR4-DQ8 (DRA1*0301$\mathrm{DQB1}{ }^{* 0302)}$ haplotypes, indicating that the susceptibility to RA is not a simple immune response gene phenomenon specific to collagen; (c) DR9 motifs are unique in that small neutral Ser is allowed at the second anchor; and (d) DQ9 and DQ8 motifs have identical frameworks, but ${ }^{57} \beta$ Ala (IDDM-susceptible), unlike ${ }^{57} \beta$ Asp allows polar residues at the most $\mathrm{C}$-terminal anchor.

\section{C-8}

Ligand specificities for HLA-A2 subtypes defined by mass spectrometry Tohru SUDO ${ }^{*}$, Nobuhiro KAMIKAWAJI", Akinori KIMURA ${ }^{* * *}$, Satoru KUHARA**, and Takehiko SASAZUKI*

*Department of Genetics, Medical Institute of Bioregulation, "*Graduate School of Genetic Resources Technology, Kyushu University, Fukuoka. "* Department of Tissue Physiology, Division of Adult Diseases, Medical Research Institute, Tokyo Medical and Dental University, Tokyo.

To investigate how single amino acid substitutions in MHC class I molecules affect differences in peptide repertoires, we eluted and sequenced the naturally processed peptides from three HLA-A2 subtypes (HLA-A*0204, $-A^{*} 0206$ and $-A^{*} 0207$ ) which differ by a single amino acid residue substitution each with $-A^{*} 0201$ at the floor of the binding groove. Allele-specific peptide-motifs for each HLA-A2 subtype substantially differed from that of -A*0201 in the dominant anchor residues. The relative signal intensities for eighteen self peptides determined by mass spectrometry precisely reflected these peptide-motifs. To rationalize the differences in peptide-motifs, possible conformations of each allele were computer modeled by energy minimization calculations based on the reported crystal structure of HLA-A*0201. According to our models, the differences in peplide-motifs could be explained by substituted-residue-driven conformational changes for each MHC-peptide complex. These results demonstrate the fine differences among HLA-A2 subtype self peptide repertoires and contribute to the prediction of antigenic peptides. 
C-9

IDENTIFICATION OF AN HLA-PEPTIDE COMPLEX CONTRIBUTING TO JAPANESE CEDAR POLLINOSIS. Toshio HORI ${ }^{1}$, Nobuhiro KAMIKAWAJI ${ }^{1}$, Akinori KIMURA $^{2}$, and Takehiko SASAZUKI ${ }^{1}$ (Dept. Genet., Med. Inst. Bioreg., Kyushu University, Fukuoka) ${ }^{1}$ (Div. Adult Diseases, Med. Research Inst., Tokyo Medical and Dental University, Tokyo) ${ }^{2}$

We investigated the association between Japanese cedar pollinosis and HLA-class II alleles by HLA-DNA typing using a PCR-SSOP method and found that the frequency of HLA-DP5 (DPA1*02022 and DPB 1*0501) was significantly increased in the patients. To investigate whether the HLA-DP5 was merely a genetic marker or rather involved in the pathogenesis of the disease, Japanese cedar pollen antigen (CPAg)-specific T cell lines were established from three patients who possessed HLA-DR4-DR53-DQ4-DP5 (DRB $1 * 0405$-DRB 401 -DQA $1 * 0302$-DQB $1 * 0401$-DPA $1 * 02022$-DPB $1 * 0501$ )

haplotype. By using these CPAg-specific T cell lines and 88 synthesized overlapping peptides spanning the entire length of two major cedar pollen allergens, Cry $\mathrm{j} 1$ and Cry $\mathrm{j}$ 2, two peptides recognized by DR53-restricted $T$ cells and one peptide recognized by DP5-restricted T cells were identified. DP5-restricted T cell lines as well as DR53restricted $T$ cell lines produced Th2-type cytokines. Therefore, HLA-DP5 may be directly involved in the pathogenesis, by helping the IgE Ab production to $\mathrm{CPAg}$.

C-10

Interaction with bone marrow derived cells is required for early $\mathrm{T}$ cell development in the thymus Ken YAMAMOTO, Yoshinori FUKUI and Takehiko SASAZUKI (Dept. Genet., Med. Inst. Bioreg, Kyushu Univ., Fukuoka)

During intrathymic $\mathrm{T}$ cell differentiation, immature thymocytes maturate to $\mathrm{CD} 4+8$ or CD4 $8^{+}$stage when their TcR recognizes self MHC molecules. Although the thymus provides a unique environment for this event, it is unknown whether positive selection is mediated by all thymic epithelial cells (TEC) or by some specialized subsets. To address this issue, we generated two strains of mice transgenic for both 2B4 TcR $\alpha \beta$ and HLA$\mathrm{DR} \alpha$ genes; $\mathrm{DR} \alpha-24 / 2 \mathrm{~B} 4 \mathrm{TcR} \alpha \beta$ transgenic mice (Tg) expressing DR $\alpha \mathrm{E} \beta$ molecule on TEC and bone marrow derived cells (BDC) and DR $\alpha-30 / 2 B 4$ TcR $\alpha \beta$ Tg expressing $\mathrm{DR} \alpha \mathrm{E} \beta$ molecule on only TEC. In an analysis for thymocyte development in these mice, we found that $\mathrm{CD} 4+8+(\mathrm{DP})$ thymocytes could maturate to $\mathrm{CD} 4+8$ stage only in the $\mathrm{DR} \alpha-$ $24 / 2 \mathrm{~B} 4 \mathrm{TcR} \alpha \beta \mathrm{Tg}$. This indicates that positive selection of $\mathrm{T}$ cells requires the interaction of their TcR with relevant MHC molecules on BDC in TcR Tg. To confirm this, $\mathrm{H}-2$ class I and II double knock-out DR $\alpha-24$ mouse (Ebra) and DR $\alpha-30$ mouse (Edun) were generated. Inconsistent with the observation in $\mathrm{TcR} \mathrm{Tg}$, DP thymocytes could maturate to $\mathrm{CD} 4+8$ - stage not only in Ebra but also in Edun, indicating that MHC molecules on BDC does not contribute to the maturation of immature thymocytes in physiological condition. Recent studies have shown the possibility that $\mathrm{p} T \alpha-\operatorname{TcR} \beta$ complex regulates early $\mathrm{T}$ cell development in the thymus. Because interaction of $2 \mathrm{~B} 4 \mathrm{TcR} \alpha \beta$ with $\mathrm{DR} \alpha \mathrm{E} \beta$ on $\mathrm{BDC}$ was essential for the development of immature thymocytes in $T c R \alpha \beta T g$ and because maturation to $\mathrm{CD} 4+8$ stage was observed in Edun, it is suggested that interaction of $\operatorname{TcR} \alpha \beta$ with relevant MHC on BDC can mimic the interaction of $\mathrm{pT} \alpha-\mathrm{TcR} \beta$ with its natural ligand and that this ligand is a non-MHC molecule expressed on BDC. 
C-11

\section{HLA-DM GENE POLYMORPHISMS IN IGA NEPHROPATHY.}

Shoii KUWATA, Masami YANAGISAWA Yoichi SHIBATA (Dept. Transf. Med., Univ. Tokyo, Tokyo), Kazuo NOSAKA, Kiyoshi KUROKAWA (1st Dept. Int. Med., Univ. Tokyo, Tokyo) and Katsushi TOKUNAGA, Takeo JUJI (Jpn. Red Cross Ctrl. Bld. Ctr.)

HLA-DMA and -DMB molecules are involved in HLA class II restricted antigen processing and presentation pathway. We investigated polymorphisms in exon 3 of DMA and DMB genes in 44 Japanese patients with IgA nephropathy by PCR-RFLP method. Four restriction endonucleases were employed respectively; FokI, HinfI, AciI and SfaNI for DMA, and BsrI, HhaI, ApaLI and Bsp1286I for DMB. 52 Japanese controls exhibited a decrease in DMB*0101 and an icrease in $\mathrm{DMB}^{*} 0102$ compared with Caucasian populations. We did not find any differences in HLA-DM allele frequencies in patinets with IgA nephropathy compared with Japanese controls. DRB1*0405-DQB1*0401 are rather involed in the development of IgA nephropathy in Japanese. Analysis of HLA-DM gene will contribute for better understnading of the pathogenesis of HLA class II associated diseases.

C-12

HLA CLASS II DNA TYPING IN PATIENTS WITH BUERGER'S DISEASE. Wulin AERBAJINAI, Yukio YASUKOCHI ( Dept. Molecul. Genet., M.R.I.,Tokyo Med.\&Den. Univ., Tokyo.) and Fujio NUMANO ( Dept. Int. Med., Tokyo Med.\&Den. Univ., Tokyo.)

We investigated the HLA class II genes: HLA-DQ, -DRB3, -DRB5, -DP alleles by DNA typing using polymerase chain reaction (PCR)-restriction fragment length polymorphism (RFLP) in 34 patients with Buerger's disease , and 90 healthy Japanese. This study showed that the significant increased frequencies of HLA-DPA1*02 ( R.R=2.68, $\chi^{2}=21.7, \mathrm{P}<0.001$ ), -DPB1*0501( R.R=3.0, $\chi^{2}=28.3, \mathrm{P}<0.001$ ), and-DQB1*0401 ( $\mathrm{R} . \mathrm{R}=2.77, \chi^{2}=5.3, \mathrm{P}<0.001$ ) alleles in the patient group as compared to the control group.The increased frequencies of HLA-DPA1*02, -DPB $1 * 0501$, $-\mathrm{DQB} 1 * 0401$ alleles in Buerger's disease were consistent with the increase in frequencies of HLA-DPA1*02-DPB1*0501-DQB1*0401 ( $\mathrm{R} . \mathrm{R}=3.28, \chi^{2}=14.4, \mathrm{P}<0.001$ ) haplotype.These observations suggests that the Buerger's disease may association with HLA-DPA1*02-DPB1*0501-DQB1*0401 haplotype. 
C-13

INCIDENCE OF STOMACH CANCER AND HLA ALLELES.

1) Mariko OHMORI, 1) Shin'ichiro YASUNAGA, 1) Iakehiko SASAZUKI,

2) Keizou SUGIMACHI, (1) Dept. Genet., Med. Inst. Bioreg., Kyushu Univ., Fukuoka. 2) 2nd Dept. Surgery., Kyushu Univ., Fukuoka. )

To investigate genetic factors in gastric cancer, we have typed 88 Japanese patients with gastric cancer for HLA-DRB1, DQA1, DQB1, DPA1, DPB1, and HLA-A genes by the HLA-DNA typing method using the PCR-SSOP technique. The frequency of DRB1*1401-DQA1*0104-DQB1*05031 was increased significantly (relative risk, $4.80 ; P<0.01$ ) and the frequency of DRB1*0101-DQA1 $0101-D Q B 1{ }^{*} 0501$ was decreased significantly (relative risk, $0.34 ; \mathrm{P}<0.05)$ in the patients with all histological types of gastric cancer. The frequency of DRB1*1501-DQA1*01021-DQB1*0602 was increased significantly in the patients with poorly differentiated type (relative risk 2.28; $P<0.05)$. The frequency of DRB1*0101-DQA1*0101-DQB1*0501 was decreased more significantly in the patients with well and moderately differentiated type than poorly differentiated type. These results show that the HLA alleles which decide on susceptibility to gastric cancer differ with histological types.

\section{C-14}

ABNORMAL SPLICING OF EXON 4 ASSOCIATED WITH THE HPRT GENE MUTATIONS. Yasukazu YAMADA, Haruko GOTO, and Nobuaki OGASAWARA (Dept. Genet., Inst. Developmental Res., Aichi Prefectural Colony, Aichi)

Complete deficiency of hypoxanthine guanine phosphoribosyltransferase (HPRT) causes Lesch-Nyhan syndrome. We have examined the HPRT gene mutations by analyses of genomic DNA and mRNA using PCR technique coupled with direct sequencing. Three mutations at the 5'-splice acceptor site of exon 4 producing abnormal mRNAs were identified. In the first case, A 4-bp (AATG) deletion at the 5'-end of exon 4 resulted in formation of three different types of abnormal mRNA: type A mRNA deleted 4 bp at the 5 '-end of exon 4 , type $B$ deleted 9 bp at the 5'-end of exon 4, and type $C$ skipped whole exon 4 . The second mutant having a single nucleotide substitution of $G$ to $T$ at the 3 '-end of intron 3 in the splicing concensus region, produced two types of abnormal mRNA: an altered mRNA skipped whole exon 4 as type $C$ in the first case, and the other having a 9bp deletion as identical to type B in the first case. As the third case, a single nucleotide substitution at the 7-bp downstream from the 5'-end of exon 4 resulted in a major altered mRNA with a nonsence mutation replacing Gln-109 (CAG) with a stop codon (TAG) and small amounts of mRNA skipped exon 4 as type $C$ in the first case. In the third case, however, an altered mRNA having a 9-bp deletion, which was detected in the first and second cases, was not found. 


\section{C-15}

A SINGLE BASE DELETION IN THE CATALASE GENE CAUSES JAPANESE-TYPE ACATALASEMIA. Akira HIRONO, Hitoshi KANNO, Shiro MIWA (Okinaka Memorial Institute for Medical Research, Tokyo), Hisaichi FUJII (Dept. Transfusion Medicine, Tokyo Women's Medical College, Tokyo), Fumika SASAYA, Fumihisa HIRAIDE, Tomoyuki YOSHIDA, Kazuo WATANABE, Eiii HAKUHISA, Soutarou FUNASAKA (Dept. Otorhinolaryngology, Tokyo Medical College, Tokyo), Yoshikazu HAMADA (Dept. anesthesiology, Tokyo Medical Collge, Tokyo)

Two different types of human acatalasemia can be distinguished clinically and biochemically. The severer type, Japanese-type acatalasemia is characterized by the almost total loss of catalase activity in red cells and is often associated with ulcerating oral lesions. A splicing mutation in intron 4 of the catalase gene has so far been a sole disease-causing mutaion found in Japnanese-type acatalasemic patients.

We recently found a patient with Japanese-type acatalasemia. The patient was a 72 -year-old Japanese male. His parents were the first cousins once removed. Molecular analysis using non-RI PCR-SSCP analysis combined with direct sequencing revealed a deletion of the 358th thymine in exon 4 of the patient's catalase gene. The proband was a homozygote and his mother and his three children were heterozygotes for this mutation. The frame shift caused by the nucleotide deletion should alter the downstream amino acid sequence and introduce a new termination codon TGA $43 \mathrm{bp} 3^{\prime}$ to the mutation. Although the truncated peptide chain consisted of 133 amino acid residues might be translated in the patient's tissue, such an aberrant protein is expected to be extremely unstable and have no catalytic function at all. Our results sugget that Japanese-type acatalasemia is heterogeneous at molecular level.

C-16

A NOVEL MUTATION OF MNK GENE IN A JAPANESE PATIENT WITH CLASSICAL MENKES DISEASE. Atsushi OGAWA, Masaki TAKAYANAGI (Division of Metabolism, Chiba Childrens' Hospital, Chiba) and Toshiaki KOUGO, Shigenori YAMAMOTO, Hiroo NIIMI (Department of Pediatrics, Chiba University School of Medicine, Chiba)

Menkes disease is an $\mathrm{X}$-linked recessive disorder of copper metabolism resulting in death in early infancy. The gene defective in Menkes disease, MNK gene, has been isolated and predicted to encode a copper -binding P-type ATPase. We identified a novel mutation (1174 ins $A$ ) in $M N K$ gene in a Japanese patient with classical Menkes disease by analyzing reverse transcription-PCR (RT-PCR) products. This mutation was also identified in exon 4 of genomic DNA. This mutation, resulting in non-sense mutation, causes a premature termination of Menkes protein, containing only 1/5 of $\mathrm{N}$-terminus. Because of this premature transcript, we consider that this mutation is the cause deriving Menkes disease in this patient. The mother of this patient was found to be heterozygous for the mutation in genomic DNA, indicating that the mutation identified in the patient is not a new mutation. 


\section{C-17}

HEMOGLOBINOPATHY IN THE SOLOMON ISLANDS AND PAPUA NEW GUINEA. Teruo HARANO, Keiko HARANO (Dept. Biochem., Kawasaki Med. Schl.), Masato KAWABATA (Internatl. Center Med. Res., Kobe Univ. Schl. Med.), Nobuo OHTA (Dept. Med. Zoology, Nagoya City Univ. Med Schl.), Ryutaro OTSUKA (Dept. Human Ecology, Faculty Med., Univ. Tokyo), Yuri UCHIDA, Akira ISHII (Dept. Med. Zoology, Jichi Med. Schl.).

Washed red cells brought from the Solomon Islands and Papua New Guinea were studied by IEF and HPLC for the detection of abnormal $\mathrm{Hb}$. Although no abnormal $\mathrm{Hbs}$ were found in the cells from the Papua New Guineans, 22 Solomon Islanders exhibited three types (A,B and $C$ ) of abnormal $\mathrm{Hb}$. Structural analysis of these $\mathrm{Hbs}$ was performed by an amino acid analysis of abnormal peptide and a nucleotide sequencing of the defective globin gene. Four $\mathrm{Hbs}$ of Type $\mathrm{A}$ had an $\alpha$ chain anomaly and their contents were approximately 36 or $46 \%$ of the total $\mathrm{Hb}$. They had an amino acid substitution of Ala $\rightarrow$ Asp, identifying to $\mathrm{Hb}$ J-Tongariki, and a nucleotide change from GCC to GAC at the 115th position of the $\alpha 2$-gene. Sixteen $\mathrm{Hbs}$ of Type B, which had a $\beta$ chain anomaly and were accompanied by an extra brownish $\mathrm{Hb}$ band, had a substitution of Lys $\rightarrow$ Glu and a mutation of $A A A \rightarrow G A A$ at $\beta 66$, identifying to unstable $\mathrm{Hb}$ l-Toulose. Two $\mathrm{Hbs}$ of Type $\mathrm{C}$ had three different types of abnormal $\mathrm{Hb}$ composed of normal $\alpha$ and $\beta, \alpha-J$-Tongariki and $\beta$-I-Toulose chains, respectively. The DNA prepared from the cells of these abnormal $\mathrm{Hb}$ carriers was studied by PCR using the specific primer sets for the $\alpha$ glboin genes. The results led us to suspect the existence of $\alpha-$ Thal- 2 and $\alpha$-Thal- 1 in most of these subjects.

C-18

A NOVEL MUTATION OF CYSTIC FIBROSIS DETECTED BY PCR-SSCP ANALYSIS. Nobuhiko HOSHI ${ }^{1}$, Jeffrey A. KANT ${ }^{2}$, Seiichiro FUJIMOTO ${ }^{1}$ ('Dept. Obstet. Gynecol., Hokkaido University School of Medicine, Sapporo, ${ }^{2}$ Dept. Pathology \& Laboratory Medicine, University of Pennsylvania, U.S.A.)

Cystic fibrosis (CF) is one of the most common and sever autosomal recessive disease in Caucasians due to various mutation in the CF transmembrane conductance regulator (CFTR) gene, which has been chromosomally allocated to $7 \mathrm{q} 31-32$, comprises 27 exons spanning some $250 \mathrm{~kb}$ genomic DNA.

In this study, we report the results of the new mutations by using PCRSSCP analysis. Twenty nine common mutations which have been reported were screened in 250 American families who were seemed to be CF clinically by using PCR-ASOs (allele specific oligonucleotide), REA (restriction endonucrease analysis), and Heteroduplex method. Fifteen families who showed negative in the screening were examined by using PCR-SSCP followed by direct sequencing of 10 exons (exon $3,4,7,10,11,12,19,20,21$, and 22) associated with severe disease including pancreatic insufficiency. Four new mutations in the CFTR gene (L129L, M470V, F508L, G509G) were identified. Although PCR-SSCP analysis thus represents a rapid and efficient method for detecting small mutations, we have to change the conditions including gel type or loading temperature in different exons. 
C-19

GENE MUTATION OF SILENT TYPE SERUM CHOLINESTERASE FOUND IN CHUGOKU AND SHIKOKU DISTRICT. KazUo HIDAKA ${ }^{1}$, To shiko YAMASAKI ${ }^{1}$, Iwao IUCH| ${ }^{1}$, Masafumi TOMITA ${ }^{2}$ (Dept. Biochem ${ }^{1}$. \& Legal Med. ${ }^{2}$, Kawasaki Med. School) and Naoki UEDA(Med., Yamaguchi Pref. Hospital)

Three types of serum cholinesterase(SChE) anomaly expressed as D, F and silent are reported to have suxamethonium hypersensitivity to the carriers. Silent SChE variants are noteworthy detection among them for the sake of high frequency all over Japan. Since past four years we studied gene mutation of silent type SChE in fifteen blood unrelated families in Chugoku and Shikoku area and 4 forms of the silent SChE variant became evident. Namely, 1) a $G \rightarrow C$ transversion at codon 365 ( Gly365Arg), which was seen in the eleven families. This mutation created a new Taq 1 restricion site. Therefore, restriction endonuclease analysis of Taq 1 digest made easy to demonstrate this mutation, 2) a frameshift mutation with an extra $A$ insertion namely Thr315Asn, resulting to produce the termination codon at 322,3 ) a compound heterozygous condition of two different mutations, namely, Gly365Arg and Thr315Asn, the same mutation aforescribed, 4) a A $\rightarrow G$ transition of (Tyr128Cys) from one family and 5) the last was C400A, causing Cys400stop.

C-20

Genetic Analysis of IgA Nephropathy ( IgAGN)

Tatsuo FUKUSHIMA ${ }^{1}$, Shinsuke NOMURA ${ }^{1}$, Shinichiro KAWAI ${ }^{1}$, Toyonori SAIKI ${ }^{1}$, $\underline{\text { Gengo OSAWA }}^{1}$, Keiko HARANO ${ }^{2}$, Teruo HARANO ${ }^{2}$ (1; Nephrology Div. Dept. of Medicine. 2; Dept. of Biochemistry, Kawaski Medical School, Kurashiki )

The cause and pathogenesis of the most common glomerular disease, IgAGN, are not clearly understood. However, a possible genetic influence in its pathogenesis of IgAGN has been suggested because of racial differences in its prevalence and clustering of the disease in some families. If it is possible to find the loci which show very high homozygosity rate of DNA markers, among patients with IgAGN who are products of consanguineous mating, it may be likely that the causative gene can be located around the locus. Therefore, we investigated the homozygosity rate of microsatellite markers which were prepared in every $30 \mathrm{cM}$ on chromosome among 16 inbred patients with IgAN and 2 1 their family members. We have found out high homozygosity rate on the loci of $1 \mathrm{p}, \mathrm{Iq}$, $2 p, 4 p, 6 p$ and $6 q$ in the patients chromosome compared with healthy families. It is suggested that there are the causative genes for IgAGN close to the regions. 
C-21

SPECTRUM OF THE COL4A5 GENE MUTATIONS IN JAPANESE ALPORT SWNDROME. Shinichiro KAWAl, Shinsuke NOMURA, Tatsuo FUKUSHMA(Dept. Nephrology. Kawasaki Medical School), Keiko Harano, Teruo HRANO(Dept. Biochemistry. Kawasaki Medical School) and Gengo OSAWA

Sixty Japanese Al port patients were screened for mutations inall exons (1-51) of the COL4A5 gene by PCR-SSCP analysis. Mobility shift was observed in 22 of 60 patients and their genomic DNA were analyzed by the direct sequence method Nine of these had missense mutations in the collagenous domain. Eight of nine were located in the glycine residues. Another missense mutation was located in the isoleucine. Five had small size deletions and one 4bp insertion. Three had a splice site mutation. One had a nonsense mutation. Three had a si lent mutation. We expect that these mutations except for the silent mutation would be pathogenic in the collagen chain but the phenotype including extra renal manifestations can vary with respect to both expression and severity.

C-22

G375C MUTATION IN THE TRANSMEMBRANE DOMAIN OF THE FIBROBLAST GROWTH FACTOR RECEPTOR-3 GENE ALSO CAUSES ACHONDROPIASIA. Shiro IKEGAWA, Yusuke NAKAMURA ( $\mathrm{I}$ ab. Molec. Medicine, IMS, Univ. of Tokyo, Tokyo), Yoshimitsu FukUSHIMA (Dept. Hygiene Med. Genet., Shinshu Univ. Matsumoto), Hirofumi oHAsHI (Div. Med. Genet., Saitama Children's Medical Center, Iwatsuki), Fumio TakADA (Dept. Pediatr. Molec. Biol., Kitasato Univ. Sagamihara)

Achondroplasia (ACP) is the most common cause of genetic dwarfism. Recently, mutations in the gene encoding fibroblast growth factor receptor-3 (FGFR3) have been found in ACP. Although more than 200 cases have been reported, all mutations had occurred at a single nucleotide (G1138), with the resulting substitution of an arginine of codon 380 for a glycine (G380R) in the transmembrane (TM) domain of FGFR3. We examined TM domain of FGFR3 gene in 23 Japanese patients with ACP. The G380R mutation was identified at 22 cases; a single familial case bore a novel mutation of a $G$ to $T$ transition at codon 375, which resulted in substitution of a cysteine for a glycine (G375C). These findings indicates allelic hetetogeneity and the role of mutations in TM domain of FGFR3 in the pathogenesis of ACP. 
A diagnosis of a sporadic case of Crouzon syndrome with a point mutation in the FGFR-2. Toyoki MAEDA, Yasuyo SUZUKI, Masanobu OGAWA, Shigehiko HAENO, Midori ASADA, Fumiaki TANAKA, Masaji OKADA and Tomokazu SUzUKI(Dept. Clin. Genet., Inst. Bioreg., Kyushu Univ., Oita)

A 54-year-old Japanese woman was diagnosed as a sporadic case of Crouzon syndrome by detection of a point mutation in the fibroblast growth factor receptor-2 (FGFR-2) gene. She has 12 brethren. All of them are healthy. Her IQ was 75 in WAIS. The patient's face showed hypertelorism. Brachydactyly was observed in both of her fifth fingers. The magnetic resonance image of her brain and neck revealed an enlargement of cerebral ventricle and a klippel-Feil anomaly. The karyotype analysis revealed no chromosomal abnormality. These findings suspected a presence of craniofacial syndrome at the basis. A point mutation was detected in her FGFR-2 gene in which the $\mathrm{C}$ to $\mathrm{G}$ transition at nucleotide 1073 involved Ser354 with predicted substitution of Cys. This mutation had been reported as one of molecular bases of Crouzon syndrome. This result suggests that mutations in FGFR-2 gene cause crouzon syndrome also in Japanese.

C-24

GENETIC ANALYSIS OF DIGEORGE SYNDROME AND RELATED DISORDERS. Hinoki KURAHASHI ${ }^{1,2}$, Tsutomu NAKAMURA ${ }^{1}$, Johji INAZAWA ${ }^{3}$, Norio NILKAWA ${ }^{4}$, Shintaro OKADA ${ }^{2}$, and Isamu NISHISHO ${ }^{1}$ ( ${ }^{1}$ Dept. Med. Genet., ${ }^{2}$ Dept. Pediatr., Osaka Univ. Med. Sch, Osaka, ${ }^{3}$ Dept. Hygene, Kyoto Pref. Univ. Med., Kyoto, ${ }^{4}$ Dept. Hum. Genet., Nagasaki Univ. Sch. Med., Nagasaki.)

Since patients with DiGeorge syndrome (DGS) commonly have deletions of $22 q 11.2$, haploinsufficiency of a certain gene(s) in this region is thought to cause the syndrome. The deletion is also seen in patients with other syndromes with cardiac anomaly and facial dysmorphism, suggesting that the syndromes are contiguous gene syndromes. We constructed two cosmid contigs in the deletion, which contained region specific repetitive sequences. The deletion map of the patients allowed us to identify three types of deletions. Most patients have apparently identical large interstitial deletions in spite of phenotypic variability, suggesting that at the breakpoint there exists a specific repetitive sequence prone to deletion. A unique deletion was identified, which did not contain the "shortest region of overlap". Subsequently, we isolated a novel cDNA located on one of the cosmid contigs. The cDNA was revealed to encode a transcriptional factor and to be expressed in vital fetal organs. Haploinsufficiency of the gene may be partly related to the development of the syndromes. 
cDNA isolation and characterization of a novel leucine zipper protein RKP1 expressed in photoreceptor cells. Ryo KUBOTA ${ }^{1,2}$,

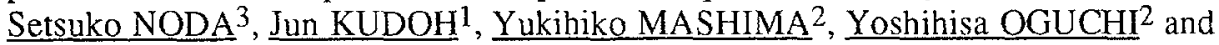
${ }_{\text {Nobuyoshi SHIMIZU }}{ }^{1}$ (Depts. of ${ }^{1} \mathrm{Mol}$. Biol. and ${ }^{2}$ Ophthalmol., Keio Univ. Sch. of Med., Tokyo and ${ }^{3}$ Dept. of Health Sci., Tokai Univ., Kanagawa)

From the retina-enriched cDNA library which we constructed last year, thirty six clones were isolated as candidates for the retina-specific cDNA. These clones were sequenced, and used for Northern analysis to determine tissue expression. We focused on one clone BB8 which was expressed only in retina and skeletal muscle among tissues we tested. We isolated a full length cDNA of 1938 bp by using clone $\mathrm{BB} 8(0.8 \mathrm{~kb})$ as a probe from human retina cDNA library. It contained an open reading frame of 490 amino acid residues having leucine zipper motif and peroxisomal targeting sequence. The deduced amino acid sequence showed $32.3 \%$ identity in 402 amino acids with neuron specific olfactomedin-related protein and $31.3 \%$ identity in 179 amino acids with olfactomedin. This protein was designated RKP1. In situ RNA hybridization showed specific signal in the outer nuclear layer of retina where photoreceptor cells are located. Polyclonal rabbit anti-serum was raised against the recombinant RKP1 protein. Immunohistochemistry revealed that RKP1 protein is expressed prominently in the inner segment of photoreceptor cell and sarcoplasmic reticulum of skeletal muscle. These observations indicate that RKP1 may play a role in anchoring the intermediate filaments onto membrane to maintain its shape in a manner similar to peripherin.

C-26

ANALYSIS OF XK GENE IN JAPANESE SUBJECTS EXPRESSING
MCLEOD-LIKE PHENOTYPES. Yoshihisa WATANABE ${ }^{1}$, Hatsue TSUNEYAMA ${ }^{1}$, Makoto UCHIKAWA ${ }^{1}$, Katsushi TOKUNAGA ${ }^{1,2}$, Takayuki ENOMOTO $^{3}$, Hideaki TSUCHIDA ${ }^{4}$, Keni TADOKORO $^{1}$, Takeo JUJI' ('Japanese Red Cross Central Blood Center., ${ }^{2}$ Dept. Hum. Genet., Univ. Tokyo, ${ }^{3}$ SaitamaIna Red Cross Blood Center., ${ }^{4}$ Yamagata Red Cross Blood Center.)

In order to clarify the molecular basis of McLeod-like phenotypes in Japanese, XK gene, which was recently cloned and considered as a candidate gene of the disease, was analyzed. McLeod syndrome is a rare, $X$-linked recessive disorder characterized by neuromuscular and hematopoietic abnormalities. Two subjects expressing McLeodlike phenotypes were screened from Japanese blood donors. They had red blood cells with acanthocytic morphology and weakened Kell antigen, although they showed no clinical symptom such as neuromuscular disorder. Family studies of the subjects supported an $\mathrm{X}$-linked recessive trait. Pulsed-field gel electrophoresis analysis revealed no large scale deletion around XK gene. Nucleotide sequence analysis of the XK from the subjects and the comparison with the published one revealed two nucleotide differences leading to two amino acid changes in exon 3 . These nucleotide differences were not specific for the disease but might be due to polymorphisms or sequencing errors of the published one, because the sequences were aiso detected from all 20 healthy Japanese controls. RT-PCR analysis of mRNAs prepared from EBV-transformed cell lines of the subjects revealed that no XK fragment was detected from one of the two subjects. Thus this phenotype may be caused by other reasons than gene deletion or amino acid substitution(s). 
C-27

Novel mutations in the zinc finger coding regions of WTI in Wilms tumors from two WAGR patients Yasuhiko KANEKO, Akiko SAKASHITA (Department of Cancer Chemotherapy and Third Clinical Department, Saitama Cancer Center Hospital, Ina, Saitama)

Patients with wilms tumor-aniridia-genitourinary abnormalities-mental retardation (WAGR) syndrome have a large hemizygous deletion encompassing WT1 and PAX6 in the constitutional celis. We present the results of PCR-SSCP analyses in these 2 tumors, followed by direct nucleotide sequencing. Tumor 299 had a base substitution from $C$ to $G$ at the 45 th nucleotide of exon 9, which converts ${ }^{394} \mathrm{Arg}$ to Gly. Tumor 165 had a base insertion of $T$ between the 69 th and 70 th nucleotides of exon 10 , which converts ${ }^{433} \mathrm{Arg}$ to Leu. The 2 mutations in the third or fourth zinc finger coding regions found in our tumors are novel, and have never been reported in wilms tumors occurring in WAGR or sporadic patients. Loss of heterozygosity in the $11 \mathrm{p} 15$ region was reported in WAGR tumors, however, our 2 tumors retained heterozygosity at the 1 lp 15 chromosomal region. Our findings suggests no involvement of the putative second wilms tumor gene on $11 \mathrm{p} 15$ in these WAGR tumors.

C-28

A TRIAL OF DNA DIAGNOSIS IN RETINOBLASTOMA. Yoshihiro HOTTA, Kazutaka ADACHI, Toshiyuki YOKOYAMA, Fumino IWATA, Kouichi TAMAKI, Keiko FUJIKI, Utako TANABE, Mutsuko HAYAKAWA, Atsushi KANAI (Dept. Ophthalmol., Juntendo Univ., Tokyo)

Since the retinoblastoma gene is huge and no hot spot of genetic defect is found, the DNA analysis for genetic counseling using molecular biological techniques is difficult. To evaluate the usefulness for genetic couseling, we performed the Southern blot analysis in patients with retinoblastoma and their families using DNA fragments of the retinoblastoma gene ( $R B$ gene) as a probe. High molecular weight DNAs were extracted from leukocyte and tumor. Southern blot analysis using 5' and 3' probe in $R B$ gene was performed in 5 families 11 individuals (2 patients including a tumor). Five polymorphisms in $R B$ gene were analyzed in 2 families 7 individuals ( 2 patients including a tumor). Although an entire $R B$ gene deletion was suspected in a bilateral tumor using $5^{\prime}$ and $3^{\prime}$ probe, no abnormality was detected in his leukocyte. Five polymorphism analyses showed very low possibility of germline mutation because the affected tumor is homozygous for the maternally derived allele. These methods are relatively easy and useful for the DNA diagnosis in retinoblastoma. 
C-29

IDENTIFICATION OF A DNA FRAGMENT WHICH ESCAPED METHYLATION INACTIVATION ON THE X CHROMOSOME BY TWO-DIMENSIONAL ELECTROPHORESIS OF HUMAN GENOMIC DNA.

Jun-ichi ASAKAWA ${ }^{1}$, Mieko KODAIRA ${ }^{1}$, Asao FUJIYAMA ${ }^{2}$, Rork KUICK ${ }^{3}$, Thomas W. GLOVER ${ }^{3}$, Satomichi KANEOKA ${ }^{1}$, Masaaki IMANAKA ${ }^{1}$, James V. NEEL ${ }^{4}$, Samir M. HANASH ${ }^{3}$, Chiyoko SATOH ${ }^{1}$ ('Dept. of Genetics, Radiation Effects Research Foundation, ${ }^{2}$ Dept. of Human Genetics, National Institute of Genetics, ${ }^{3}$ Dept. of Pediatrics, University of Michigan, ${ }^{4}$ Dept. of Human Genetics, University of Michigan)

Genomic DNA was digested with NotI and EcoRV and labelled at the NotI recognition sites. After first-dimension electrophoresis, DNA in the disc gel was further digested in situ with HinfI prior to second dimension electrophoresis. Approximately 2000 endlabelled fragments were visualized simultaneously. We have analyzed the two-dimensional preparations derived from six mother/father/child trios by using a computer assisted image analyzer. In the quantitative study, a separate fragment (spot 369) was observed in which male appeared to have a one-copy spot, while female always exhibited a spot twice this size. This could be interpreted as the result of a Not $\mathrm{I}$ site on the $\mathrm{X}$ chromosome that is not methylated on either $X$ in females (escaped methylation inactivation on the $X$ chromosome). We have cloned this DNA fragment to confirm that the DNA fragments really existing on the $X$ chromosome. The cloned DNA fragment was mapped to Xp11.4 by FISH analysis. We have also sequenced the DNA fragment, but there was no identical sequence in the DNA data base.

$\mathbf{C}-\mathbf{3 0}$

CLONING AND SEQUENCING OF ALLELIC DNA FRAGMENTS DETECTED BY TWO-DIMENSIONAL ELECTROPHORESIS OF HUMAN GENOMIC DNA Mieko Kodaira ${ }^{1}$, Jun-ichi Asakawa ${ }^{1}$, Rork Kuick ${ }^{2}$, Masaaki Imanaka ${ }^{1}$, Satomichi Kaneoka $^{1}$, Chiyoko Satoh ${ }^{1}$ ('Dept. of Genetics, Radiation Effects Research Foundation, Hiroshima, ${ }^{2}$ Dept. of Pediatrics, University of Michigan Medical School, USA)

The two-dimensional (2-D) separation of end-labeled genomic restriction fragments at the Not $\mathrm{I}$ recognition site permits the visualization on a single preparation of approximately 2000 spots. Genomic DNA was digested with NotI and EcoRV prior to first-dimension electrophoresis. DNA in gel was further digested with HinfI prior to second dimension electrophoresis. 2-D DNA patterns of 6 Japanese mother/father/child trios were analyzed by an image analyzer equipped with computer algorithms. On the basis of family studies, a group of 184 fragments could be organized into 85 polymorphic systems in which all allelic fragments were detectable in the 2-D pattern. We have developed several methods which confirm that these fragments are the same allele products. We have constructed a vector containing a Hinf l cloning site which permits the cloning of NotI/HinfI fragments directly recovered from the 2-D gels. The DNA fragment obtained by target cloning can be used as a probe for the screening of clones corresponding to the allelic DNA fragments in a genomic DNA library. We have also successfully identified the allelic spots by Southern blot analysis of the 2-DE sheet gels. By using these novel methods, we have cloned and characterized spot 24 and spot 31 which seemed to be allelic. 
C-32

CHARACTERIST IC UNBALANCED CHROMOSOMES FOR RECIPROCAL TRANSLOCATION INHERITED FROM VARIOUS BALANCED PARENTS.

Hidetsune 0ISHI(Dept. Genet., Inst. Develop. Res., Aichi Pref. Colony, Kasugai) and Tsutomu YAMANAKA(Cent. Hosp., Aichi Pref. Colony, Kasugai)

Since the fertility of mothers with balanced reciprocal translocation was about $50 \%$ higher than that of fathers with the same condition (0ishi et al 1994), it was required to clarify the difference of abnormal chromosomes of children among these parents. Familial reciprocal translocations ascertained for birth of malformed children were collected from our records and published papers. Of 587 cases examined, 294 male and 293 female probands were counted, while their balanced fathers and mothers were 204 and 383 , respectively. Frequencies of unbalanced chromosomes with adj-1, adj-2 and $3: 1$ by parental segregation of reciprocal translocations were 183,4 and 17 in paternal, and 259,12 and 112 in maternal, respectively. It was frequently noticed acrocentrics with unbalanced segments in all of adj-2 and 92 cases of $3: 1$ segregation. Averages of trisomic parts were 1.29 (as \% of total haploid sutosome length) for adj-1 and 1.63 for adj-2 and $3: 1$. Partial trisomies of maternal no. 9 chromosome were also observed in 5 out of 12 cases in adj-2 and 19 of 101 in $3: 1$, and were measured 2.57 and 2.79 , respectively. These values reflected on excessive unbalanced segments for maternal transmission and possibly on the parental fertility.

C-33

A CASE OF BILATERAL MICROTIA AND MICROGNATHIA WITH DE NOVO RECIPROCAL TRANSLOCATION, 46, XX, t $(6 ; 9)(\mathrm{p} 24 ; \mathrm{p} 23)$. Kiyoshi IMAIZUMI, Mihoko NAKAMURA, Mitsuo MASUNO, Yoshikazu KUROKI. (Div. Med. Genet. , Kanagawa Children's Medical Center)

We report a 2-year-old dysmorphic female patient with de novo reciprocal translocation. Patient is the first child of healthy unrelated parents and the family history is unremarkable. She showed frontal bossing, hypertelorism, antimogoloid slant, micrognathia, bilateral microtia, bilateral low-set and malformed ears, cleft soft palate. Her somatic and mental development was delayed. Chromosome analysis revealed balanced reciprocal translocation, $46, X X, t(6 ; 9)(\mathrm{p} 24$; p23). Endotherin-1 (ET-1) is a potent vasoconstrictor produced by endothelial cells and also produced in many tissue such as central nervous system. The findings of dysrupted ET-1 gene homozygoous mice showed craniofacial anomalies which were quite similar to the human congenital disease known as pharyngeal arch syndrome. In human, ET-1 gene was mapped on 6p23-24 by in situ hybridization. Dysmorphic findings of our patient might result from disruption of ET-1 gene. 
$\mathbf{C}-\mathbf{3 4}$

A STUDY ON THE MODE OF INHERITANCE IN del $22 q 11$.

Rumiko MATSUOKA, Misa KIMURA, Shin-ichiro IMAMURA, Atsuyoshi TAKAO, Kazuo MOMMA (Tokyo Women's Medical College, Tokyo)

There are overlapping features between DiGeorge syndrome (DGS), conotruncal anomaly face syndrome (CAFS), and velo-cardio-facial syndrome, similar phenotypes, sharing and a deletion of $22 q 11$ as a common feature. One hundred and fifteen CAFS and 16 DGS probands, and 136 of their family members were examined by fluorescent in situ hybridization using a N25 (D22S75) DGCR probe. Monosomy for a region of 22q11.2 was found in $97 \%$ of the patients. For the control, 292 patients without CAF who had no deletion of $22 q 11.2$ were examined. Then, we studied familial occurrence in 81 families who had del22q11.2. Fifteen of the 81 families (17\%) had familial del22q11 and 13 of the $15(87 \%)$ affected parents were mothers. Thirty eight del22q11 de novo were examined for microsatellite polymorphism. Nineteen of the 31 test subjects $(61 \%)$ with CAFS were from the mother's side. On the other hand, 5 out of the $7(71 \%)$ with DGS were from the father's side. Therefore, the results may indicate a different mode of transmission between CAFS and DGS.

C-35

WAARDENBURG SYNDROME WITH HYPOHIDROTIC ECTODERMAL DYSPLASIA AND HIRSCHSPRUNG DISEASE. Yoshimitsu FUKUSHIMA, Hirofumi OHASHI, Masatomo MATSUMOTO, Satohiko IMAIZUMI (Saitama Children's Medical Center, Saitama and Shinshu University School of Medicine, Nagano)

The patient, a $2 y 5 \mathrm{~m}$ boy, was born at $37 \mathrm{w} 4 \mathrm{~d}$. His birth weight was $2020 \mathrm{~g}$ and the parents were healthy and non-consanguineous. He suffered from abdominal distention just after his birth and was diagnosed as having Hirschsprung disease (HD) with extensive aganglionosis. He had an operation of ileostomy and artificial-anus-plasty at $1 \mathrm{~m}$, and thereafter nutrients were parenterally supplied. His sparse hair and hypohidrosis lead to the diagnosis of hypohidrotic ectodermal dysplasia (HED). He had hypopigmentation of the iris and bilateral sensorineural deafness, which were symptoms of Waardenburg syndrome (WS). He had a normal karyotype. He died of septic shock at $2 \mathrm{y} 5 \mathrm{~m}$.

WS is an autosomal dominant disorder related to migration abnormality of neural crest. A mutation in PAX3 genes mapping to $2 q 35$ has been found in WS, type I and that in MITF genes mapping 3p13 in WS, type II. HD is sometimes complicated with both WS, type I and II. No patients with WS and HED have not been reported. This patient has a new combination of malformation syndromes including WS, HED and HD. 


\section{C-36}

A CASE WITH BALANCED DOUBLE COMPLEX TRANSLOCATIONS: 46 , $\mathrm{XY}, \mathrm{t}(3 ; 8 ; 14)(\mathrm{q} 11 ; \mathrm{q} 22.3 ; \mathrm{q} 11), \mathrm{t}(3 ; 6)(\mathrm{p} 26.2 ; \mathrm{q} 16.1)$.

Tadashi MATSUBASA and Makoto SHINOHARA (Ashikitagakuen Hospital, Kumamoto), Yoshimitsu FUKUSHIMA (Dept. Hygiene, Shinshu Univ. School of Med., Matsumoto), Hide KOROGI (Ezuko Ryouikuen, Kumamoto), Soroku NISHIYAMA(Dept. Ped. Kumamoto Univ., Kumamoto)

A 36-year old male patient with mental retardation, blindness, and dysmorphologies in the face has developed polydipsia in several years. He drank about 10 litters of water a day. Serum ADH level was normal.

Chromosome examination revealed balanced double complex translocations: 46 , $\mathrm{XY}, \mathrm{t}(3 ; 8 ; 14)(\mathrm{q} 11 ; \mathrm{q} 22.3 ; \mathrm{q} 11), \mathrm{t}(3 ; 6)(\mathrm{p} 26.2 ; \mathrm{q} 16.1)$. Chromosomes of his parents were normal.

Along with drinking water, he sticked to daily schedule in the ward and wore 10 sweaters at one time.

\section{C-37}

A CASE OF ORAL-FACIAL-DIGITAL (OFD) SYNDROME WITH UROGENITAL ANOMALY. Ikuma FUJIWARA, Yoshiaki KONDO, Kazuie IINUMA (Dept. Pediatr., Tohoku University School of Medicine, Miyagi)

A new case of OFD syndrome with abnormal vaginal opening to bladder and bilateral hydronephrosis was reported. She was noticed of postaxial polydactyly in both hands and feet, left central polydactyly, and syndactyly in left hand and feet at birth. She was diagnosed as OFD syndrome because she had multiple frenula in gingiva, irregular ridge of gingiva, two small hamartomatous nodules on tongue, micrognathia, low setting of ears, long philtrum, and alar hypoplasia of the nose. She also complained abdominal distension and poor sucking. Abdominal CT scan revealed two cystic mass above the bladder and severe bilateral hydronephrosis. Cystoscopy found out three openings in bladder and they were revealed to be bilateral ureters and vagina. Two cystic mass were uterus and vagina filled with urine. X-ray film showed dysplasias of left ulna, right fibula and tibia, and phalanges. Hypothalamic hamartoma and atrophy of left cerebral hemisphere were noticed on brain MRI. At four months of age, breast budding and vaginal bleeding were observed with elevated serum LH, FSH and E2. Both LH and FSH response were exaggerated following LHRH stimulation and she was diagnosed as central precocious puberty.

At least eight types of this syndrome have been described to date according to clinical features and mode of inheritance. Most of the abnormalities found in our patient are consistent with an OFD syndrome, but urogenital anomalies in the syndrome have not been reported except polycystic kidneys in type I, renal agenesis or dysplasia in type VI and congenital hydronephrosis in type VII. Despite the similarities between the clinical findings in the case and types III, IV and VI, this patient might be a new type of OFD. 


\section{C-38}

X-LINKED MENTAL RETARDATION SYNDROME WITH SEIZURES AND HIGH TTT AND ZTT TITER. Akira OKITSU, Fumiko ISA, Hirokuni BEPPU(Dept. Neurol., Tokyo Metropolitan Kita Medical Rehabilitation Center., Tokyo), Naohiko SEKI(Lab. Gene Structure I, Kazusa DNA Res. Inst., Chiba) and Tada-aki HORI (Div. Genet., Natl. Inst. Radiol.Sci., Chiba)

A family with $X$-linked mental retardation is reported. Two out of three affected males(uncle and nephew) alive were studied, but the third case(nephew) refused medical examination. Chromosomal analysis and southern blot analysis revealed neither fragile sites on the $X$ chromosome nor an expansion of trinucleotide(CCG) repeats or methylation in FRAXA. The possibility of fragile $X$ syndrome can be excluded based on these results. Both cases showed similar clinical features; mental retardation and epileptic seizure associated with a high titer of TTT and ZTT. Dysarthria and scoliosis were observed in the nephew; cataract and thracic vertebral deformities were seen in the uncle. Although the final diagnosis of these cases was unclear, further accumulation of similar case reports and linkage analysis are neede to discover and identify new clinical entities.

$$
\text { C-39 }
$$

A FAMILY OF ELLIS-VAN CREVELD SYNDROME. Yoshihiko KITOH Mie TODOROKI, Aiju KAMEDA Kazuo IGA (Dept. Pediatrics, Kawanishi City Hospital(KCH), Hyogo), Kazuya FUJMOTO, Mariko AKAl Toshiaki TATSUMI Shozo TAIRA (Dept. Obstet. Gynecol, KCH), Shinji KAWAI and Hideto NAKAO (Div. Neonatology, Matemal and Fetal Center, Kobe Children's Hospital, Kobe)

Ellis-van Creveld syndrome (ECS) is an inherited disease, but pheno-type is variable. We reported a family of ECS. The 1st pregnancy was normal, and this boy is healthy. In the 2nd pregnancy, it was terminated at 21 st week of gestational age, because of demonstration of short limbs and thoracic hypoplasia using by ultrasonography and fetography. This baby was female, she had short limbs, postaxial polydactyly, severe thoracic hypoplasia, and low-set ear. Her karyotype was 46XX. In the third pregnancy, it was demonstrated of dwarfism, single atrium, and thoracic hypoplasia using by ultrasonography at 27 th week of gestational age. 'This baby was born at 37 weeks' gestation, he had severe thoracic hypoplasia, postaxial polydactyly, hypoplastic nail, dental dysplasia and single atrium. He was died at 121 st day. His karyotype was $46 \mathrm{XY}$.

In future, genetic diagnosis may be available. But, prognosis in ECS depends on severity of thoracic hypoplasia and congenital heart disease. The method of the evaluation of thoracic hypoplasia of fetus is not confirmed, at present, therefore, prognostic diagnosis in prenatal period is difficult. 
C-40

PRECOCIOUS PUBERTY DUE TO OPTIC GLIOMA IN TWO CASES WITH VON RECKLINGHAUSEN DISEASE (NEUROFIBROMATOSIS 1)

Naoya KODA, Katsuya AIZU, Hiroshi MOCHIZUKI, Shuichi YAMAGUCHI, Takeshi SUMA, Yasuhide MAKIYAMA, Hiroshi NISHIMOTO and Hirofumi OHASHI (Saitama Children's Medical center)

We reported on two male patients with neurofibromatosis 1(NF1) who represented precocious puberty due to optic glioma. Case 1 was a 5-year-2-month-old male. He had typical café au lait spots and enlargement of penis and testes. His weight, height and head circumference $(H C)$ were $27.1 \mathrm{~kg}, 120.1 \mathrm{~cm}(+3.1 \mathrm{SD})$ and $56.2 \mathrm{~cm}(+3.5 \mathrm{SD})$, respectively. His bone age was 7years. Endocrinological examinations were as follows; $\mathrm{LH} 2.2 \mathrm{mlU} / \mathrm{ml}$, FSH $5.2 \mathrm{mlU} / \mathrm{ml}$, testosterone $126 \mathrm{ng} / \mathrm{dl}$ and SM-C $2.75 \mathrm{U} / \mathrm{ml}$. The basal concentrations of testosterone and SM-C were elevated. LH secretory response to LH-RH was exaggerated. Cranial MRI revealed mass at the chiasmal region of the hypothalamus. Case 2 was a 3-year-9-month-old male. He had typical café au lait spots and enlargement of testes. His weight, height and $\mathrm{HC}$ were $22.6 \mathrm{~kg}$, $110.3 \mathrm{~cm}(+2.8 \mathrm{SD})$ and $56 \mathrm{~cm}(+4.4 \mathrm{SD})$, respectively. His bone age was 6years. Endocrinological examinations were as follows; $\mathrm{LH} 0.9 \mathrm{mlU} / \mathrm{ml}$, FSH $4.1 \mathrm{mlU} / \mathrm{ml}$, testosterone $9.4 \mathrm{ng} / \mathrm{dl}$ and SM-C $6.79 \mathrm{U} / \mathrm{ml}$. The basal concentrations of testosterone and SM-C were elevated. LH secretory response to $\mathrm{LH}-\mathrm{RH}$ was exaggerated. Cranial MRI revealed mass at the chiasmal region of the hypothalamus. In both cases, clinical features, hormonal profile and MRI findings were consistent with NF1 with precocious puberty and optic glioma.

In the literature, precocious puberty is considered to be rare in NF1. The possibility exsists, however, that careful physical measurement will be able to discover more numerous precocious puberty.

C-41

SPONASTRIME DISPLASTA: REPORT ON A FEMALE PATIENT WITH SEVERE SKELETAL CHANGES. MitSUO MASUNO, Gen NISHIMURA $^{1}$, Mihoko NAKAMURA, Kiyoshi IMAIZUMI and Yoshikazu KUROKI (Div. of Med. Genet., Kanagawa Children's Med. Ctr., Yokohama and ${ }^{1}$ Dept. of Radiol., Dokkyo Univ. School of Med., Tochigi, Japan)

We report on a 6-year-old Japanese girl with SPONASTRIME dysplasia, characterized by short-limb dwarfism, moderate deformity of the vertebral bodies, striated metaphyses, midfacial hypoplasia, and relatively large head. The present patient shows severe skeletal changes including remarkably delayed epiphyseal ossification, evident metaphyseal dysplasia, and much denser osteophathia striata, compared with those of the previously reported patients except for one male patient [Camera et al. Pediatr. Radiol. 1994;24:322-4]. Recently, a variant form of SPONASTRIME dysplasia with microcephaly and mental retardation has been reported, suggesting a genetic heterogeneity. The present patient and the case described by Camera et al. [1994] with severe skeletal changes may indicate further evidence that SPONASTRIME dysplasia is a genetically heterogeneous disorder. 
C-42

A CASE OF KABUKI MAKE-UP SYNDROME WITH PULMONARY HEMORRHAGE. Takaya TOHMA, Kyomi HIRAYASU, Makoto SUNAGAWA, Yasutsugu CHINEN, Yoshinori IZUMIKAWA, Kenji NARITOMI and Kiyotake HIRAYAMA (Department of Pediatrics, Universityof the Ryukyus School of Medicine)

A boy with Kabuki make-up syndrome who had massive pulmonary hemorrhage is reported. To our knowledge, this association has not been described. A 6-year-old boy had 6 times hospitalization due to recurrent respiratory infections. In march 1995, he visited our hospital for fever, cough, wheezing, hematemesis and worsening of pallor. His hemoglobin level was $9.2 \mathrm{~g} / \mathrm{dl}$ and the chest X-ray revealed bilateral diffuse pulmonary infiltration. There was progressive worsening of respiratory failure after another episode of hematemesis. Intubation showed fresh blood pouring out from the larynx. He was treated with gamma-globulin, dexamethazone and surfactant. He discharged after 22 days hospitarization. We failed to determine its etiological basis of pulmonary hemorrhage. It is unknown whether this comlication is related to the etiology of Kabuki make-up syndrome or not, but we should be aware of this possible complication in patients with this syndrome who have recurrent respiratory infections and persistent hypochromic anemia.

C-43

BACTERICIDAL ACTIVITY OF THE NEUTROPHILS FROM A PATIENT WITH PELGER-HUET ANOMALY. Noriaki SUZUKI, Osamu USHIYAMA, Akihide OHTA, Kohei NAGASAWA(Dept. Int.Med. ,Saga Med.Sch. , Saga)

M.A.HAQUE, Osamu KOHASHI (Dept.Microbiol. , Saga Med.Sch. , Saga)

Polymorphonuclear leukocytes( IMN) obtained from a patient with familial Pelger-Huet( $\mathrm{P}-\mathrm{H})$ anomaly were tested for the prodution of superoxide anion and the killing of microorganisms. The production of superoxide anion was relatively higher in the patient with $\mathrm{P}-\mathrm{H}$ anomaly, and correlated with the neutrophil bactericidal activity for Shigella dysenteriae 1. BMNs from a healthy adult, the patient and the mother of the patient with the leukocyte anomaly, functioned with equal efficiency in the killing of staphylococcus aureus. Although an increased incidence of local infections due to neutrophil dysfunction has been claimed in $\mathrm{P}-\mathrm{H}$ patients, our data demostrate that the neutrophil bactericidal activities of $\mathrm{P}-\mathrm{H}$ patient are normal. 
C-44

GENETIC SCREENING IN HEREDITARY MULTIPLE ENDOCRINE NEOPLASIA TYPE 1 (MEN1). Akihiro SAKURAI, Miyuki KATAI, Yasunori ITAKURA, Koji NAKAJIMA, Kiyoshi HASHIZUME (Dept. Geriat., Endocrinol., Metab., Shinshu Univ. Sch. Med. Matsumoto)

Familial multiple endocrine neoplasia type 1 (MEN1) is a disease characterized by hyperplastic or neoplastic disorder of endocrine organs, and is inherited in an autosomal dominant trait with high degree of penetrance. The genetic locus for MEN1 has been assigned to a long arm of chromosome 11 (11q13) by linkage analysis, although the gene responsible for this disease is yet to be identified. We applied microsatellite polymorphism for the genetic screening in families with hereditary MEN1, and identified five adolescent asymptomatic disease carriers. Unlike MEN1 families in Tasmania or Newfoundland, a founder effect was not observed among affected families studied. The identification of disease carriers is of substantial clinical importance for early management, genetic counseling and to avoid unnecessary screening for non-disease carriers. Although it is known that PYGM locus lies close to MEN1 gene and thus used for analysis of MEN1 family, we observed that dinucleotide repeat polymorphism in PYGM locus is prone to have mutation, of which one should be cautious on genetic screening.

\section{C-45}

A NONSENSE MUTATION AND INTRAGENIC POLYMORPHISMS IN THE BLOOD COAGULATION FACTOR XI LOCUS, F11. Noriyuki HACHIYA ${ }^{1)}$, Minoru ${\underline{\text { OGAWA }^{2)}}}^{\text {Mitsuru SATO }}{ }^{1)}$, Yukiko TAKAHASH $^{2)}$, Shoko SHINDO $^{1)}$, Kiyotaka FUJITA $^{3)}$, Ikunosuke SAKURABAYASHI ${ }^{4}$, Naofumi YOSHIOKA ${ }^{1)}\left({ }^{1)}\right.$ Akita University School of Medicine, Akita, ${ }^{2)}$ Yokote Hospital, Yokote, ${ }^{3)}$ Hanazono Hospital, Omagari, ${ }^{4)}$ Jichi Medical University, Omiya)

Factor XI, a serine protease involved in the cascade reaction of blood coagulation, is coded by F11 locus located on 4q35. A new nonsense mutation was found in a Japanese pedigree with factor XI deficiency. Proband is male manifesting loss of factor XI activity $(<1 \%)$, elongation of activated partial thromboplastin time (APTT) and slightly prolonged clotting time recognized at a hospital examination preceded to gastric operation. In his family, two daughters and a niece exhibit partial declines (85-88\%) and a deficiency $(<5 \%)$ of factor XI activity, respectively. In spite of their reduced level of the clotting factor, no bleeding tendency nor hemostatic problem had been experienced in both of the proband and the relatives. A PCRSSCP analysis and direct sequencing demonstrated a nonsense mutation of codon 263 in exon 8: CAA (Gln) to GAA (Stop), and two silent mutations of codons 586 and 595 in exon 15: CGG (Arg) to CGT and GAG (Glu) to GAA, respectively. Haplotype frequency was determined among Japanese population by PCR-RFLP analysis using the resulting loss of restriction sites by the base changes, and $4.8 \%$ was caring both of the two silent mutations. 
C-46

KERATIN K9 GENE MUTATION IN EPIDERMOLYTIC PALMOPLANTAR KERATODERMA. KazUo NOMURA, Kaoru. UMEKI, Mayuko HIRASUE, Katsuto TAMAI, Daisuke SAWAMURA and Isao HASHIMOTO (Dept. Dermatol. Hirosaki Univ.School of Medicine, Hirosaki)

Epidermolytic palmoplantar keratoderma (EPPK) of Voerner type is an autosomal dominant inherited disorder of keratinization with histologic features of epidermolytic hyperkeratosis. We studied members of the Japanese family with EPPK. The affected members have remarkable hyperkeratosis and erythema on their palms and soles. Histological change of the skin revealed hyperkerats is with epidermolys is (granular degeneration). Sequencing of genomic DNA samples from the proband (one-year-old female) and her affected 29 -year-old father established the substitution from A to $G$ at 529 bp position. This substitution produces amino acid change from threonine to alanin (T155A) in the 1 A region of the alpha-helical rod domain of keratin K9. The disruption of highly conserved threonine residue may affect the probable importance of the amino terminus of the central rod in maintenance of the normal helical-helical interactions in keratin proteins.

$\mathrm{C}-\mathbf{4 7}$

EFFECTS OF VITAMIN D RECEPTOR GENE POLMMORPHISM AND LIFESTYLE ON BONE MINERAL DENSITY. Zentaro YAMAGATA (Health Care Center, Yamanashi University), Toshihiro MIYAMURA, Yingning Zhang, Sumio IIJIMA, Akio ASAKA (Dept. Health Sciences, Yamanashi Medical University)

We investigated the relationship of BMD, VDR gene polymorphism and frequency of food group intakes. We used the FGIF score (food group intake frequency score). The FGIF score was derived from factor analysis of frequency of food group intakes. The number of the eigevalues that showed large changes was three. The First and second factors presumably reflected the extent of contribution of salad and primary sources of culcium, respectively and third foctor presumably reflected luxury items. The relative weight of food groups was scored in consideration of their relationships with BMD. The total score was regarded as the FGIF score. By multiple regression analysis for BMD as the dependent variable, the number of years after menopause, FGIF score and VDR genotype were significant independent variables. $\mathrm{BMD}=0.684-0.014 \mathrm{x}$ (Number of years after menopause) $+0.104 \times$ (Number of VDR allele b) $+0.023 \times$ (FGIF score) $\left(R^{2}=0.585, F=34.83, p<0.001\right)$. Among subjects with bb genotype BMD correlated with FGIF score $(r=0.481, p=0.0013)$, although no correlation among $\mathrm{BB}$ or $\mathrm{Bb}$, despite no significant different sore shown among all genotypes. This result indicates the response of bone metabolism to food intake might be different according VDR genotype. 
A SPLICE MUTATION IN THE GROWTH HORMONE RECEPTOR GENE OF A JAPANESE PATIENT WITH LARON S YNDROME. Takako OTSUKA, Noritaka IWATANI, Mihoko KODAMA, Teruhisa MIIKE (Dept. Child Develop., Kumamoto Univ. Sch. Med., Kumamoto) and Yoshihiro JINNO, Norio NIIKAWA (Dept. Hum. Genet., Nagasaki Univ. Sch. Med., Nagasaki)

We reported a splice mutation in a Japanese patient with the syndrome. Using the patient's genomic DNA as a template, all exons and flanking portions of introns of $G H R$ were amplified with polymerase chain reaction (PCR). Sequencing of the PCR products showed that the patient had a $G$ to A transition at the first position of intron 4 and was homozygous for the transition. This base change occurred at the $5^{\prime}$ splice consensus sequence of intron 4 , resulting in the abolition of a $B$ anI restriction site. Since this substitution was not detected in 28 control individuals by a $B$ anI restriction analysis, it is less likely a polymorphism but most likely a disease-related mutation. The mutation in our patient was predicted to destroy the original $5^{\prime}$ splice site of intron 4 of $G H R$ and to produce a new cryptic splice site, leading to abnormal mRNA processing. This is the first detection of a $G H R$ mutation among Asian patients with Laron syndrome. As the identical mutation was reported in a Spanish and a north European patients with the syndrome, it is most likely that this GHR mutation is not race-specific.

\section{C-49}

LINKAGE ANALYSIS OF FAMILIAL SCOLIOSIS. 1,2Masatoshi INOUE, ${ }^{2}$ Hideshige MORIYA, ${ }^{2}$ Hiroshi KITAHARA, ${ }^{2}$ Syohei MINAMI, ${ }^{3}$ Yoshimitsu FUKUSHIMA and ${ }^{1}$ Yusuke NAKAMURA. ( ${ }^{1}$ Lab. Mol. Med., Inst. Med. Sci., Univ., Tokyo. '2Dept. Orthop., Sch. Med.,

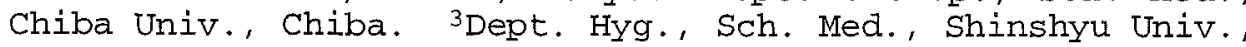
Matsumoto)

The pathogenesis of idiopathic scoliosis has not elucidated yet. However, there have been some reports concerning the familial incidence of idiopathic scoliosis, called "familial scoliosis". We performed familial survey on the basis of both clinical examination and radiography, and twenty-four pedigrees of familial scoliosis considered as dominant trait were obtained. We also found Smith-Magenis syndrome with del(17) (p11.2) that had the curve totally like an idiopathic scoliosis. It suggested that the deletion of this region was associated with the etiology of idiopathic scoliosis, and we investigated linkage analysis with microsatellites markers to this region. We yielded Maximum lod score of only 0.33 at $\theta=0.40$, with marker AFM192yh2 at locus D17S799, and we could not confirm linkage with a disease locus for familial scoliosis to microsatellites on chromosome $17 \mathrm{p} 11.2$. 
$\mathbf{C}-\mathbf{5 0}$

\title{
APPLICATION OF FLUORESCENCE IN SITU HYBRIDIZATION TO THE IDENTIFICATION OF ANEUPLOIDS IN AMNIOTIC FLUID CELLS
}

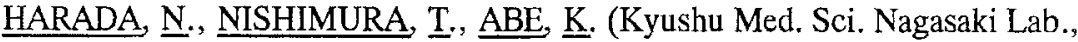 \\ Nagasaki), NIIKAWA N. (Dept. Hum. Genet., Nagasaki Univ., Nagasaki)
}

We report the results of FISH analysis for possibly rapid identification of chromosome aneuploids in amniotic fluid cells. Interphase cell preparation was made from $5 \mathrm{ml}$ amniotic fluid at 14 - 32 weeks' gestation. FISH probes, D13Z1/D21Z1, D18Z1 and DXZ1/DYZ1, that detect paracentromeric heterochromatin or the $\mathrm{X} / \mathrm{Y}$ chromosome-specific regions were purchased from ONCOR. The probes were hybridized onto the interphase cells. Among 30 cells which gave FISH signals, the number of signals were counted. FISH result in each sample was compared with that of chromosome analysis.

Of a total of 30 cases analyzed, 27 were karyotypically normal and three aneuploidy, such as $47, \mathrm{XX}+18,47, \mathrm{XY},+21$ and $45, \mathrm{X}$. There was no discrepancy between the results of cytogenetic and FISH analyses. It is thus concluded that FISH with these probes is useful for the diagnosis of aneuploidy in amniotic fluid cells, especially for a perinatal diagnosis.

C-51

NUCLEATED CELLS OF FETAL ORIGIN COLLECTED BY UTERINE CAVITY FLUSHING FOR PRENATAL DIAGNOSIS. Naomi OYA, Mamami KAWAMURA,Yuka HAYASHI, Mitsuyo TANEMURA, Tadashi IIDA, Setsuo OKADA, Kaoru SUZUMORI and Yoshiaki YAGAMI, Department of Obstetrics and Gynecology, Nagoya City University Medical School, Nagoya, Aichi.

Since it has been reported that fetal nucleated cells are present in the uterus during early pregnancy, in the present study we have investigated whether it would be possible to obtain fetal genetic information from these cells. The subjects comprised 9 women in whom missed abortion was diagnosed during early pregnancy and 14 women undergoing induced abortion during early pregnancy. Just prior to termination of the pregnancy a $10 \mathrm{Fr}$ Nelaton catheter was inserted just over the internal os, then $10 \mathrm{ml}$ sterilized physiological saline was flushed in the uterine cavity, the saline recovered, the obtained cells treated with a hypotonic solution, and specimens prepared in Carnoy's fixative. Fluorescence in situ hybridization (FISH) was performed with a Y chromosome-specific probe. Sex differentiation was determined according to the presence/absence of a signal in the interphase nuclei on the specimens, the frequency of appearance of nuclei having a signal was calculated, and the results compared with those of karyotype obtained from cultured chorionic villus cells. A Y-specific signal was detected in all of the 13 cases with male fetuses. The frequency of nuclei having a signal ranged from 5 to $20 \%$. It was strongly suggested that fetal nucleated cells could be procured in early pregnancy by flushing the uterine cavity, an easy and only slightly invasive procedure as compared to chorionic villus sampling. 
C-52

SEPARATION OF FETAL CELLS BY FLUORESCENCE-ACTIVATED CELL SORTER. Satoshi SOHDA, Hiromi HAMADA, Takeshi KUBO (Dept. Obstet. Gynecol., Univ. of Tsukuba, Ibaraki), Tadao ARINAMI, Hideo HAMAGUCHI (Dept. Med. Genet., Univ. of Tsukuba, Ibaraki), and Hiromitsu NAKAUCHI (Dept. Immunol., Univ. of Tsukuba, Ibaraki),

The purpose of this study was to develop a method to purify fetal cells in maternal blood using fluorescence-activated cell sorter (FACS). We used monoclonal antibodies CD71, CD36 and glycophorin A (GPA). The sample blood was sorted with combination of the antibodies. Nucleated erythrocytes (NRBC) were enriched by FACS from blood samples of patients with hemolytic diseases, non-pregnant women, fetuses between 17 and 40 weeks' gestation at the time of cordocentesis for prenatal diagnosis, and pregnant women between 9 and 35 weeks' gestation. The average proportions of GPA ${ }^{+} \mathrm{CD}_{71}{ }^{+}$cells were estimated to be $0.009 \%$ in three non-pregnant women blood, $0.77 \%$ in eight fetal blood, $0.11 \%$ in ten pregnant women by FACS. FISH signals using Y-specific probe were observed in the enriched $\mathrm{GPA}{ }^{+} \mathrm{CD} 71^{+}$cells from pregnant women who gave birth to boys. Fetal cells are extremely rare in maternal blood, though it is possible to enrich fetal cells by using FACS.

\section{C-53}

POLYMERASE CHAIN REACTION ANALYSIS IN THE PREIMPLANTATION SEX DETERMINATION OF HUMAN PRE-EMBRYOS. Yukiko KATAGIRI, Yoshiko SHIROSHITA, Yuji ABE, Susumu KATAYAMA, Harumi KUBO, Shun HIRAKAWA (The 1st Dept. Obstst. Gynecol. Toho Univ. School of Med., Tokyo)

The SRY and ZFX genes were coamplified as target sequences of the $Y$ - and $\mathrm{X}$-chromosomes to establish a noninvasive method of pre-implantation diagnosis. Sensitivity of the single and nested PCR method were examined followed by amplification of single amniocytes by the nested PCR. Then, the sex of single blastomeres at the 3- and 9-cell stages were identified by the nested PCR. The nested PCR was $10^{4}$ fold more sensitive than single PCR. When amniocytes were analyzed sex could be determined as males in $94.4 \%$ of the amniocytes. Sex determination was possible in $97.5 \%$ blastomeres. But the correspondence rate of the all blastomeres within a whole embryo was $60 \%$. Only one blastomere showed different results of sexing from these of the remaining blastomeres in all embryos. 


\section{C-54}

PRENATAL MOLECULAR DIAGNOSIS OF INFANTILE HYPOPHOSPHATASIA. Hideo ORIMO $^{1}$, Eiitsu NAKAJIMA ${ }^{1}$, Zuisei HAYASHI ${ }^{1,2}$, Kazuhiro KIJIMA $^{1,2}$, Atsushi WATANABE ${ }^{1}$, Hisako TENJIN ${ }^{2}$, Tsutomu ARAKI ${ }^{2}$ and Takashi SHIMADA ${ }^{1}$ ( ${ }^{1}$ Dept. Biochem. Molec. Biol., ${ }^{2}$ Dept. Obstet. Gynecol., Nippon Medical School, Tokyo)

Hypophophatasia is an autosomal recessive disease due to tissue-nonspecific alkaline phosphatase (TNSALP) deficiency. We performed a prenatal diagnosis at the request of the parents whose first child had been a compound heterozygote with novel mutations for infantile hypophosphatasia. The mutation sites were G1068A (K281E), C1190T (321H, silent), both transmitted from the father, and deletion of T1735 (frameshift dowmstream from 503) which was transmitted from the mother. PCR-RFLP and PCR-ASO analysis of chorionic villus DNA samples obtained at 10 weeks of gestation showed that the fetus was heterozygous for the three mutations. PCR-SSCP analysis of exons containing the mutation sites confirmed transmission of the abnormal bands and SSCP patterns showed no contamination of maternal blood and tissues in the fetal sample. These results indicated that the fetus was the same genotype as the affected sibling.

\section{$\mathbf{C}-\mathbf{5 5}$}

FIFTY SIX CASES WITH BALANCED CHROMOSOMAL ABNORMALITIES IN THIRTY SEVEN FAMILIES. Mashio KITATANI, Mamoru OZAKI, Hiroaki TAKAHASHI (Clini. Genet., Dept. of Hum. Genet., Med. Res. Inst., Kanazawa Med. Univ., Ishikawa)

Balanced chromosomal abnormalities can lead to a variety of unbalanced products. Over a period of ten years.(1985-1995), 56 balanced chromosomal abnormalities in 37 families were diagnosed. Of the 20 families were ascertained through the birth of malformed children. 11 were through recurrent miscarriage, 3 were through fetal abnormalities, and 3 were through amniocentesis for maternal age. Non-Robertsonian translocations were in 23 families. Pericentric inversions were in 8 , Robertsonian translocations were in 6 . Paracentric inversion, insertion, and both of translocation and inversion was in one family respectively. Among them, 29 prenatal diagnoses carried out by amniocentesis. Abnormal results were found in 12 cases. The 9 of them were derived from parental balanced chromosomal abnormalities. The 3 of them were de novo aneusomies. The 17 of them were normal karyotypes and/or balanced carriers. He suggest that with a previous history of a possibly associated reproductive abnormality, karyotyping of parents should be offered in advance of prenatal diagnosis. 
C-56

CHROMOSOME ANALYSIS OF 632 CASES USING AMNIOTIC FLUID CELLS.

Michio TERAOKA, Shoko MIZUTA, Satoko ITO, Shinsuke NINOMIYA, Kazushiro TSUJI, Yuji YOKOYAMA, Kouji NARAHARA, Yoshiki $\overline{\text { SEINO(Dept.Pediatr. ,okayama University Medical School, okayama) }}$ and Ryozo KASAI (Asahikawa Jidouin Hospita1,okayama)

We have been analysing the karyotypes from amniotic fluid cells of 632 cases. The indications for amniocentasis are as below: advanced maternal age $375(59.3 \%)$, previous chromosome abnormality $94(14.9 \%)$, fetal abnormality detected ultrasonically $80(12.7 \%)$, carrier of chromosome balanced translocation $20(3.2 \%)$, others $63(10.0 \%)$. We detected 23(3.6\%) abnormal karyotypes $(21$ trisomy: 7 cases, 18 trisomy: 5 cases, 13 trisomy: 1 case, 45,X: 3 case, Tetraploid: 1 case, Unbalanced translocation: 6 caeses). The frequencies of chromosome abnormality are $1.3 \%, 1.1 \%, 15 \%$, $25 \%, 0 \%$, respectively.

We failed to cultivate amniotic cells in 14 cases $(2.2 \%)$. The 7 of these 14 cases(50\%) were examined at over 19 weeks of gestation for fetal abnormalities and we obtained the results from fetal umbilical blood cultures which were sampled at the same time of the amniocentasis.

C-57

ANALYSIS OF FACTORS AFFECTING DISCORDANT TWINS AMONG TOTAL 35,985 PAIRS OF TWINS BORN DURING 1988-1991 IN JAPAN. Akio ASAKA(Yamanashi Med. University) and Noriko KATO(National Institute of Public Health)

Discordant twins were designated as follows: the ratio of weight difference between pairs divided by the weight of heavier twin was greater than $20 \%$. The number of discordant twins was 7,044 pairs(19.6\%). Discordant twins was significantly higher in live-still(L-S) twins(72.4\%) followed by still-live(S-L) (61.5\%), still-still(S-S)(30.4\%)and live-live(L-L)(17.2\%). Combined discordance relative risk of $L-S, S-L$ and S-S was $2.344(95 \%$ C.I. 2. 230-2.464), if compared to L-L. As gestational age decreased, the percentage of discordant twins were increased. The relative risk of under 31 weeks was 1.695 compared to over 32 weeks(95\% C.I. 1.608-1.786). Relative risk of primipara to multipara was $1.843(95 \%$ C.I. 1.702-1.996). No association was found with respect to sex composition, maternal age, paternal age, job of the family, born-place and born year. 
C-59

INCIDENCE AND MORTALITY RATES OF CYSTIC FIBROSIS IN JAPAN, 1969-1992. Yoko IMAIZUMI (Institute of Population Problems, Ministry of Heal th and Welfare, Tokyo)

The gene of cystic fibrosis (OF) was assigned to chromosame 7 [Knowlton et al., 1985], and cloned in 1989 [Riordan et al., 1989; Kerem et al., 1989]. The incidence rate and the death rate of CF in Japan were analyzed using Japanese Vital Statistics. Data consisting of 102 deaths from CF were obtained during the period 1969-1992. Data for marital status (54 males and 34 females) were obtained during the period 1969-1985.

The incidence rate was 3.2 per million live births during the period 1969-1980, where the rate was 1.5 times higher in rural than urban areas. The proportion of deaths from $\mathrm{CF}$ under 5 years old was $82 \%$ and under 20 years old was 94\% Overall death rates of $O F$ per million population under 20 years of age were 0.15 for males and 0.10 for females, the difference being significant; the death rate was also significantly higher in males (2.2 per million) than females (1.3) in the first year of life. The death rate decreased from the period 1969-1973 to the period 1989-1992 for males. There were geographical variations in the incidence and the death rates among 9 districts. These rates of $\mathrm{CF}$ were observed with the highest being in Hokkaido and the lowest in Okinaw. The death rate from CF was negat ively correlated with the average temperature. The death rate was higher in rural than in urban areas during the period 1969-1985. The mean age at death from CF was 3 years for bath sexes during the period 1969-1985, the value has been increased since 1979.

\section{$C-60$}

GENETIC STUDY OF THE PREVALENCE OF AUTOSOMAL RECESSIVE RETINITIS PIGMENTOSA IN JAPAN. Mutsuko HAYAKAWA, Keiko FUJIKI, Atsushi KANAI (Dept. of Ophthalmol., Juntendo Univ., Tokyo), Miyo MATSUMURA, Yoshihito HONDA (Dept. of Ophthalmol., Kyoto Univ., Kyoto), Norio OHBA (Dept. of Ophthalmol,, Kagoshima Univ., Kagoshima) and Mizuo MATSUI (Dept. of Ophthalmol., Nihon Univ., Tokyo)

Typical retinitis pigmentosa (RP) is a heterogeneous disease including autosomal recessive (AR), autosomal dominant and $\mathrm{X}$-linked inheritance patterns. ARRP is the most frequent pattern among them in Japan. A genetic analysis was conducted to determine the prevalence of ARRP. Data on the consanguinity rate and marriage years of normal parents of 59 ARRP patients, obtained from a nationwide multicenter survey of RP conducted in 1990, were used to calculate the gene frequency and homozygosity rate of ARRP. The percentage of symptomatic homozygotes, in each 10 year - age group, was also used to calculate the prevalence of symptomatic ARRP patients.

The ARRP gene frequency was calculated to be 0.01145. In 1990, the number of young patients decreased, while that of patients older than 40 increased. The total number of symptomatic ARRP patients in 1990 was nearly $21 \%$ higher than that in 1970. Despite a dramatic decline in consanguinity in recent decades in Japan, the number of ARRP patients has not decreased. We attribute this increase to greater longevity and overall population growth. This result suggests that total number of RP patients has not decreased. 